Characteristics and effects of intensive training in young children with cerebral palsy and parents' experiences of family-centred services investigated in a survey, a systematic review and a randomised controlled trial

\author{
Hilde T. Myrhaug \\ Faculty of Health Sciences
}

Oslo and Akershus University College of Applied Sciences

\author{
Faculty of Medicine \\ University of Oslo
}

Thesis submitted for the degree of Doctor of Philosophy (Ph.D.)

to the University of Oslo

2015 


\section{(C) Hilde T. Myrhaug, 2015}

Series of dissertations submitted to the Faculty of Medicine, University of Oslo No. 2049

ISBN 978-82-8333-051-9

All rights reserved. No part of this publication may be reproduced or transmitted, in any form or by any means, without permission.

Cover: Hanne Baadsgaard Utigard.

Printed in Norway: AIT Oslo AS.

Produced in co-operation with Akademika Publishing.

The thesis is produced by Akademika Publishing merely in connection with the thesis defence. Kindly direct all inquiries regarding the thesis to the copyright holder or the unit which grants the doctorate. 


\section{Table of contents}

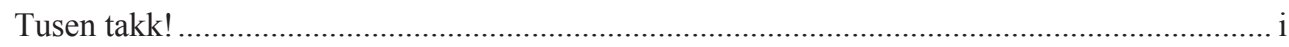

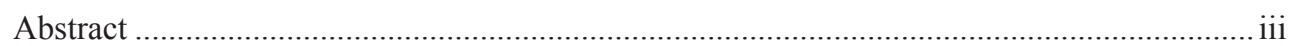

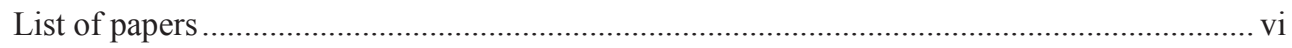

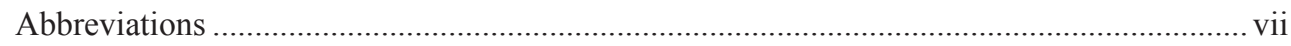

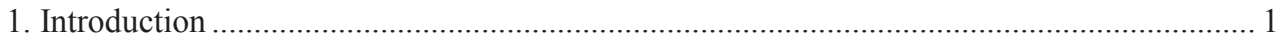

2. Descriptions of concepts and theoretical frameworks......................................................... 3

$2.1 \mathrm{CP}:$ definitions, prevalence, and risk factors ............................................................. 3

2.2. ICF, theories of motor development and the brain's plasticity ..................................... 4

2. 3 Definitions and the effects of intensive training, including CE .................................. 6

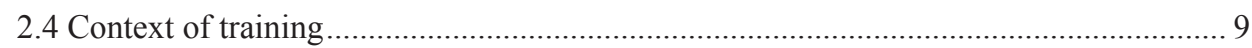

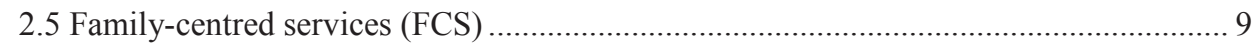

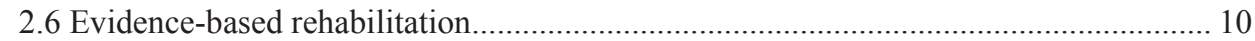

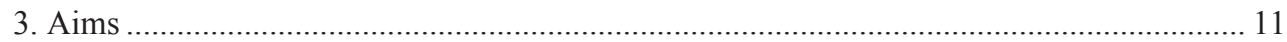

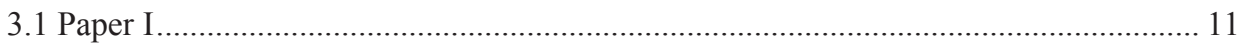

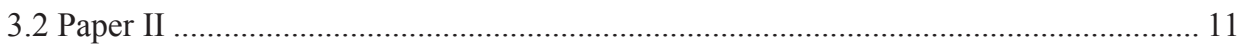

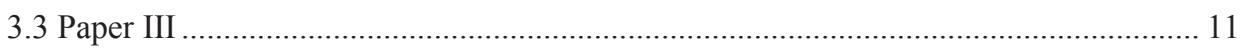

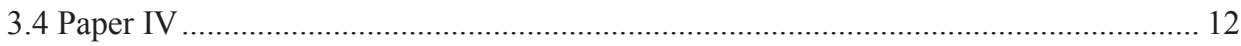

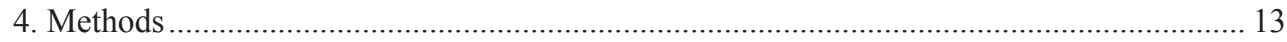

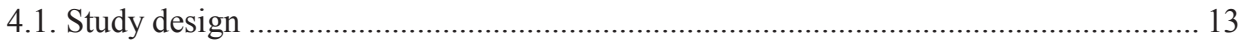

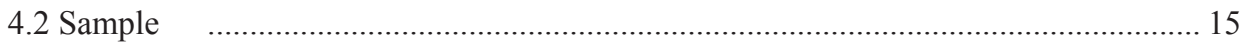

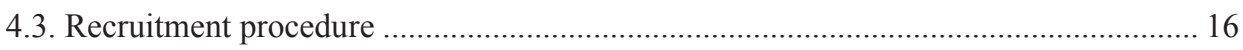

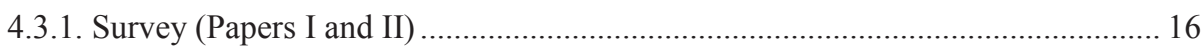

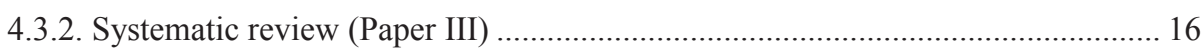

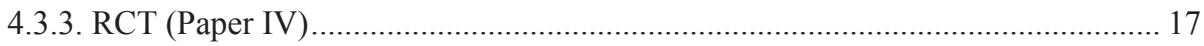

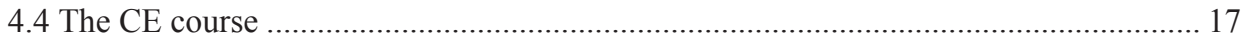

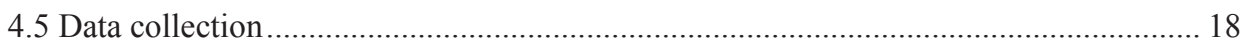

4.5.1. Background information about the child and family ........................................ 19

4.5.2. The Habilitation Service Questionnaire (HabServ) ............................................. 19

4.5.3. Assessment of parents' perceptions of the level of FCS .................................... 20

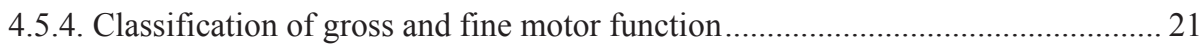

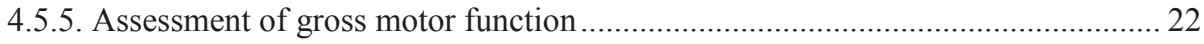

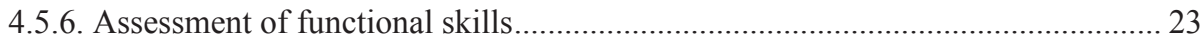


4.5.7. Assessment of health-related quality of life for the child 23

4.5.8. Assessment of quality of life for the parents ...................................................... 24

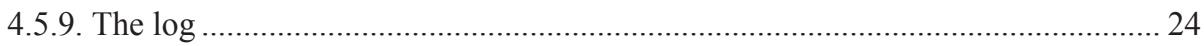

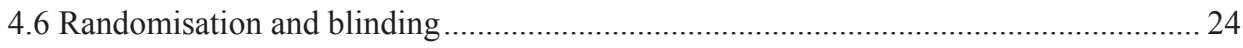

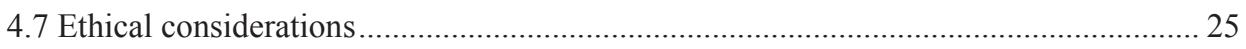

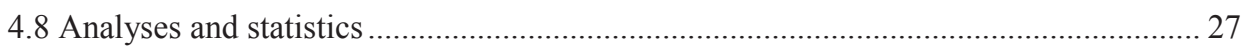

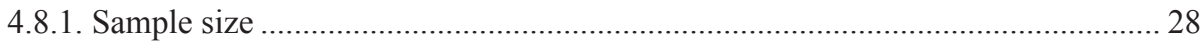

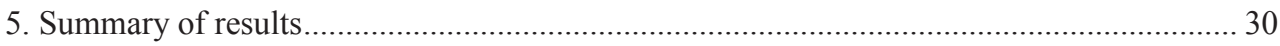

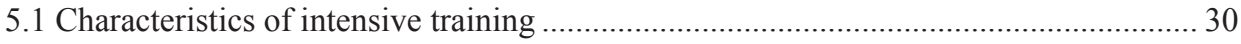

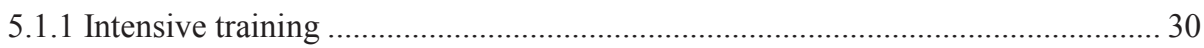

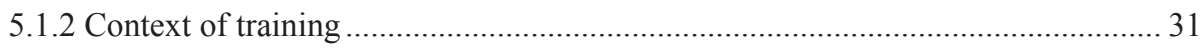

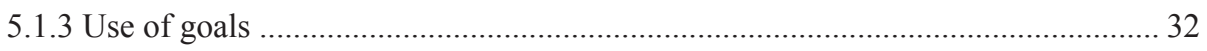

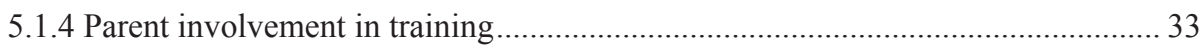

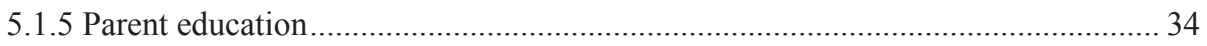

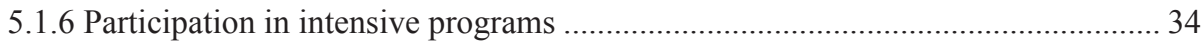

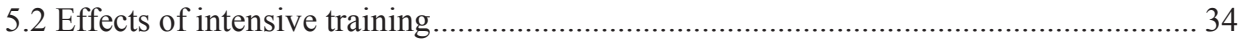

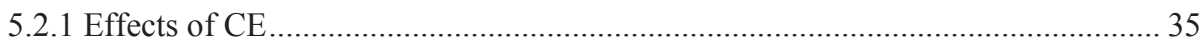

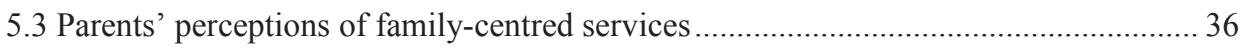

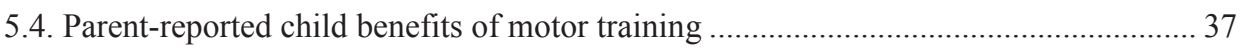

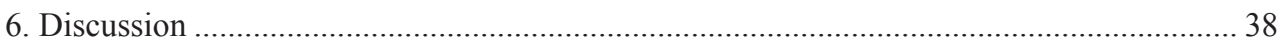

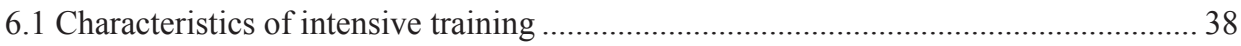

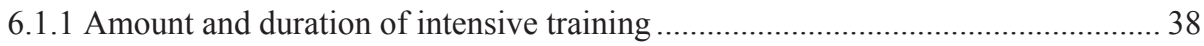

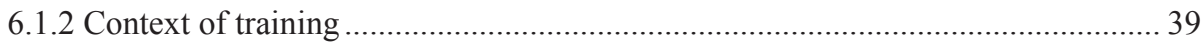

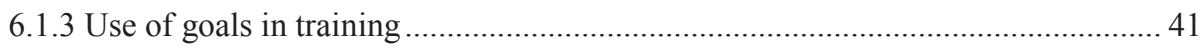

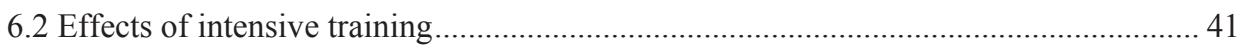

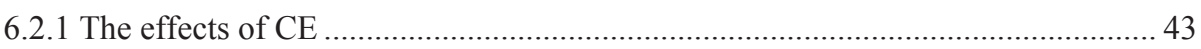

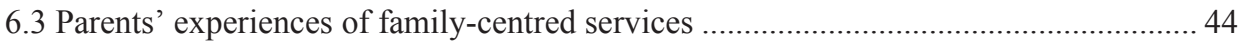

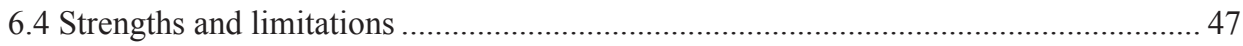

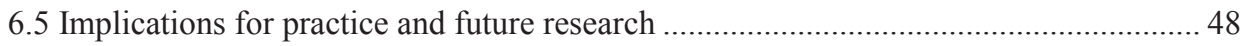

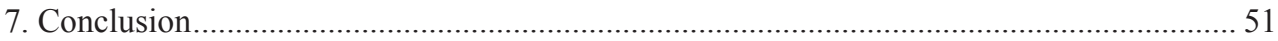

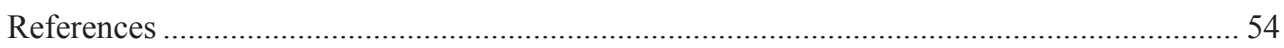

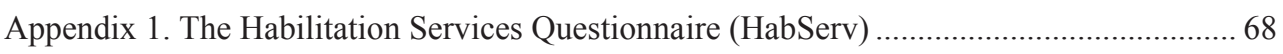

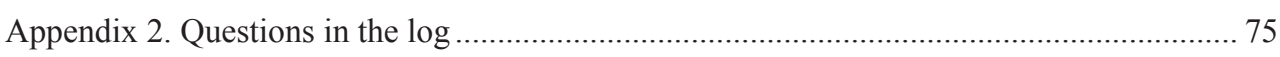




\section{Tusen takk!}

Da jeg startet dette Ph.d.-prosjektet, hadde jeg kun skrevet en kunnskapsoppsummering om intensiv trening for barn med hjerneskade. Jeg har beveget meg i "fysioterapiland" uten å være fysioterapeut. Læringskurven har vært bratt. Dere som kjenner meg vet at det har vært andre utfordringer også. Uten støtte fra mange hadde det vært umulig å gjennomføre og ferdigstille denne avhandlingen.

Aller først vil jeg takke Ivar, min kjære mann, som har støttet meg hele veien. Ivar holdt "fortet" og klaget aldri selv om mye har falt på han. Tusen hjertelig takk!

Dernest vil jeg takke mine veiledere Reidun Jahnsen og Nina Vøllestad. Stor takk til Reidun som overtok rollen som hovedveileder. Hun delte av sin kunnskap, gav meg tillitt, ro og støtte til å utvikle meg som forsker. Tusen takk! Nina kom sterkere inn på slutten av prosjektet. Hun utfordret meg med andre perspektiver og kom med viktige bidrag i PTØ-studien og kappen. Takk også til Sigrid Østensjø, min første hovedveileder, for bidrag i alle artiklene.

Spesielt må jeg rette en varm takk til alle foreldrene som var med i PTØ-studien. Takk for alle bidrag som utfylte spørreskjemaer og logger, og at dere så betydningen av at målinger og PTØ-kurs ble gjennomført etter protokollen. Takk til alle ansatte på PTØ-Hamar og PTØStavanger for at dere tok vel imot meg. Dagene på Hamar var lærerike og inspirerende. En spesiell takk til Marthe Gulbrandsen og Wenche B. Nordli som har vært mine kontakter på Hamar. Stor takk også til Christine Rognlien, Birte Hammer og Gerd Myklebust som gjennomførte kliniske målinger.

Jeg har hatt stor nytte av mine kjære kollegaers kompetanse på Kunnskapssenteret. Først må jeg takke mine ledere Gro Jamtvedt og Liv Merete Reinar for å ha gitt meg rom til å fullføre avhandlingen når stipendiattiden på HIOA var over. Stor takk til Gro som støttet meg i utviklingen av prosjektplanen. Videre ønsker jeg å takke Lillebeth Larun for viktige bidrag inn i SRen, Kariann Thune Hammerstrøm og Elisabeth Hafstad for støtte til søk, Oluf Jensen for å sette opp og drifte loggen, og Torbjørn Wisløff for å administrere randomiseringen. Stor takk også til Jan Odgaard- Jensen for statistiske og metodiske bidrag. 
En spesiell takk til mine medstipendiater Kariann Krohne, Wenche Bekken, Gro Idland, Therese Brovold, Karin Hesseberg og Elisabeth Bø. Takk for støtte og fellesskap, og hyggelige arbeidsdager på LaTornaia! Takk også til damene på gangen (Bjørg Fallang og Ingvild Øien) som har svart på fysioterapi spørsmål og som jeg kunne lufte tanker med. Jeg ønsker også å rette en takk til tidligere instituttleder på HIOA, Nina Bugge Rigault for god støtte.

Stor takk til "storfamilien", mine kjære foreldre, søstre med familie og venner. Godt å ha en heiagjeng! Spesielt takk til mamma som har bidratt med praktisk hjelp. Til slutt, takk til Ella og Lars som har vært tålmodige med en "distré" og opptatt mamma! Jeg gleder meg til å få mer tid med dere!

14. februar 2015, Hilde T. Myrhaug 


\begin{abstract}
Background: All young children must practice to learn everyday skills. However, children with cerebral palsy $(\mathrm{CP})$ must practice substantially more than their typically developing peers. Therefore, some of this practicing is organised as intensive training and is performed more than twice per week and up to several times per day. The effects of intensive training, except for intensive training of hand functions, are often inconclusive and have been poorly described, particularly in young children. Studies investigating the effects of Conductive Education (CE) have been similarly inconclusive. Family-centred services have been widely acknowledged. However, so far, no studies have investigated parents' experiences of familycentred services in primary health care.
\end{abstract}

Aims: The overall aims of this thesis were twofold: 1) to increase the knowledge of intensive training in young children with CP; and 2) to increase the knowledge of parents' experiences of intensive motor function, functional skills training and family-centred services.

Methods: This thesis includes four papers with three different study designs.

Papers I and II are based on a survey of 121 parents of young children with CP in Norway. This survey collected information about interventions and services that the child and family received over the previous six months using the Habilitation Services Questionnaire (HabServ) and data from the Norwegian Cerebral Palsy follow-up program (CPOP). The response rate was 34\%. In Paper II, the parents' experiences of family-centred services were explored using the Measure of Processes of Care (MPOC-20) within primary health care settings in Norway.

In Paper III, which is a systematic review, we searched ten databases for controlled trials that included young children (mean age younger than seven years old) with CP and assessments of the effects of intensive motor function and functional skills training. Studies that met the inclusion criteria were critically assessed using the risk of bias tool (RoB) and were categorised for intensity and contexts of training.

In Paper IV, which was an RCT, children with CP, who were 3-6 years old and had varied motor function, were randomised to one CE course, followed by conventional training or conventional training on a waiting list. Four months after baseline, the primary outcome of the children's gross motor function was assessed. In addition, the secondary outcomes of functional skills, the children's health-related quality of life, the parents' global quality of life and the parents' experiences of family-centred services were measured. A Web-based log was created to collect data on the target and amount of conventional training. 
Results: Paper 1 (survey): The parents reported that the gross and fine motor training was highly goal-directed, was often performed at least three times per week to several times per day, and was frequently incorporated into daily routines, often with a high level of parental involvement. The use of goals was associated with higher parent-reported child benefits. Paper II (survey): Of the MPOC scales, "respectful and supportive care" received the highest rating, and "providing general information" received the lowest rating. Our findings were lower than those reported in specialist health care. However, because of the low response rate, the results from the survey must be interpreted cautiously.

Paper III (systematic review): Thirty-eight studies were included. The studies that targeted gross motor function were fewer and older and had fewer training sessions over longer training periods than the studies that targeted hand function. Home training often increased the amount of training and was most common in studies of hand function and functional skills. In a majority of the included studies, equal improvements were identified between intensive and conventional training or between two different intensive training programs. Six meta-analyses summarised the effects of constraint induced movement therapy (CIMT) on hand function and functional skills, supporting the existing evidence for CIMT.

Paper IV (RCT): Twenty-one children were included. According to the parents' log reports, a majority of the children in both groups performed conventional training more than two times per week after the CE course and while on the waiting list. At follow-up, no differences in gross motor function could be established between the two groups. Only one significant difference was identified in the secondary outcomes, showing that the parents in the CE group reported higher scores for "Providing specific information about the child" than the waiting list group. However, because of the small sample size, the results must be interpreted cautiously.

Conclusion: Intensive training is characterised by training sessions and home training, often with the incorporation of goal-directed activities into daily routines or a combination of both. Home training is less controllable and is often included in both intensive training and conventional training, making it difficult to define intensive training. The amount, duration, context, and manner in which the training is organised, in addition to the child's characteristics, might contribute to explaining the outcomes of intensive training as identified in the systematic review and the RCT. The large amount of conventional training at follow-up might explain the lack of additional effects of the CE course in the RCT. Large, rigorous studies on intensive gross motor training are required, particularly on $\mathrm{CE}$, where differences might be identified in sub-groups. Further research also must address how to increase the 
participatory aspects of family-centred practice and the barriers and facilitators of information-sharing behaviours in paediatric rehabilitation services. 


\section{List of papers}

Paper I

Myrhaug HT, Østensjø S. Motor Training and Physical Activity Among Preschoolers with Cerebral Palsy: A Survey of Parents’ Experiences. Phys Occup Ther Pediatr. 2014 May;34(2):153-67. doi: 10.3109/01942638.2013.810185.

\section{Paper II}

Myrhaug HT, Jahnsen R, Østensjø S. Family-centred practices in the provision of interventions and services in primary health care: A survey of parents of preschool children with cerebral palsy. J Child Health Care. 2014 Oct 21. pii: 1367493514551312. [Epub ahead of print]. PMID: 25336236

\section{Paper III}

Myrhaug H Tinderholt, Østensjø S, Larun L, Odgaard-Jensen J, Jahnsen J. Intensive training of motor function and functional skills among young children with cerebral palsy: a systematic review and meta-analysis. BMC Pediatrics 2014, 14:292 doi:10.1186/s12887-0140292-5

\section{Paper IV}

Myrhaug H Tinderholt, Odgaard-Jensen J, Østensjø S, Vøllestad N Køpke, Jahnsen R. The short-term effects of a Conductive Education-course on gross motor function in young children with cerebral palsy: a pragmatic stepped-wedge randomised trial. Submitted: BMC Pediatrics 19.01.2015

In this thesis, the articles are referred to by the number they have been assigned above.

Copyright: Article 1 is reproduced with permission from Informa Plc.

Article 2 is reproduced with permission from SAGE Publications Inc. 


\section{Abbreviations}

Note that most of the concepts used in this thesis are defined the first time that they appear in the text.

\begin{tabular}{|c|c|}
\hline $\mathrm{CE}$ & Conductive Education \\
\hline $95 \% \mathrm{CI}$ & 95\% Confidence Interval \\
\hline CIMT & Constraint Induced Movement Therapy \\
\hline CONSORT & Consolidated Standards of Reporting Trials \\
\hline $\mathrm{CP}$ & Cerebral Palsy \\
\hline СРOP & Cerebral Palsy Follow-up Program \\
\hline CPRN & The Norwegian Register of Cerebral Palsy \\
\hline DST & Dynamic Systems Theory \\
\hline EBP & Evidence-based Practice \\
\hline EBR & Evidence-based Rehabilitation \\
\hline FS & Functional Skills \\
\hline FCS & Family-centred Service \\
\hline HabServ & The Rehabilitation and Services Questionnaire \\
\hline $\mathrm{HF}$ & Hand Function \\
\hline GM & Gross Motor Function \\
\hline GMFCS E\&R & Gross Motor Function Classification System Extended and Revised \\
\hline GMFM-66 & Gross Motor Function Measure 66 \\
\hline ICF & International Classification of Functioning, Disability and Health \\
\hline MACS & The Manual Ability Classification System \\
\hline MD & Mean Difference \\
\hline MPOC & Measure of Processes of Care \\
\hline NDT & Neurodevelopmental Treatment \\
\hline PEDI & Paediatric Evaluation of Disability Inventory \\
\hline PEDSQL & Paediatric Quality of Life Inventory \\
\hline PRISMA & Preferred Reporting Items for Systematic Reviews and Meta-analyses \\
\hline QOLS & Quality of Life Scale \\
\hline $\mathrm{RCT}$ & Randomised Controlled Trial \\
\hline SMD & Standardised Mean Difference \\
\hline
\end{tabular}





\section{Introduction}

In 2007, I led a group of researchers, clinicians and a consumer representative in summarising the effects of intensive training and rehabilitation in children with brain damage (1). This systematic review showed that more rigorous research was required, contributing to the start of this Ph.D. project. The aims of this Ph.D. project and thesis were to increase the knowledge both of intensive training in young children with cerebral palsy $(\mathrm{CP})$ by focusing on the characteristics and effects of intensive motor function and functional skills training performed more than twice per week and of parents' descriptions of their children's motor training and their experiences of family-centred services (FCS).

$\mathrm{CP}$ is characterised by motor impairments that limit activity and restrict participation (2). Consequentially, children with $\mathrm{CP}$ receive a variety of interventions to support functional motor performance and to reduce motor impairments, as shown in systematic reviews (3-9). Today, FCS and the provision of evidenced-based interventions have been acknowledged and discussed in the field of paediatric rehabilitation $(3,4,6,10)$. These concepts have also been acknowledged in Norway $(11,12)$. FCS are different from the traditional health care service delivery in that they focus on the entire family and engage the family in training and goalsetting (10). Evidence-based rehabilitation (EBR) is characterised by clinical decision-making that is based on the best available evidence, integrated with clinical expertise and the parents' experiences (13). Therefore, parental descriptions and experiences of training might illuminate whether health authorities' recommendations of FCS and EBR practices are followed. Another aspect of EBR is to provide the proper effective intervention, to the right child at the right time. Novak (14) suggested that providing the correct amount of training was also of interest in EBR.

The demand for intensive training by parents of young children with CP has increased during the 21 st century because of increasing knowledge about the brain's plasticity $(15,16)$ and increasing evidence for the positive effects of more intensive motor training (17-20). When children are preschool aged, basic motor function and everyday skills are developed and learned $(21,22)$. However, children with CP require more support and practice in this developmental process than their typically developing peers; therefore, these children receive a variety of training with different intensities $(3,4,6)$. Unfortunately, the research on the intensive training of gross motor function and functional skills has been limited and inadequately 
described, and its effects have been inconclusive (6-8). In contrast, the evidence for intensive fine motor training has shown promising results and has been well documented (3-5, 9,23). Currently, no systematic reviews have summarised the effects of intensive training alone that targets both the gross and fine motor skills of young children with CP.

Some parents and therapists find intensive training controversial (24) because some types of intensive training are very time-consuming and expensive, and they lack rigorous documenttation (25). Other parents who perceive that their children are not receiving sufficient conventional training tend to seek alternative therapies as intensive training (26). Conventional training in young children with $\mathrm{CP}$ has typically been reported as 1-2 physiotherapy (PT) or occupational therapy (OT) sessions per week $(27,28)$. In Norway, intensive training programs, such as Doman, Conductive Education (CE) and different types of local intensive programs (such as the "Buskerud intensive program" [BIP], "Prosjekt intensiv trening/habilitering" $[\mathrm{PITH}]$ and "Program intensivert habilitering" $[\mathrm{PiH}]$ ) are offered to preschool children in Norway (1). One difference among these intensive training programs is that a child can only attend a local intensive program for a limited period of time, whereas a child can attend the international programs of CE and Doman for years (1). However, the documentation of the effects of the international and local intensive programs has not been rigorously investigated. 


\section{Descriptions of concepts and theoretical frameworks}

This chapter describes different aspects of the CP diagnosis, the International Classification of Functioning, Disability and Health (ICF) (29) model, different motor developmental theories, the brain's plasticity, definitions of intensive interventions, contextual factors, FCS and EBR.

\subsection{CP: definitions, prevalence, and risk factors}

$\mathrm{CP}$ is defined as "a group of permanent disorders of the development of movement and posture, causing activity limitations that are attributed to non-progressive disturbances that occurred in the developing fetal or infant brain. The motor disorders of cerebral palsy are often accompanied by disturbances of sensation, perception, cognition, communication and behavior, epilepsy, and by secondary musculoskeletal problems" (2). CP is slightly more prevalent in boys than in girls. Subtypes of CP are classified according to the classification of the Surveillance of Cerebral Palsy in Europe (SCPE), the International Classification of Disease (ICD-10) (30) or as a combination of both. Based on the classification of the SCPE, a study in a complete Norwegian cohort found that $33 \%$ of children with $\mathrm{CP}$ had spastic unilateral CP, 49\% had spastic bilateral CP, $6 \%$ had dyskinetic $\mathrm{CP}, 5 \%$ had ataxic $\mathrm{CP}$, and $7 \%$ were not classified (31). The overall prevalence of CP has been stable over the last 40 years at 2-3.5 cases per 1000 live births, according to CP registries and population-based studies (3236). In Norway, the prevalence of CP is 2.1 cases per 1000 children (31), and the time from birth until diagnosis is typically 18 months.

The risk factors that are significantly associated with $\mathrm{CP}$ are placental abnormalities, major and minor birth defects, low birth weight, meconium aspiration, emergency Caesarean section, birth asphyxia, neonatal seizures, respiratory distress syndrome, hypoglycaemia, neonatal infections, breech presentation and multiple pregnancies (37-39). A majority of CP cases result from interference in brain development in utero. Magnetic resonance imagining (MRI) scanning is important in understanding these processes (30). Today, increasing numbers of premature and low-birth weight $(<1500$ grams) babies that survive have resulted in a new generation of people with CP in developed countries (40). 


\subsection{ICF, theories of motor development and the brain's plasticity}

The ICF is an important international framework for defining disability and for choosing the target of interventions for children with CP and their families (29). This framework is divided into two parts: 1) function and disability; and 2) environment. The ICF model is presented in Figure 1.

Figure 1. The ICF model

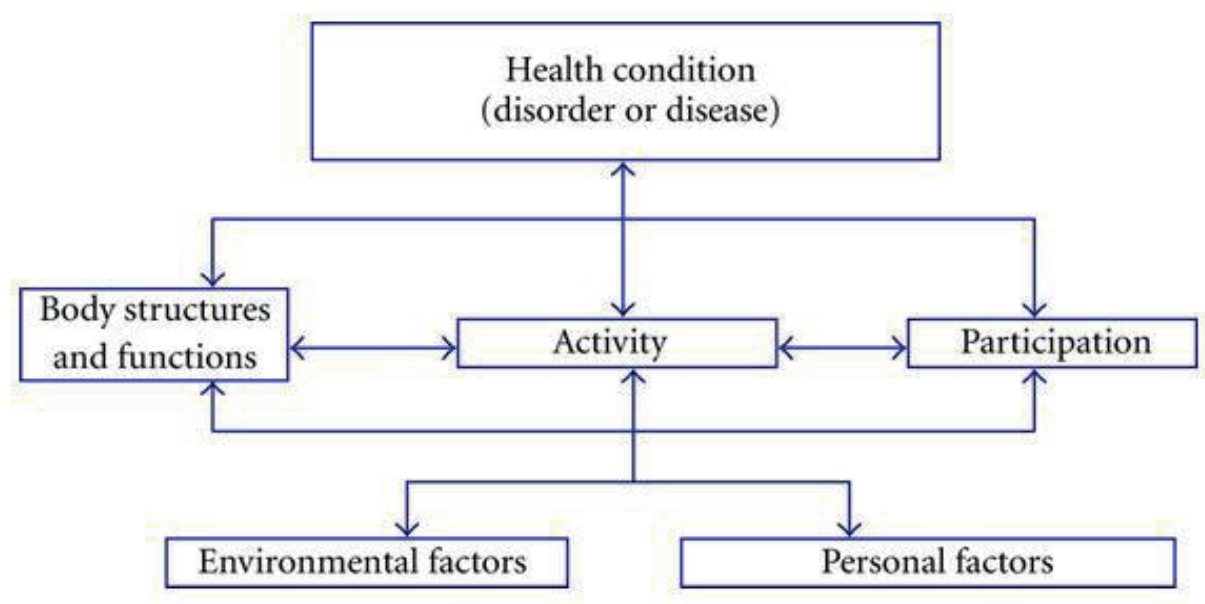

Three components of function and disability are distinguished: 1) body structures (e.g., limbs) and functions (e.g., intellectual function), 2) activities (e.g., walking), and 3) participation (e.g., playing football). Each component can influence the others, and there is no causative progression from impairment of a structure to participation. The interactions among components are influenced by the context in which an individual lives; therefore, the ICF distinguishes two additional components: environmental (e.g., architectural accessibility) and personal factors (e.g., motivation) (40) (Figure 1).

The ICF has redefined the manner in which clinicians understand disability and think about human functioning and intervention options, from emphasising the impairment of the child to focusing on other aspects, such as the context and resources of the child and the family. The ICF can be a useful communication model for therapists and parents when assessing an individual's functioning level for the purpose of individual treatment planning, goal setting, in decision making, and research (40). The included studies in this thesis were interpreted within 
the framework of the ICF, particularly within the components of activity and participation. Activity is defined as the execution of a task or action by an individual, and participation is defined by involvement in a life situation. Two qualifiers can be used to describe activities and participation, based on the generic qualifier and the constructs of performance and capacity. Capacity describes an individual's ability to execute a task or an action in a uniform or standard environment, whereas performance describes what an individual does in his or her current environment (40).

Dynamic Systems Theory (DST) is a commonly accepted theory that is useful for understanding how motor skills develop and change and for gaining insight into a child's readiness to acquire new motor skills (41). In DST, motor development is assumed to emerge from the cooperative interactions of multiple subsystems within a task context (42). These subsystems are as follows: 1) the child's characteristics, 2) the demands of the task, and 3) environmental influences (43). First, the child's characteristics refer to physical impairments, such as increased muscle tone, reduced range of motion, and balance problems, and non-physical characteristics, such as the lack of motivation and challenges with attention and cognition. Second, the demands of the task refer to what the child is trying to accomplish and the characteristics of the task (e.g., shape, size, and weight of a ball for the task of throwing). Third, the environmental influences are physical, social, and attitudinal influences that present barriers to or are facilitators of successful completion of the identified task or goal. Spontaneous interactions among these three sub-systems are assumed to influence the specific motor solution and the completion of functional tasks or goals.

Being in transition is another important concept within DST. This concept refers to when a child begins to experiment with different motor skills. Motor development is not regarded as a linear process within DST. However, a small change in one sub-system can cause changes in the entire system, which can in turn result in the acquisition of new motor skills and cognitive development $(41,44)$. After the transition period, a period of rest often follows, during which the child can be encouraged to practice the new motor skills in a different context. Within the DST perspective, parents and therapists are recommended to be aware and to encourage the child to experiment with different motor skills to acquire new motor skills. One study suggested that parents' perception of readiness in their children might be a better indicator of a developmental motor transition than the therapists' perceptions of readiness (45). The transition is assumed to be self-organising as a shift towards a more efficient motor skill pattern. 
To identify when a child is in transition might also be important for deciding when intensive interventions might produce the greatest improvements in motor function, mostly occurring during the first seven years $(21,22)$.

The development of DST was a reaction to the assumption that motor skills emerged in motor milestones as a genetically driven process identified in all infants (46). Traditional neurodevelopment treatment (NDT) was based on the assumption that motor skills emerged in motor milestones and the assumptions of hierarchical skill development and normalisation of the child's movements (47). The neuronal group selection theory (48) suggests that motor development is the result of a complex interaction between the environment and genes. This theory acts as a bridge from former motor theories to contemporary theories that influence current practice. Today, more functional, goal-oriented intervention approaches, which include the family and child as integral participants in decision making, can be found in the literature (49). Examples of such interventions include functional (50), goal-directed (51) and context-focused therapies (52) that are interpreted within the framework of the ICF and are based on DST and the theory of neural plasticity.

Neural plasticity refers to the brain's ability to learn and recover after an injury through the neurons' and other brain cells' ability to change their structures and functions (plasticity) throughout the lifespan, in response to a variety of external and internal pressures $(15,53)$. Activity-dependent plasticity is used to describe the changes induced in the central nervous system (CNS) associated with movement activity (17). These changes are believed to result in the learning of new skills, accelerated by intensive repetition of goal-directed activities (e.g., constraint induced movement therapy [CIMT]) $(17,18,54)$. Other factors that have been associated with activity-dependent plasticity are progressive challenges to the learner with increased difficulty, the presence of motivators and rewards (16) and the environment (55).

\section{3 Definitions and the effects of intensive training, including $C E$}

Intensive motor training for children with $\mathrm{CP}$ refers to how often the training sessions are performed (amount), how long the training sessions last (minutes or hours), and the duration of the entire training period (weeks or months) (56,57). Palisano and Murr (56) categorised intensive interventions that were defined by the amount of therapy sessions or by the practice of activities in natural environments. No common definition exists of what constitutes inten- 
sive training or what the optimal intensity of motor training is in young children with $\mathrm{CP}$ $(3,4,7,9,52)$. In systematic reviews, intensive gross motor training has often been described as the amount of therapy or training sessions $(6-8,57)$. Arpino (8) defined intensive physiotherapy (PT) as any treatment provided more than three times per week. However, intensive training that targets hand function is typically practiced 2-6 hours per day for 2-8 weeks $(3,5,23,58)$. Conventional therapy has typically been described as performed 1-2 times per week $(27,28)$. Therefore, we defined intensive training of motor function and functional skills as training performed three or more times per week.

Currently, the research on intensive gross motor training in children with disabilities is limited. The content of gross motor training has often been inadequately described, and the effects have been described as inconclusive $(4,6-8)$. In contrast, the increasing body of evidence targeting intensive interventions for hand function has demonstrated promising results $(3-5,9)$. Sakzewski et al. (3) showed that CIMT led to better hand function than conventional therapy. When CIMT was compared to the same intensity of bimanual training or to more training hours of CIMT per day, improvements in hand function were the same for both groups $(3,5)$. The questions of the type and optimal intensity of intervention and the optimal age are ongoing issues $(3,7,9,39,52)$.

Systematic reviews that have assessed the effects of intensive training among children with $\mathrm{CP}$ have included the entire age range from 0 to 18 years old $(3,4,6-8)$. However, the development and learning of basic motor functions and functional skills are essential during the first seven years of life (59-62). Therefore, there is a need to summarise the effects of intensive gross and fine motor function and functional skills training in young children (mean age younger than 7 years old) and to systematise the characteristics of these types of training.

$\mathrm{CE}$ is an intensive training program offered to children, teenagers, and adults with $\mathrm{CP}$ in Norway. The physician Andreas Petø originally developed CE in Hungary in the late 1940s. The pedagogical aim was for children with disabilities to attain "orthofunction": independence according to its own conditions in daily activities (63). Andreas Petø's successor, Mari Hari, was invited to the United Kingdom in the 1960s and later to the Czech Republic, Denmark, Belgium and France, where she presented the pedagogy of CE (64). Since then, the CE pedagogy has spread to Australia, the United States, Asia, and Canada $(65,66)$. This spread has led to a variety of modified CE approaches regarding the intensity (67), organi- 
sation of training (home, kindergarten, regular schools, special schools, outpatient clinics and as courses and summer camp programs) $(68,69)$, attitudes, use of technical equipment (68), and diagnostic groups $(65,68)$. Both Andrea Petø and Mari Hari left little documentation of the $\mathrm{CE}$ pedagogy, resulting in a major problem for the implementation of $\mathrm{CE}$ across the world.

CE has been criticised as lacking an underpinning theory (70). However, Sutton (71) claimed that CE has commonality with the developmental psychology of Vygotski and his successors and with Luria's neuropsychology, particularly regarding brain plasticity. Moreover, CE claims to be based on educational theories, such as Feuerstein's mediated learning approach (72), rather than medical theories. Therefore, the consequences of CP are considered a learning problem within the philosophy of $\mathrm{CE}$ and accordingly must be met with educational principles $(63,65,68,73)$. Motor learning within CE is claimed to be based on the work of Nicolai Bernstein (74), who also influenced the current treatment methods for traditional therapists, as well as task-oriented approaches and DST.

CE training is typically provided in groups and is characterised by a structured program, the use of task series, CE equipment, facilitation by a conductor, and rhythmical intentions. The rhythmical intention is the verbal self-direction of a child when he or she attempts a task, performed as rhythmical speech, counting, singing, or rhythm to reinforce movement. The aim of the task series is to facilitate the child in gaining control and learning new movements (65). The conductors are specially trained in the CE method, and their main tasks are to facilitate, motivate and inspire the child to participate during the training sessions (65).

Recent systematic reviews that have summarised the effects of motor function and functional skills training, including $\mathrm{CE}$, have demonstrated inconclusive results, and there has been a lack of large, rigorously controlled CE trials $(4,6)$. These deficiencies were also supported by older reviews, such as those by Darrah et al. (68) and Ludwig et al. (69). Thus, the effects of $\mathrm{CE}$ remain unclear, and the need for rigorous research is eminent. In Norway, CE training is performed in adjacent to conventional training. As far as we know, no studies have investigated the effects of $\mathrm{CE}$ followed by conventional training, compared to conventional training alone. 


\subsection{Context of training}

Home practice has been shown to increase the amount of training and has often been a part of intensive training (3). However, parents have been found to be less compliant with home programs established by therapists and taught to the parents than with practice at home in which the parents use everyday activities as learning opportunities to increase the child's practice $(75,76)$. Another aspect of home training and practice at home is that contextual factors are important for the learning of motor function and functional skills because they enhance the transfer of new skills to the environments in which they are meant to be used (75,77-79). Humphry and Wakeford (80) even claimed that training and practicing in natural environments promoted higher levels of generalisation and long-term maintenance of acquired skills than unfamiliar clinics or lab settings. The term "natural environment" is often used to describe training at home, in kindergartens or in other natural environments of the child. However, the natural environment is not only characterised by where the intervention is implemented but also by the type of child learning opportunity afforded in the setting (child initiated versus adult directed) and by the person who provides the learning opportunities (parent versus therapist) (78). In systematic reviews of studies in children with $\mathrm{CP}$, the context of training has not been systematically described and discussed as a variable that might explain the outcomes of interventions. Therefore, there is a need for systematic reviews to investigate the importance of the context of training.

\subsection{Family-centred services (FCS)}

FCS have been acknowledged as best practices in many countries (39), including Norway (12). In FCS, the child's development and needs are placed within the context of his or her family and community. Each family is considered unique and constant in the child's life, and the family members are considered experts on the child's ability and needs (81). Currently, parents' experiences with FCS have been extensively investigated in specialist health care settings but not in primary health care settings (10). Because the child and family are most often in contact with therapists from primary health care in Norway, it is important to record their experiences with this part of the health care system.

Systematic reviews have associated FCS with greater family satisfaction, stronger family selfefficacy, greater family perceptions of the helpfulness of services (82), and better functional abilities in children with disabilities (83). New research has indicated that rehabilitation 
interventions emphasising FCS and functional improvement could be more effective in promoting participation (84).

The essential components of FCS are parental involvement in the child's rehabilitation process, partnership building, information sharing, and respectful and supportive care (85-87). Relational and participatory help-giving practices are two distinct and different aspects of FCS that were identified by Dunst (82). Relational help-giving practices are typically characterised by professional behaviour, such as active listening, empathy, and respect, whereas participatory practices are typically characterised as ways to involve the parents in interventions and decision making. Shared decision making is also accepted and advocated in $\operatorname{EBR}(88,89)$.

\subsection{Evidence-based rehabilitation}

Today, evidence-based practice (EBP) is part of every health care discipline, including rehabilitation. EBR is defined as "a combination of information from what we know from research, what we have learned from clinical wisdom and what we have learned from information from the client and their family. This combination of information enables us to work together with clients and families to make the best use of knowledge (88,p14)." This definition is consistent with the definitions of EBP $(90,91)$. Additionally, in Norway, the health authorities have acknowledged EBR as an important tool for improving the quality of paediatric rehabilitation services (11). However, to improve rehabilitation practices, EBP resources, such as systematic reviews, clinical practice guidelines, clinical pathways, databases of evaluations, critically appraised articles and EBP journals, have been developed, and more are required (92). Moreover, EBR promotes the idea that practice should be based on well-documented effective and safe interventions, whereas FCS focus on how the interventions are provided. Both EBR and FCS acknowledge user involvement (parental involvement), the user's experiences of clinical practice and shared decision making as methods with which to improve clinical practice. EBR and FCS play important roles in the work of improving paediatric rehabilitation services. This thesis was influenced by these two concepts because it aimed to increase the knowledge for the effects of intensive training and the parents' experiences of training and FCS.

In the next chapter, the aims of this thesis, including the aims of the studies, are presented. 


\section{Aims}

The general aims of this thesis were twofold: first, to increase the knowledge of intensive training for young children with $\mathrm{CP}$ by describing the characteristics and investigating the effects of intensive training; and second, to increase the knowledge of motor training in young children with CP in Norway by including parents' experiences of this training and their experiences with FCS.

The specific aims for each paper are described below.

\subsection{Paper I}

Title of Paper I: Motor training and physical activity among preschoolers with cerebral palsy: A survey of parents' experiences

Paper I had two aims. The first was to describe motor training and physical activity among preschoolers with cerebral palsy (CP) in Norway. The second aim was to assess the associations among child, parent, motor intervention characteristics and parent-reported child benefits from the interventions.

\subsection{Paper II}

Title of Paper II: Family-centred practices in the provision of interventions and services: A survey of parents of preschool children with cerebral palsy

Paper II had two aims. The first was to assess, using the MPOC-20, how the parents of preschool children with CP viewed the family-centredness of the services provided in a Norwegian primary health care context. The second was to investigate the associations between the MPOC-20 scores and: 1) parental involvement in everyday skills training; 2) the reported child benefits from these interventions; and (3) the parents' satisfaction with the amount of the provided services.

\subsection{Paper III}

Title of Paper III: Intensive training of motor function and functional skills among young children with cerebral palsy: A systematic review and meta-analysis 
The aims of paper III were to describe and categorise intensive motor function and functional skills training among young children with $\mathrm{CP}$, to summarise the effects of these interventions, and to investigate the characteristics that might explain the observed variations in effects.

\subsection{Paper IV}

Title of Paper IV: The short-term effects of a Conductive Education course in young children with cerebral palsy: A pragmatic stepped-wedge randomised trial

Paper IV had two aims. The primary aim of the current study was to evaluate the short-term effects of a three-week CE course followed by conventional training, compared to conventional training on a four-month waiting list, on the gross motor function of young children with CP. The secondary aim was to compare the effects on the child's functional skills and quality of life, the parents' quality of life, and their experiences with FCS.

The following chapter describes how these studies were conducted. 


\section{Methods}

In this chapter, the study designs, samples, recruitment procedures, CE courses, data collection, randomisation and blinding, ethical considerations, analyses and statistics are presented.

\subsection{Study design}

This thesis consisted of four different papers using three different study designs.

\section{Survey (Papers I and II)}

For Papers I and II, a postal survey (a type of cross-sectional study) was used, in which the parents of children with $\mathrm{CP}$ were mailed three questionnaires and were asked to report on the types of interventions and rehabilitation services that their child had received over the previous six months and their experiences with these interventions and services. The three questionnaires were sent in March 2011 to the families of all children 0-6 years old who were registered in the Cerebral Palsy Follow-up Program (CPOP) database. Because the dependent variables (e.g., parent-reported child benefits of training) and the independent variables (e.g., child's age and type of CP, parents' education levels) were not followed over time, this study was not able to explain cause and effect.

\section{Systematic review (Paper III)}

In Paper III, a systematic review was conducted. This systematic review aimed to provide an overview of the evidence base for the effects of intensive motor function and functional skills training of young children with CP by summarising all of the relevant studies of this topic in a systematic and implicit manner. We used the methodology of a systematic review and followed the Preferred Reporting Items for Systematic Reviews and Meta-analysis (PRISMA) guidelines (93). A protocol of this systematic review was registered in the PROSPERO database (94) with the registration number CRD42013004023.

\section{Randomised controlled stepped-wedge design (paper IV)}

It was not deemed possible to conduct a parallel randomised controlled trial to evaluate the effects of a CE course in a Norwegian context because of the small number of eligible participants and the limited capacity of the CE centre. In addition, it would have been 
unethical and not possible to withhold the CE course from a proportion of the participants because their parents had applied for this course. As an alternative, a stepped-wedged design was used to evaluate the effects of a CE course at a CE centre in Norway. The stepped-wedge design is a sequential roll-out of an intervention for study participants over a number of time periods (95). In this study, the CE courses were offered to eligible children every four months. The children were randomised to participation in the first available $\mathrm{CE}$ course or to the waiting list (participating in a CE course approximately 4 months later), in the order in which they were entered into the trial (Figure 2). At the end of the study, all of the participants had received at least one $\mathrm{CE}$ course. Each new group of children starting the $\mathrm{CE}$ course represented a step in the design. This design led to a longer trial duration than a traditional parallel randomised controlled trial, which is common for the stepped-wedge design (95).

Figure 2. The stepped-wedge design

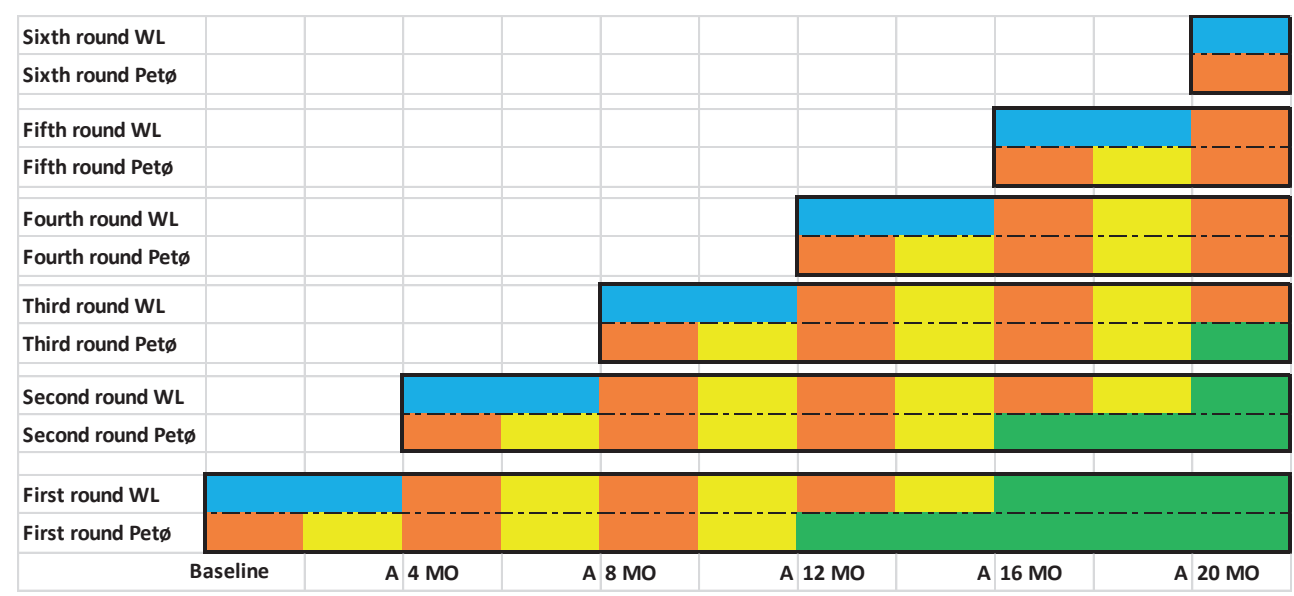

Orange $=$ at $\mathrm{CE}$ course $($ Pet $\varnothing)$, yellow $=$ at home receiving conventional training, blue $=$ at waiting list and home receiving conventional training $(\mathrm{WL})$, green=rolled out of the study, $\mathrm{A}=\mathrm{assessment}$

In Paper IV, only the effects of the first of three course gatherings were evaluated, indicating that the short-term effects of one CE course were compared to the effects of the subjects on the waiting list. The reason for applying this method was to secure appropriate and optimal reporting of the short-term effects. The analysis of long-term effects and trends over time requires advanced statistical methods based on repeated measures, in which short-term effects might be diluted because of the possibly limited sample size. 
Generally, in rehabilitation studies, the main threats to internal validity include maturation effects, which are changes that occur over time as a result of individual and contextual influences. Using a control or comparison group, these threats are prevented (96). This study was conducted as a pragmatic clinical trial, indicating that the intervention (CE courses) was administered in accordance with the usual practices at PTØ-Hamar. Such studies are less focused on treatment adherence and blinding of the participant/parents and therapists than conventional RCTs. Pragmatic trials are characterised by high external validity and lower internal validity $(97,96)$. In addition, this study was not a typical stepped-wedge design study because the participants were not available at the onset of the study but rather were included over a long period. We used the method suggested by the CONSORT statement (98), and a protocol was registered in www.controlled-trials.com with the registration number ISRCTN95218693.

\subsection{Sample}

\section{Inclusion and exclusion criteria}

The participants included in the survey were parents of preschool children with CP living in Norway. In the systematic review, the participants were young children with CP included in controlled trials evaluating the effects of intensive motor and everyday interventions that aimed to enhance activity and participation. Finally, the participants in the RCT were young children with CP who were eligible for CE courses at the PTØ Centre, Norway. The inclusion and exclusion criteria of the three studies are presented in Table 1. 
Table 1. Inclusion and exclusion criteria for the participants included in the studies

\begin{tabular}{llll}
\hline Study & $\begin{array}{l}\text { Data } \\
\text { collected } \\
\text { from }\end{array}$ & Inclusion criteria & Exclusion criteria \\
\hline $\begin{array}{l}\text { Survey } \\
\text { (Papers I, II) }\end{array}$ & $\begin{array}{l}\text { The database } \\
\text { of CPOP }\end{array}$ & $\begin{array}{l}\text { Parents of children with all } \\
\text { subtypes of CP and varied } \\
\text { motor functions, six years old } \\
\text { or younger and registered in } \\
\text { the database of CPOP }\end{array}$ & $\begin{array}{l}\text { Non-Norwegian- } \\
\text { writing and - } \\
\text { reading parents }\end{array}$ \\
$\begin{array}{l}\text { Systematic } \\
\text { review } \\
\text { (Paper III) }\end{array}$ & $\begin{array}{l}\text { The studies } \\
\text { included in } \\
\text { the systematic } \\
\text { review }\end{array}$ & $\begin{array}{l}\text { CP and varied motor functions } \\
\text { and with a mean age younger } \\
\text { than 7 years old in the included }\end{array}$ & $\begin{array}{l}\text { Mean age older } \\
\text { than 7 years old }\end{array}$ \\
$\begin{array}{l}\text { Children who } \\
\text { RCT } \\
\text { (Paper IV) }\end{array}$ & $\begin{array}{l}\text { Children 3-6 years old, with all } \\
\text { subtypes of CP and varied } \\
\text { for the CE } \\
\text { course }\end{array}$ & $\begin{array}{l}\text { motor function, who were } \\
\text { eligible for CE courses at the }\end{array}$ & $\begin{array}{l}\text { Attended CE- } \\
\text { training previously } \\
\text { Non-Norwegian- } \\
\text { writing and - } \\
\text { reading parents }\end{array}$ \\
\hline
\end{tabular}

\subsection{Recruitment procedure}

\subsubsection{Survey (Papers I and II)}

The survey included the parents of children registered in the CPOP database. The CPOP includes children with all subtypes of CP, aged 0-18 years old. Participation is based on informed consent from the parents, including the use of data for research. Parents of children who were born after December 31, 2004, were sent a postal survey, together with an information letter and informed consent form. There were 360 eligible children who were six years old or younger at the start of the data collection. One month after the 360 questionnaire packages were sent, the non-responding parents received a postal reminder. The total response rate was $34 \%$.

\subsubsection{Systematic review (Paper III)}

Eligible studies for the systematic review were identified through an extensive search by an experienced librarian of the following databases: MEDLINE, Embase, PsycINFO, Cochrane Library, ERIC, OT Seeker, CINAHL, ISI Web of Science, SveMed+, and PEDro; these databases were searched in October 2012. The inclusion criteria for the studies were: 1) enrolled a study population with $\mathrm{CP}$ and with a mean age younger than seven years old; 2) evaluated the effects of motor function (e.g., mobility and grasping) and functional skills training (e.g., eating and playing) performed three or more times per week in a clinic, at 
kindergarten, or at home; 3) undertook a comparison to an intervention provided less frequently or to another intensive intervention; and 4) reported outcomes of the activity and participation components of the ICF, measured as hand function, gross motor function, and/or functional skills. An updated search was conducted in September 2014.

\subsubsection{RCT (Paper IV)}

Children found eligible for the CE courses by the CE conductors at the PT $\varnothing$ centres were included from October 2010 to April 2014. After being found eligible, the parents were asked whether the project leader could contact them. If the parents agreed, an informational letter about the study with an informed consent form was sent.

\subsection{The CE course}

In the RCT, the included children were randomised to the immediate CE course (intervention) or the delayed CE course (waiting list). The CE course consisted of groups of four to six children, matched by age and functional level. Two CE conductors led the courses, together with 2-3 assistants. The course consisted of training four hours per day, five days per week for three weeks. In Paper IV, eleven children were randomised to the immediate CE course and ten children to the delayed CE course four months later.

The daily CE program consisted of six different structured and planned programs: targeted standing, lying and sitting, walking, fine motor training, arts and crafts, and an individual program. In addition, the children received supervision and assistance during meals, on visits to the toilet, and while dressing and undressing. The parents, together with the conductor, set goals for the course on the first day of the course. These goals were often a follow-up of the goals set in kindergarten and at home, and they might be short-term and long-term specific goals. Often the child's personal assistant in kindergarten or the physiotherapist would visit the PTØ centre to learn more about the CE training and to follow up with some of the training at the kindergarten. Each course had a topic that was often chosen by the children. Examples of topics were fairy tales, carnivals, and shopping for clothes. The chosen topic was implemented into the activities of the different training programs. In addition to motivating the children during $\mathrm{CE}$ training and leading the $\mathrm{CE}$ training, the conductor was taught to fill the different roles that are found on a current paediatric rehabilitation team, e.g., physiotherapist, occupational therapist, special educator, and speech therapist. 


\subsection{Data collection}

In this thesis, different types of data collection methods were used, such as standardised tests (Gross Motor Function Measures 66 [GMFM-66]) (99), classification systems (Gross Motor Function Classification System-Expanded \& Revised [GMFCS \& ER] (100) and the Manual Ability Classification System [MACS]) (101), a structured interview (Paediatric Evaluation of Disability Inventory [PEDI]) (61), self-reported questionnaires (Background information about the child and family, Measures of Processes of Care [MPOC-20] (81), child's healthrelated quality of life [PedsQL] (102), parents' global quality of life [QOLS] (103), and the Habilitation and Services Questionnaire [HabServ]) and a Web-based log. In the systematic review, we were dependent on the outcome measurements that were reported in the included studies. However, we only included studies that measured the ICF components of activity and participation. 
Table 2. Data collection tools used in the studies

\begin{tabular}{|c|c|c|c|c|}
\hline Study & Outcome & $\begin{array}{l}\text { Outcome } \\
\text { measurements }\end{array}$ & $\begin{array}{l}\text { Source of } \\
\text { information }\end{array}$ & Reported by \\
\hline $\begin{array}{l}\text { Survey } \\
\text { (Papers I } \\
\text { and II) }\end{array}$ & $\begin{array}{l}\text { Socio-demographic data on } \\
\text { the family and data on the } \\
\text { child's impairment }\end{array}$ & $\begin{array}{l}\text { Background } \\
\text { information about } \\
\text { the child and } \\
\text { family (modified } \\
\text { PACSNO) }\end{array}$ & $\begin{array}{l}\text { Child and } \\
\text { family }\end{array}$ & Parents \\
\hline $\begin{array}{l}\text { Survey } \\
\text { (Papers I } \\
\text { and II) }\end{array}$ & $\begin{array}{l}\text { Parents reports of receiving } \\
\text { training and rehabilitation } \\
\text { interventions and parents' } \\
\text { experiences with these } \\
\text { interventions }\end{array}$ & HabServ & Child & Parents \\
\hline $\begin{array}{l}\text { Survey } \\
\text { (Paper II) }\end{array}$ & $\begin{array}{l}\text { Perception of level of } \\
\text { family-centred services }\end{array}$ & MPOC-20 & Family & Parents \\
\hline $\begin{array}{l}\text { Systematic } \\
\text { review } \\
\text { (Paper III) }\end{array}$ & Activity and participation & $\begin{array}{l}\text { E.g., GMFM-88, } \\
\text { GMFM-66, and } \\
\text { PEDI }\end{array}$ & Child & $\begin{array}{l}\text { Outcome } \\
\text { assessors in } \\
\text { included studies }\end{array}$ \\
\hline \multirow[t]{5}{*}{$\begin{array}{l}\mathrm{RCT} \\
\text { (Paper IV) }\end{array}$} & Gross motor function & GMFM-66 & Child & $\begin{array}{l}\text { Outcome } \\
\text { assessors }\end{array}$ \\
\hline & Functional skills & PEDI & Child & Parents \\
\hline & Health-related quality of life & PedsQL & Child & Parents \\
\hline & Global quality of life & QOLS & Parents & Parents \\
\hline & $\begin{array}{l}\text { Perception of level of } \\
\text { family-centred services }\end{array}$ & MPOC-20 & Family & Parents \\
\hline
\end{tabular}

\subsubsection{Background information about the child and family}

A questionnaire inquiring about background information about the child and family was used in the survey (Papers I and II). It included socio-demographic questions from the modified Norwegian version of the Parental Account of Children's Symptoms (PACSNO) (104) and requested the parents' levels of education and occupations, the family structure, and residential and economic concerns. The last modification of the PACSNO (105) was found to be valid in the Norwegian context. In addition, data about the child's impairments, including vision, hearing, cognition, speech and communication, behaviour, nutrition, sleep, pain, epilepsy, and respiratory functions, were also requested.

\subsubsection{The Habilitation Service Questionnaire (HabServ)}

The Habilitation Service Questionnaire (HabServ) included information about all of the interventions and services provided to the child and family over the six months preceding the survey (Appendix 1). The questionnaire consists of five sections and is based on coded responses. The first section requests the targets and characteristics of interventions (motor 
skills, communication, activities of daily living (ADLs), play, and social function)) and the parent-reported child benefits of the received interventions, rated on a five-point scale $(1=$ no or small benefits to $4=$ very large benefits; $5=$ unsure). The second section of the questionnaire collects data on assistive technology, and the third and fourth sections collect data on parentdirected interventions (individual supervision and courses) and parent-reported child benefits of these interventions, respectively, rated on a five-point scale. The fifth section targets all types of received services (e.g., physiotherapy, special education, individual service plan, respite services, financial support) and the parents' satisfaction with these services, rated on a four-point scale ( $1=$ not satisfied, $4=$ very well satisfied). The questionnaire was developed for the survey (Papers I and II) and for a forthcoming longitudinal study (106). It was pilot-tested in 19 parents of preschoolers with CP in three rounds. After the first round of pilot testing, examples of motor skills and physical activity were included. Based on the second round, questions about intensive training, which had existed in a separate section, were incorporated into the service section. Finally, no revisions were made after the third round of testing. The questionnaire is under psychometric testing for reliability as part of the longitudinal study.

\subsubsection{Assessment of parents' perceptions of the level of FCS}

The Measures of Processes of Care (MPOC-20) (81) were used in the survey (Paper II) and the RCT (Paper IV) to include the parents' experiences of FCS. The questionnaire was selfreported. In the survey, the parents were asked the extent to which they experienced the primary health care services as family-centred. In the RCT, the parents in the CE group and the waiting list group reported the extent to which they experienced the primary health care to be family-centred. At follow-up, the parents in the CE group reported the degree to which they experienced the services at the PTØ centre to be family-centred.

The MPOC-20 consists of 20 items organised into five scales. These scales are: 1) Enabling and partnership, 2) Providing general information, 3) Providing specific information about the child, 4) Coordinated and comprehensive care for the family and child, and 5) Respectful and supportive care $(81,107)$. The respondents reported the degree to which they felt that the service providers displayed family-centred behaviour, using a 7-point scale that ranged from "not at all" ( score $=1)$ to "a very great extent" ( translations have been shown to be valid and reliable $(81,107,108)$, including being found reliable (ICC: 0.78-0.86) and valid in Norway (109). 


\subsubsection{Classification of gross and fine motor function}

In the RCT, the included children were classified according to the GMFCS and MACS by three experienced physiotherapists because of the few eligible participants and long travel distances. No inter-rater agreement was assessed.

The GMFCS-E\&R classifies motor function at five clinically meaningful levels, with an emphasis on sitting, transfers and mobility (100). The GMFCS-E\&R emphasises usual performance at home, at school, and in community settings. Distinctions between levels of motor function are based on functional limitations, the need for assistive technology, including mobility devices (such as walkers, crutches, and canes) and wheeled mobility, and, to a much lesser extent, the quality of movement. The aim is to classify a child's present gross motor function. Levels I and II indicate fewer functional limitations (independent walkers), whereas levels III-IV indicate more severe limitations (using walking aids or wheeled mobility).

Age-specific descriptions of the levels are presented as before the $2^{\text {nd }}$ birthday, between the $2^{\text {nd }}$ and $4^{\text {th }}$ birthdays, between the $4^{\text {th }}$ and $6^{\text {th }}$ birthdays, between the $6^{\text {th }}$ and $12^{\text {th }}$ birthdays, and between the $12^{\text {th }}$ and $18^{\text {th }}$ birthdays $(100)$. The classification systems also offer distinctions between the levels. Otherwise, the GMFCS level of a child with CP is found to be stable (110). According to a population-based study in Norway, the GMFCS classification showed the following distribution: $46 \%$ at level I, $9 \%$ at level II, $8 \%$ at level III, $10 \%$ at level IV, $20 \%$ at level V, and 7\% not classified (27). The prognosis for gross motor function among children with CP is variable. However, the use of the GMFM-66 motor development curves (60) could assist parents and therapists in understanding how the gross motor functions of individuals with CP develop over time and in evaluating individual function compared to other children of a similar age and severity of CP. This tool is also useful in goal-setting processes.

The Manual Ability Classification System (MACS) (101) classifies a child's ability to handle objects in daily activities on five levels. Level I indicates the highest, and level V indicates the lowest level of manual ability. The child's usual performance is classified and not the maximal capacity. The level is determined by asking someone who knows the child about his or her typical performance and need for assistance in handling objects. This classification system can be used in children with CP from 4 to 18 years old. The development of hand 
function in children with unilateral CP indicates that a high score on the Assisting Hand Assessment (AHA) in 18-month-old children is associated with a higher ability level than children with a low 18-month-old AHA score (22). In 2009, the MACS classification of young children with CP in Norway showed the following distribution: $35 \%$ at level I, $27 \%$ at level II, $12 \%$ at level III, $11 \%$ at level IV, and $16 \%$ at level V (27).

\subsubsection{Assessment of gross motor function}

The Gross Motor Function Measure (GMFM -66) is a standardised observational tool that was used in the RCT as a primary outcome measurement to detect changes in gross motor function, and it was identified in some of the studies included in the systematic review. Three experienced physiotherapists performed the GMFM-66 assessments in the RCT. The GMFM has been widely used for measuring gross motor function in children with $\mathrm{CP}$, from 5 months to 16 years of age $(111,112)$. The tool measures the gross motor capacity of the child in a standardised environment.

The original GMFM (GMFM-88) consists of 88 items and five dimensions: lying and rolling (17 items), sitting (20 items), crawling and kneeling (14 items), standing (13 items), and walking, running and jumping (24 items) (112). The scores range from 0 (does not initiate) to 3 (completes) and allows for the option of not tested. The interval scores range from 0 (lowest motor function) to 100 (highest motor function). The GMFM-66 was created using Rasch analysis. This analysis allowed the hierarchical structure of the items to be revealed and created interval-level scores from ordinal-level scores (113). The gross motor ability estimator (GMAE) (114), a software program, was created for clinicians and researchers to compute GMFM-66 scores.

The GMFM-66 has a floor effect on children with lower motor abilities and a ceiling effect in children older than 5 years old (115), indicating that children with GMFCS IV-V reach their gross motor potential at an earlier age than children with GMFCS I-III. In addition, children older than 5 years old have often reached their gross motor potential (115). The test-retest reliability for the GMFM-66 was found to be high, with an intraclass correlation coefficient of 0.99 (115). The GMFM-66 was also found to be more sensitive to changes and more clinically useful than the GMFM-88 and has therefore been recommended in research and in clinical practice $(116,117)$. The GMFM-66 has been translated into Norwegian (118). 


\subsubsection{Assessment of functional skills}

The Paediatric Evaluation of Disability Inventory (PEDI) was used in the RCT to assess the child's functional skills during day-to-day life, and it was used in some of the studies included in the systematic review. This semi-structured interview, in which parents are interviewed by therapists or researchers, is widely used for evaluating children with disabilities aged 6 months to 7.5 years old, for functional capabilities (what a person can do in his/her daily environment), performance and changes in functional skills (61). The instrument measures the capability and performance of selected functional activities in the child's natural environment within the domains of self-care, mobility and social function. The PEDI contains three scales: 1) Functional skills (current capability of selected tasks in most situations), 2) Caregiver assistance (current performance and the extent of help the caregiver provides), and 3) Modifications (i.e., environmental or technical modifications required to enhance the child's function). In the RCT, only scale 1 was used (functional skills). This scale consists of 197 items; each item was scored as "unable" (0) or "capable" (1). The self-care domain (73 items) covers eating, grooming, dressing, and personal hygiene. The mobility domain (59 items) covers transfers, for example, in and out of bed, a wheelchair and a bathtub, indoor and outdoor locomotion, and using stairs. The social functioning domain (65 items) covers communication, problem-solving, playing with peers, and safety. Each domain yields an aggregate score. Rasch analysis was also used to place each of the 197 PEDI items on an item map, which provides an estimate of the relative degree of difficulty for each item on the same metric as the 0-100 summary scaled score systems (119). The PEDI is a commonly used questionnaire in Norway and was tested for reliability (ICC from 0.64-0.74 and Cronbach's alpha of 0.95-0.99) (120), and it was validated in the Norwegian context (121).

\subsubsection{Assessment of health-related quality of life for the child}

In the RCT, the parents reported their child's health related quality of life using the PedsQL (2-4 years old) (102). This questionnaire contains four scales: 1) physical functioning (items related to problems of, e.g., walking, running, participating in activities and playing during the last month), 2) emotional functioning (items related to problems of, e.g., being scared or frightened, sad or depressed during the last month), 3) social functioning (items related to problems of, e.g., playing with other children over the last month), and 4) functioning in kindergarten (items related to problems of, e.g., participating in activities together with peers over the last month). The respondents displayed the degree to which these items are a 
problem, using a 5-point scale $(0=$ never, $5=$ almost always $)$. Higher scores indicate increased problems. This questionnaire was found to be reliable (Cronbach's alpha 0.77) and valid in the Norwegian context (122).

\subsubsection{Assessment of quality of life for the parents}

The parents' global quality of life was measured using the Norwegian version of the Quality of Life Scale questionnaire (QOLS-N) $(103,123)$. This self-reported questionnaire consists of 16 different items including information about the level of satisfaction at the time. These items were related to material and physical well-being, relationships with other people, social, community, and civic activities, personal development and fulfilment, and recreation. Each item is rated on a 7-point scale (1=not satisfied at all, 7=very satisfied). The QOLS is a valid instrument for measuring quality of life across patient groups and cultures, and it is conceptually distinct from health status or other causal indicators of quality of life. The QOLS has been found to be reliable (Cronbach's alpha: 0.86-0.89) and valid in stable chronic illness groups and in the general Norwegian population $(103,123)$. However, we do not know whether this questionnaire captures the challenges of being a parent of a child with $\mathrm{CP}$.

\subsubsection{The $\log$}

In the RCT, a Web-based log was developed to collect information on the targets of training, the frequency of training, the people responsible for the everyday training, the use of CE equipment at home and at kindergarten, the use of rhythmical intensions at home and at kindergarten, and parental attendance of courses between CE courses (Appendix 2). The parents completed this log once per month. The log consisted of 22 items. This Web-based $\log$ was developed in cooperation with an ICT system architect at the Norwegian Knowledge Centre for the Health Services. The system database is located on a LAN (local area network) under the administration of the Norwegian Knowledge Centre for the Health Services. Only authorised personnel have access to this database. In the RCT (Paper IV), we only extracted data on the targets and amounts of conventional training and the number of rhythmical intentions and $\mathrm{CE}$ equipment used after the $\mathrm{CE}$ course.

\subsection{Randomisation and blinding}

Randomisation and blinding were only relevant in the RCT (Paper IV). A statistician performed fixed block randomisation using software from randomisation.com. The block size 
was four. With this technique, for every four children included, two were assigned to the CE course immediately, and two were assigned to the CE course 4 months later. The statistician kept the randomisation table concealed from the researchers and assessors. When informed consent was received, the study coordinator at the $\mathrm{CE}$ centre contacted the statistician, informed him of the inclusion, and asked for the random allocation status of the newly included child. Then, the child was assigned to the first next course or was placed on a fourmonth waiting list. The included children continued their conventional training offered by primary health care or specialist health care during the periods when they were not in the CE course.

The CE study was single-blinded. The participants (parents and children) and the interventionist (CE conductors) were aware of the assignment groups, whereas the outcome assessors (the physiotherapists who performed the GMFM-66, GMFCS and MACS assessments) were blinded to the group allocation.

\subsection{Ethical considerations}

These studies were undertaken in accordance with the Declaration of Helsinki and were approved by the Regional Ethics Committee for Medical Research (REK) in Norway. All of the participants in the survey and RCT provided informed consent. On the information paper in which the parents provided their consent, the potential participants were reassured that they were free to withdraw from the RCT whenever they wanted. In the survey, withdrawals were possible by not completing and returning the questionnaires. Additional approval was obtained in the survey from the scientific board of the CPOP and the Norwegian Cerebral Palsy Register (CPRN), to gain access to the addresses, ages, sexes, sub-diagnoses and functional levels of the eligible children in the CPOP database. This survey was approved by the REK (approval number 2011/194-1). Because participation in the CPOP is based on informed consent, including the use of the data for research, analyses of differences between participants and non-participants were possible and were approved by the REK.

All of the participants in the RCT were informed by the CE conductors about the study at the assessment of eligibility prior to the courses. If the parents accepted contact with the project leader, they were telephoned. All of the parents of eligible children agreed to participate. One child withdrew because of the serious illness of a sibling. The parents were informed of the 
possibility to continue the $\mathrm{CE}$ courses and how to withdraw from the study in the information letter. Because these parents were motivated to attend the CE courses on their child's behalf, and participation in the study was quite demanding (see Table 2), this information was important. In addition, the parents were asked to complete the log monthly. The log data were collected in a closed database only accessible by the ICT system architect. The project leader met the parents at the courses to answer questions about the data collection, the progress of the study or other relevant questions. The REK approved the RCT and the log (approval numbers 2010/1518-1 and 2010/1518-2, respectively).

The children who participated in the RCT were 3-6 years old when they were included in the study. The parents assented to participation on their children's behalf. Today, it is standard practice to seek the child's agreement to participate in clinical trials when the child is deemed capable of making such a decision $(124,125)$. The lower age for recommendations to seek consent is suggested at 7-14 years old. Other factors that are important when discussing the ability to consent are developmental level, health status, emotional well-being, personality, social competence, emotional maturity, previous experience with research, and the complexity of the research (125). Based on the age and developmental level of the participating children and the complexity of the research, our decision not to seek consent from the children thus complied well with the recommendations.

The RCT was conducted as a pragmatic study, indicating that the administration of the intervention was similar to current practice in Norway. It is common to remain for some months on a waiting list before entering the first CE course, and two to three courses per year constitute standard practice. In addition, it is common that children continue their conventional training while waiting for the first CE course and between CE courses. To offer no interventions to the waiting list group would be unethical. Therefore, we planned the design of the study with a three-week CE course followed by conventional training, compared to conventional training on the four-month waiting list to avoid ethical issues. The children continued their conventional training in their communities because they were in need of constant training to prevent activity limitations and restrictions of participation; therefore, not to offer treatment would have been unethical.

To maintain anonymity, the location of the included PTØ centre was not presented in Paper IV. The participants in this study came from different parts of Norway. To facilitate the data 
collection procedure, the GMFM assessments were conducted by an experienced assessor, often at the PTØ centre on the first day of the CE course to avoid long travelling distances, or by two other experienced assessors located in Oslo and Stavanger, respectively. The time of the PEDI interview was chosen in accordance with the parents' wishes and in accordance with the study protocol.

\subsection{Analyses and statistics}

The main statistical methods used in the survey, systematic review and RCT are presented below.

\section{The survey}

Descriptive analyses were conducted for all of the relevant variables in Papers I and II. In Paper I, most of the data were categorical, the sample was small, and there were skewed distributions in some data sets. Therefore, Fisher's exact test was used to detect differences between the participants and non-participants and to assess associations among the child, parent and motor intervention characteristics and between intervention characteristics and parent-reported child benefits.

In Paper II, the MPOC scale scores were calculated according to established scoring rules (81). To investigate associations between the MPOC scale scores and the characteristics of the interventions and services, both the variables and their categories were collapsed because of the small number of participants and because most of the original variables were skewed. The collapsing process is described in Paper II. The MPOC-20 scores were analysed as continuous variables. Therefore, the Mann-Whitney U test was used to detect differences between the MPOC scale scores and: 1) the parental involvement and child benefits of the interventions and 2) the parents' satisfaction with the services.

An alpha level of 0.01 was used in both of the papers because of multiple testing. All of the analyses were performed using IBM SPSS Statistics software, version 20.

\section{The systematic review}

In the systematic review, the intervention characteristics were categorised according to the outcome (hand function, gross motor function, and functional skills), intensity (amount and 
duration), and context of the intervention (setting, organisation, goals, and parental involvement). The characteristics were coded as met or not met.

The standardised mean differences (SMDs) were computed for all relevant outcomes using Review Manager Software (RevMan5; Cochrane Information Management System). Moreover, meta-analyses were performed in RevMan5 if the included randomised controlled data were comparable in terms of outcome, type, and amount of training. The outcomes were categorised in the meta-analyses as unimanual or bimanual capacity, gross motor capacity, and functional skills. A random effects model was used to account for pooling effects because of the clinical heterogeneity of the included studies. We aimed to perform meta-regression analyses. However, such analyses could not be performed because of the small number of studies and the clinical heterogeneity among the study samples.

\section{The RCT}

The characteristics of the participants and conventional training were presented with descriptive statistics. Differences in the categorical characteristics (child's sex, CP type, GMFCS level, MACS level, additional CP-related problems, mother's education and father's education) in the two groups were investigated using Fisher's exact test. Differences in age between the groups were analysed using the Mann-Whitney U test.

Changes in the primary outcome of the GMFM-66 total score represented the mean difference between the baselines scores and the follow-up score (4 months later). The two-sample t-test was conducted to detect differences between the two study groups in the mean changes from baseline to follow-up. Because of the small sample size, non-parametric sensitivity analyses were performed using the Mann-Whitney $U$ test. To investigate the changes from baseline to follow-up within the groups, Wilcoxon's signed rank test was performed separately for each study group. In all of the analyses, a p-value $<0.05$ was regarded as statistically significant. All of the analyses were performed according to the intention-to-treat principle, based on available cases. We did not impute values for missing data. All of the analyses were performed using IBM SPSS Statistics software, version 20.

\subsubsection{Sample size}

In the RCT, the design, change, sample size and power calculations for the RCT were estimated using the primary outcome of the GMFM-66. The smallest important clinical 
difference of the GMFM-66 was set at 5 points, and the SD was assumed to be 4.5 for this age group (112). Based on power of $80 \%$, an alpha of 0.05 and the above-mentioned assumptions, a total of 22 participants were required for this trial.

The main results of the four papers are presented in the following chapter. 


\section{Summary of results}

This chapter summarises the main results of the survey, the systematic review and the RCT (Papers I-IV) on the characteristics and effects of intensive motor function and functional skills training and on parents' perceptions of FCS. More detailed descriptions of the characteristics of the included children in Papers I, II and IV and of the included studies in Paper III, and the results are presented in the attached papers (I-IV).

\subsection{Characteristics of intensive training}

\subsubsection{Intensive training}

Intensive training was identified in the survey, in the systematic review and in the RCT as 3-7 training sessions per week or as practicing several times per day (Table 3). More than onethird of the children in the survey and in the RCT performed gross motor training several times per day, whereas gross motor training at a similar level was identified in one-third of the studies in the systematic review. In contrast, a majority of the included studies in the systematic review reported fine motor training performed several times per day, whereas fewer than one-third of the parents reported fine motor training performed several times per day in the survey and in the RCT. 
Table 3. Intensive training across Papers I-IV

\begin{tabular}{|c|c|c|c|c|c|c|c|}
\hline \multirow[t]{2}{*}{ Amount of } & \multicolumn{2}{|c|}{ The survey $(\mathrm{N}=121)$} & \multirow{2}{*}{$\begin{array}{c}\text { The } \\
\text { systematic } \\
\text { review: } \\
\text { Paper II }\end{array}$} & \multicolumn{4}{|c|}{ The RCT-Paper IV $(\mathrm{N}=21)$} \\
\hline & Paper I, n & Paper II, $\mathrm{n}$ & & $\begin{array}{l}\text { CE group } \\
\text { Baseline }\end{array}$ & $\begin{array}{c}\text { Waiting } \\
\text { list group } \\
\text { Baseline }\end{array}$ & $\begin{array}{l}\text { CE group } \\
\text { Follow-up }\end{array}$ & $\begin{array}{c}\text { Waiting } \\
\text { list group } \\
\text { Follow-up }\end{array}$ \\
\hline & & & $\begin{array}{c}\mathrm{N}=38 \\
\text { studies } * *\end{array}$ & $\mathrm{n}=11$ & $\mathrm{n}=9$ & $\mathrm{n}=11$ & $\mathrm{n}=8$ \\
\hline $\begin{array}{l}\text { Gross } \\
\text { motor } \\
\text { training, 3- } \\
7 \text { sessions } \\
\text { per week }\end{array}$ & 35 & & $11^{* *}$ & 11 & 2 & 4 & 1 \\
\hline $\begin{array}{l}\text { Gross } \\
\text { motor } \\
\text { training, } \\
\text { several } \\
\text { times per } \\
\text { day }\end{array}$ & 43 & & $5 * *$ & & 4 & 5 & 5 \\
\hline $\begin{array}{l}\text { Fine motor } \\
\text { training, 3- } \\
7 \text { sessions } \\
\text { per week }\end{array}$ & 46 & & $3 * *$ & 11 & 4 & 7 & 4 \\
\hline $\begin{array}{l}\text { Fine motor } \\
\text { training, } \\
\text { several } \\
\text { times per } \\
\text { day }\end{array}$ & 26 & & $20 * *$ & & 2 & 2 & 3 \\
\hline $\begin{array}{l}\text { Everyday } \\
\text { skills } \\
\text { training*, } \\
\text { 3-7 sessions } \\
\text { per week }\end{array}$ & & 5 & $6^{* *}$ & 11 & 4 & $4 * * *$ & $4 * * *$ \\
\hline $\begin{array}{l}\text { Everyday } \\
\text { skills } \\
\text { training, } \\
\text { several } \\
\text { times per } \\
\text { day }\end{array}$ & & 55 & $14 * *$ & & 2 & $4 * * *$ & $1 * * *$ \\
\hline
\end{tabular}

*Everyday skill training (includes training of gross motor and fine motor function, eating, dressing, toileting, and playing); **38 studies were included in the systematic, review of which 16 targeted gross motor functioning, 23 targeted hand functioning, and 20 targeted functional skills, *** Only reported numbers of children training to dress themselves.

\subsubsection{Context of training}

In the survey, gross motor training was performed at home and in clinics by two-thirds and one-third of the children, respectively (Table 4). Fine motor training was performed by more than half of the children at home but only by very few children at the clinics. The studies 
included in the systematic review (Paper III) reported a different picture, namely that intensive gross motor training occurred in clinics but occurred less often at home. In contrast, fine motor training occurred both at home and in clinics in a majority of the studies. Parents' reports in the RCT log follow-up showed that gross and fine motor training and everyday skill training occurred most often at home and less often in clinics.

Table 4. Context of training

\begin{tabular}{|c|c|c|c|c|}
\hline $\begin{array}{l}\text { Context* of } \\
\text { intensive }\end{array}$ & $\begin{array}{l}\text { The survey } \\
(\mathrm{N}=121) \\
\text { (includes both } \\
\text { intensive and non- } \\
\text { intensive training) } \\
\text { Paper I and II, } \mathrm{n}\end{array}$ & $\begin{array}{l}\text { The systematic } \\
\text { review - Paper III } \\
\mathrm{N}=38 \text { studies** }\end{array}$ & $\begin{array}{l}\text { CE group } \\
n=11\end{array}$ & $\begin{array}{l}\mathrm{r} I V(\mathrm{~N}=21) \\
\text { veek 14) }\end{array}$ \\
\hline $\begin{array}{l}\text { Gross motor } \\
\text { training at home }\end{array}$ & 80 & $7 * *$ & 11 & 6 \\
\hline $\begin{array}{l}\text { Gross motor } \\
\text { training in the } \\
\text { clinic }\end{array}$ & 36 & $16^{* *}$ & 6 & 3 \\
\hline $\begin{array}{l}\text { Fine motor } \\
\text { training at home } \\
\text { Fine motor }\end{array}$ & 62 & $20 * *$ & 11 & 7 \\
\hline $\begin{array}{l}\text { training in the } \\
\text { clinic }\end{array}$ & 9 & $18 * *$ & 5 & 1 \\
\hline $\begin{array}{l}\text { Everyday skills } \\
\text { training*** at } \\
\text { home }\end{array}$ & NR & $14 * *$ & 10 & 8 \\
\hline $\begin{array}{l}\text { Everyday skills } \\
\text { training in the } \\
\text { clinic }\end{array}$ & NR & $16^{* *}$ & 3 & 1 \\
\hline
\end{tabular}

\subsubsection{Use of goals}

Approximately two-thirds of the children performed goal-directed gross and fine motor training and everyday skills training as reported in the survey (Table 5). Goal-directed training was less often reported in the systematic review studies targeting gross motor function than in the studies targeting fine motor function and everyday skills. All of the children in the $\mathrm{CE}$ group received goal-directed training in the CE course, but this information was not collected from the waiting list group in the RCT. 
Table 5. Reported use of goals across Papers I-IV

\begin{tabular}{lccc}
\hline Use of goals in & $\begin{array}{c}\text { The survey }(\mathrm{N}=121) \\
\text { includes both intensive and non- } \\
\text { intensive training) }\end{array}$ & $\begin{array}{c}\text { The systematic } \\
\text { review - Paper } \\
\text { III } \\
\mathrm{N}=38 \\
\text { studies* }\end{array}$ & $\begin{array}{c}\text { The RCT- Paper IV } \\
\text { Paper I, } \mathrm{n} \quad 21) \\
\text { CE group }\end{array}$ \\
$\begin{array}{l}\text { Gross motor } \\
\text { training }\end{array}$ \\
$\begin{array}{l}\text { Fine motor } \\
\text { training }\end{array}$ \\
$\begin{array}{l}\text { Everyday skills } \\
\text { training ** }\end{array}$
\end{tabular}

* 38 studies were included in Paper III, of which 16 targeted gross motor functioning, 23 targeted hand functioning, and 20 targeted functional skills, ${ }^{*}$ Everyday skill training (includes training of gross motor and fine motor function, eating, dressing, toileting, and playing)

\subsubsection{Parent involvement in training}

Approximately two-thirds of the parents in the survey reported that they were actively involved in gross motor training, whereas in the systematic review, only 6 of 16 studies reported parent involvement in gross motor training (Table 6). For fine motor training, more than half of the participating parents acted as performers in the survey, and approximately half of the included studies in the systematic review reported active parental involvement. A majority of the parents reported in the log that they acted as performers in the conventional training during follow-up (Paper IV).

Table 6. Parental involvement in training

\begin{tabular}{|c|c|c|c|c|c|}
\hline \multirow[t]{3}{*}{$\begin{array}{l}\text { Parent } \\
\text { performer of }\end{array}$} & \multirow{2}{*}{\multicolumn{2}{|c|}{$\begin{array}{l}\text { The survey }(\mathrm{N}=121) \\
\text { (includes both } \\
\text { intensive and non- } \\
\text { intensive training) }\end{array}$}} & \multirow{3}{*}{$\begin{array}{c}\text { The systematic } \\
\text { review - Paper } \\
\text { III } \\
\mathrm{N}=38 \text { studies* }\end{array}$} & \multicolumn{2}{|c|}{$\begin{array}{c}\text { The RCT - Paper IV }(\mathrm{N}=21) \\
\text { Follow-up }\end{array}$} \\
\hline & & & & CE group, & $\begin{array}{l}\text { Waiting list } \\
\text { group, }\end{array}$ \\
\hline & Paper I, n & Paper II, n & & $\mathrm{n}=11$ & $\mathrm{n}=9$ \\
\hline $\begin{array}{l}\text { Gross motor } \\
\text { training }\end{array}$ & 83 & & $6^{*}$ & 11 & 6 \\
\hline $\begin{array}{l}\text { Fine motor } \\
\text { training }\end{array}$ & 65 & & $12 *$ & 11 & 7 \\
\hline $\begin{array}{l}\text { Everyday skills } \\
\text { training** }\end{array}$ & & 56 & $8^{*}$ & 10 & 8 \\
\hline
\end{tabular}




\subsubsection{Parent education}

Approximately half of the parents reported receiving supervision or attending courses targeting motor training in the survey. In the systematic review, parent education was often reported in intensive training regarding hand function and functional skills and less often in studies of gross motor training. Among the participating parents in the RCT, only one parent in the CE group reported parental education during follow-up (Table 7).

Table 7. Parent education

\begin{tabular}{|c|c|c|c|c|c|}
\hline \multirow{3}{*}{$\begin{array}{l}\text { Received } \\
\text { parental } \\
\text { education* } \\
\text { in }\end{array}$} & \multirow{2}{*}{\multicolumn{2}{|c|}{$\begin{array}{l}\text { The survey }(\mathrm{N}=121) \\
\text { (includes both intensive } \\
\text { and non-intensive training) }\end{array}$}} & \multirow{3}{*}{$\begin{array}{c}\text { The systematic } \\
\text { review - Paper } \\
\text { III } \\
\mathrm{N}=39 \\
\text { studies** }\end{array}$} & \multicolumn{2}{|c|}{$\begin{array}{c}\text { The RCT - Paper IV }(\mathrm{N}=21) \\
\text { Follow-up }\end{array}$} \\
\hline & & & & The CE & The waiting \\
\hline & Paper I, n & Paper II, $\mathrm{n}$ & & $\mathrm{n}=11$ & $\mathrm{n}=8$ \\
\hline $\begin{array}{l}\text { Gross motor } \\
\text { training }\end{array}$ & $64 * * *$ & NR & $7^{* *}$ & \multirow{3}{*}{1} & \multirow{3}{*}{0} \\
\hline $\begin{array}{l}\text { Fine motor } \\
\text { training }\end{array}$ & & NR & $19 * *$ & & \\
\hline $\begin{array}{l}\text { Everyday } \\
\text { skills training }\end{array}$ & NR & 15 & $15 * *$ & & \\
\hline
\end{tabular}

\subsubsection{Participation in intensive programs}

Twenty-eight percent of the parents in the survey reported that their children participated in an intensive program such as CE, Doman, the Family Hope centre, or other local intensive programs. Such programs were only identified in 6 of the 38 studies included in the systematic review. Five of these studies evaluated the effects of $\mathrm{CE}$, whereas one evaluated the effects of Vojta therapy. Finally, 20 children participated in the RCT, which evaluated the effects of CE compared to conventional training while being on a waiting list.

\subsection{Effects of intensive training}

The effects of intensive motor function and functional skills training are summarised in Paper III. Thirty-eight controlled studies were included, of which 23 targeted hand function, 16 targeted gross motor function, and 20 targeted functional skills. Six meta-analyses, based on 10 studies summarising the effects of CIMT on hand function and functional skills, were performed. The studies targeting gross motor function were too heterogeneous to be pooled. 
In addition, the updated search in Paper III yielded seven controlled trials, of which four targeted hand function, and three targeted gross motor function. The four studies (127-130) evaluated the effects of CIMT compared to conventional training or intensive bimanual training, supporting the exciting evidence base of CIMT. The three studies of gross motor function (131-133) investigated the effects of intensive PT and mirror neuron stimulation. These studies showed inconclusive results and were characterised by small sample sizes, thus supporting the findings of Paper III.

To summarise, the systematic review with the updated search showed the following.

- In a majority of the included studies, equal improvements were identified between intensive training and conventional training or between two different intensive interventions.

- Intensive gross motor training that was mostly performed 3-7 times per week, compared to conventional training or another intensive intervention, showed small or no differences in gross motor skills.

- CIMT performed for more than one hour per day compared to conventional training showed improved hand function, compared to conventional training ( $\mathrm{n}=2$ studies).

- CIMT performed at least 2-7 sessions per week, including home training, showed improvements in functional skills, compared to conventional training $(n=3)$.

- CIMT performed at least 2-7 sessions per week, including home training, showed improvements in functional skills, compared to intensive bimanual training $(n=4)$.

\subsubsection{Effects of CE}

In the systematic review, five studies evaluated the effects of $\mathrm{CE}$ in young children with $\mathrm{CP}$. It was impossible to pool the studies included in meta-analyses because of the heterogeneity among the studies. CE compared to conventional rehabilitation or intensive PT/OT showed few significant improvements in gross motor function, hand function and functional skills in the systematic review. Only two significant findings were reported, on feeding and dressing, in one single study with a high risk of bias (67). The results from the RCT showed no significant differences between the study groups regarding the primary outcome of gross motor function (GMFM-66: MD -1.55 [95\% CI: -4.67, 1.56], p=0.31). In addition, we could not establish group differences in secondary outcomes regarding the child's functional skills and health-related quality of life, the parents' global quality of life, and the parents' 
experiences of FCS. However, one significant finding was found on the MPOC-20, which showed that parents in the $\mathrm{CE}$ group received more specific information about their children than parents in the waiting list group (MD -1.52 [95\% CI: $-2.69,-0.35], p=0.01$ ). The CE results from the RCT were consistent with the results of the systematic review.

\subsection{Parents' perceptions of family-centred services}

Parents' experiences of FCS in primary health care in Norway were assessed in the survey and in the RCT using the MPOC-20 (Table 8). The level of family-centredness in primary health care was assessed at baseline and at follow-up in the waiting list group and only at baseline in the $\mathrm{CE}$ group. At follow-up, the parents in the $\mathrm{CE}$ group reported their experiences with the CE course. In general, the parents in the survey and in the RCT reported that familycentred behaviour varied between "happens to a small extent" to "happens to a fairly great extent." In the MPOC-20 scale, "Providing general information" achieved the lowest rating, and scale 5, "Respectful and supportive care," received the highest rating. The parents in the CE group reported higher scores in the "Providing specific information about the child" (scale 3) section than the parents in the waiting list group.

Table 8. Parent experiences with family-centred services measured in the MPOC-20

\begin{tabular}{|c|c|c|c|c|c|}
\hline \multirow{3}{*}{$\begin{array}{l}\text { Parent experiences } \\
\text { with family-centred } \\
\text { services }\end{array}$} & \multirow{2}{*}{$\begin{array}{l}\text { The survey } \\
\text { - Paper II, } \\
\text { mean (SD) }\end{array}$} & \multicolumn{4}{|c|}{ The RCT - Paper IV $(\mathrm{N}=21)$} \\
\hline & & \multicolumn{2}{|c|}{ CE group, mean (SD) } & \multicolumn{2}{|c|}{$\begin{array}{c}\text { Waiting list group, } \\
\text { mean (SD) }\end{array}$} \\
\hline & $\mathrm{N}=120$ & $\begin{array}{c}\text { Baseline } \\
\mathrm{n}=11\end{array}$ & $\begin{array}{c}\text { Follow-up } \\
\mathrm{n}=11\end{array}$ & $\begin{array}{c}\text { Baseline } \\
\mathrm{n}=10\end{array}$ & $\begin{array}{c}\text { Follow-up } \\
n=9\end{array}$ \\
\hline $\begin{array}{l}\text { Scale 1: Enabling } \\
\text { and partnership }\end{array}$ & $4.08(0.33)$ & $3.85(1.30)$ & $4.24(1.37)$ & $3.96(1.60)$ & $3.30(1.59)$ \\
\hline $\begin{array}{l}\text { Scale 2: Providing } \\
\text { general information }\end{array}$ & $3.18(0.31)$ & $2.76(1.51)$ & $2.56(1.42)$ & $3.26(1.56)$ & $3.29(1.58)$ \\
\hline $\begin{array}{l}\text { Scale 3: Providing } \\
\text { specific information } \\
\text { about the child }\end{array}$ & $4.27(0.45)$ & $4.45(1.42)$ & $5.17(0.93)$ & $4.20(1.52)$ & $3.61(1.41)$ \\
\hline $\begin{array}{l}\text { Scale 4: Coordinated } \\
\text { and comprehensive } \\
\text { care }\end{array}$ & $4.63(0.17)$ & $4.91(1.02)$ & $4.50(1.07)$ & $4.45(1.40)$ & $4.66(0.90)$ \\
\hline $\begin{array}{l}\text { Scale 5: Respectful } \\
\text { and supportive care }\end{array}$ & $4.99(0.23)$ & $4.82(0.73)$ & $5.10(0.99)$ & $4.73(0.95)$ & $4.89(0.69)$ \\
\hline
\end{tabular}

*Score $0=$ not applicable; $1=$ does not happen at all; 2 = happens to a very small extent; 3 = happens to a small extent; $4=$ happens to some extent; 5 = happens to a fairly great extent; $6=$ happens to a great extent; $7=$ happens to a very great extent 


\subsection{Parent-reported child benefits of motor training}

The parent-reported child benefits were described in the survey, and they are summarised in Table 9. More than half of the parents reported large to very large child benefits from the gross and fine motor training. In contrast, fewer than half the parents reported large to very large child benefits from the everyday skills training.

Table 9. Parent-reported child benefits of training

\begin{tabular}{|c|c|c|}
\hline \multirow[t]{2}{*}{ Parent-reported } & \multicolumn{2}{|c|}{ The survey $(\mathrm{N}=121)$} \\
\hline & Paper I, n & Paper II, n \\
\hline $\begin{array}{l}\text { No or some benefits of gross motor } \\
\text { training }\end{array}$ & 14 & \\
\hline $\begin{array}{l}\text { Large or very large benefits of gross } \\
\text { motor training }\end{array}$ & 76 & \\
\hline $\begin{array}{l}\text { No or some benefits of fine motor } \\
\text { training }\end{array}$ & 27 & \\
\hline $\begin{array}{l}\text { Large or very large benefits of fine } \\
\text { motor training }\end{array}$ & 60 & \\
\hline $\begin{array}{l}\text { No or some benefits of everyday skills } \\
\text { training* }\end{array}$ & & 59 \\
\hline $\begin{array}{l}\text { Large or very large benefits of } \\
\text { everyday skills training* }\end{array}$ & & 50 \\
\hline
\end{tabular}




\section{Discussion}

The aim of this thesis was to increase the knowledge of intensive training in young children with cerebral palsy (CP) by focusing on the characteristics and effects of intensive training and on parents' experiences. This chapter is an integrated discussion of the main results from the survey, the systematic review and the RCT, in relation to other relevant research. Five topics are discussed: 1) characteristics of intensive motor function and functional skills training; 2) effects of this intensive training, including CE; 3) parents' experiences of FCS; 4) strengths and limitations of the included papers in this thesis; 5) and implications of clinical practice and future research.

\subsection{Characteristics of intensive training}

\subsubsection{Amount and duration of intensive training}

When the recent literature has described or investigated the intensity of training, both the amount and the duration of training have been combined $(23,134)$. In our systematic review, it was challenging to use the term "intensity" because more than half of the included studies reported home training, in which the amount and duration of training were scarcely reported. Some therapist-set home programs reported the amount and duration of training; however, these data were not reported when home training was incorporated into daily activities.

Defining intensive training is also problematic because the amount of training sessions is not a relevant indicator to all types of intensive training, and how intensive training is defined in research does not reflect clinical practice (28). Activities incorporated into the families' everyday lives are not easy to count. As far as we know, no studies have counted the numbers of repetitions of activities in natural environments among young children with $\mathrm{CP}$. Some of the studies included in our systematic review reported fewer than three training sessions per week but included home training incorporated into daily activities. Therefore, this category of training was defined as intensive training. In contrast, some of the included studies of gross motor training typically applied the training for 30 minutes three times per week, with no additional reported home training. It is questionable whether this amount of training is sufficient to improve outcomes, so it might therefore be defined as conventional training. Another example of the problems that might occur when categorising training as intensive or 
non-intensive (conventional training) was found in the parents' logs and in the survey, which showed that predefined, non-intensive, conventional training was practiced at home, at kindergarten and in clinics (not reported in Paper IV) at least three times per week and accordingly might be redefined as intensive conventional practicing. However, perhaps this high amount of conventional training should not be defined as "intensive training" and should rather be described as multiple repetitions of functional skills that are expected to be learned at a young age by all children and therefore are incorporated into the everyday life of the family. To summarise, it is problematic to categorise interventions into intensive or conventional (non-intensive) training when the amount and context of training are not adequately described.

\subsubsection{Context of training}

On the ICF-CY (135), contextual factors, such as where the training occurs and how the training is organised, are suggested to influence the child's development. As far as we know, our systematic review was the first review that systematically described the context of intensive training in young children with CP. According to the studies included in the systematic review, gross motor function training was primarily conducted in clinics, whereas in the survey and in the RCT, this training was performed at home, at kindergarten and in the clinic. Palisano et al. (28) showed that parents of children who received PT or OT in more than one training context reported more PT and OT sessions per month than children who received $\mathrm{PT}$ and $\mathrm{OT}$ in only one setting. One possible explanation for the different findings related to training context might be that the parents in the survey and in the RCT were specifically asked about different training contexts, whereas this question was not asked in the studies included in our systematic review. Another reported difference suggested that gross motor training was performed several times per day and was more common in young children with CP than fine motor training, according to the survey and the RCT (Papers I and IV). In contrast, the systematic review, which did not include any Norwegian studies, reported more studies targeting fine motor training several times per day, rather than gross motor training. In Norway, more physiotherapists than occupational therapists are employed as part of paediatric rehabilitation services. In addition, the tasks between the two professional groups are divided; the physiotherapists' domain is gross motor function training, whereas the occupational therapists' domain is fine motor training. This organisation of services might contribute to explaining the differences identified between the characteristics of gross and fine motor training in Norway, compared to other countries. 
According to the systematic review, additional home training is common in intensive training to increase the amount of training sessions, practice in daily activities, or a combination of both. The adherence of home training varied (23). This variation might be random or the result of different clinical practices. Two single studies $(75,76)$ suggested that parents were less compliant with therapist-set home programs than with programs with which the parents learned to use everyday activities as learning opportunities (family-set home programs). We did not collect data on compliance from any of the included papers. The issue of compliance might contribute to explaining the variation in the effects of intensive training.

Evidence has suggested that capacity-building of the parents might strengthen families' ability to provide their children with interest-based natural learning opportunities, to improve child learning and development, and to have caregiver competency-enhancing effects $(82,136,137)$. In the survey and the RCT, approximately two-thirds of the parents reported that they were involved in home training and had attended parent education about motor training, whereas these activities were less often reported in studies of gross motor function included in the systematic review. This difference might be explained by home training being less often reported in studies of gross motor training (Paper III). CIMT studies have shown that parents can provide CIMT at home if relevant parent education and supervision are provided $(138,139)$.

In the systematic review, individual training, such as home training, showed more promising improvements than group training, found in the CE studies $(67,70,140-142)$. Ødman et al. (143), who investigated the effects of CE and included children 3-16 years old, suggested that older children benefitted more from group training than younger children. Because the children in the RCT were six years old or younger, and half of them had GMFCS levels IV-V, this fact might indicate that some of the children were too young or were not sufficiently mature cognitively to benefit from the added effect of group training. Eliasson et al. (23) recommended further investigation of how different contexts influence treatment efficacy and compliance with CIMT. Based on the findings of the systematic review and the RCT, it is equally important to investigate how different contexts (home and/or clinics and individual and/or group training) influence treatment efficacy with regard to intensive gross motor and functional skills training. 


\subsubsection{Use of goals in training}

The current evidence base for goal-directed training is promising and well documented $(3,4,6)$. Novak et al. (4) claimed that goal-directed functional training was effective and should be part of the standard care for children with CP. In participatory family-centred practices (82), the therapists are encouraged to set specific goals together with the child and the family. Øien et al. (144) found that the use of goals based on child and family concerns changed the parents' perceptions of training, from exercises performed in defined sessions to the practice of skills in naturally occurring situations. The ICF-CY could be useful in goalsetting processes with parents because it offers a method with which to understand disability that also emphasises the context and resources of the child and the family. The results from the survey reported that approximately two-thirds of the training was goal-directed and was often incorporated into daily activities, indicating a significant association between goaldirected training and higher parent-reported child benefits of training. This finding might imply that the parent-reported training in the survey and in the CE course was according to "best practice" and might explain the significant parent-rated child benefits of training. However, these high ratings might also be explained by the family-set home training, which was based on the families' wishes and was incorporated into daily activities. The results must be interpreted cautiously because of the low response rate.

\subsection{Effects of intensive training}

Intensive motor function and functional skills training resulted in similar improvements in gross motor function, hand function and functional skills, compared to conventional training (non-intensive) or another intensive training, according to recent systematic reviews $(3-8,23)$, the results from our systematic review (Paper III) and the updated search in Paper III. Only the well-documented CIMT showed significant effects on hand function and functional skills compared to conventional training in two meta-analyses (Paper III) and two recent single studies $(127,128)$, consistent with the current evidence base for CIMT.

Eliasson et al. (23) suggested investigating the differences in the effects between smaller amounts and longer durations ( $\geq 6$ months) of intensive training, compared to larger amounts with shorter durations. This question is not only interesting when investigating the optimal intensity of CIMT, but it is even more interesting when comparing the effects of intensive gross motor training and fine motor training. The intensity appeared to differ between studies 
targeting hand function (CIMT studies) and studies targeting gross motor function in the systematic review. In studies targeting gross motor function, the intensity was reported as three to five training sessions per week of 30-60 minutes each, often for more than six months without home training, whereas hand function training was often practiced 2-6 hours per day for 14-21 days to up to 8 weeks at home (Paper III). Moreover, evidence has suggested that intensive repetitions of goal-directed activities, such as CIMT, change the brain's structure and function and result in the learning of new skills $(17,18,54,145)$. Our review supported these promising results, but similar results were not identified in the studies of gross motor function. However, motor learning is specific, and gross motor function training requires different physical and cognitive individual resources and different contexts and might require a different intensity than hand function training. This issue is unresolved and requires further investigation.

Other aspects, in addition to the intensity and context of training, which might influence the training outcome, are the children's characteristics, such as the type of CP, age, level of gross motor function and hand function. We did not focus on these characteristics in the systematic review. In the consensus paper by Eliasson et al. (23), the authors posed the question of whether the impairment influenced the outcome of CIMT training. In these CIMT studies, the participants generally had moderately impaired hand function (MACS I-III), whereas the studies of gross motor function often included all GMFCS levels (Paper III). Because the level of MACS often corresponds to the level of GMFCS (146-148), less impaired children were included in the studies targeting hand function than were included in the studies on gross motor function, according to our review. Evidence has suggested that children with GMFCS levels I-II achieved more improvements on the GMFM-66 than children with GMFCS levels III-V (112,149). In addition, children with GMFCS levels IV-V reached their gross motor developmental potential earlier than children with GMFCS I-III (99).

The evidence related to age and outcomes of intensive gross and fine motor training have been inconclusive $(8,150-152)$. One might believe that early treatment is better, considering the theory of neuro-plasticity (7). However, children of all ages appear to benefit from CIMT (23). In systematic reviews, early interventions, including in infants and children younger than 3 years old, have shown promising results; however, the effects are often of short duration $(153,154)$. Therefore, not only the type, amount, and context and how the training was delivered matter, but the characteristics of the child can also influence the results. 


\subsubsection{The effects of CE}

The evidence base for CE is inconclusive and has been characterised by studies with a high risk of bias $(4,6,68,155,156)$. The results from the RCT (Paper IV) showed similar improvements in motor function and functional skills between the CE group and the waiting list group. A majority of the parents reported in the log that conventional training was performed at least three times per week. This high amount of conventional training, which was often practiced at home, might contribute to explaining the lack of added improvements from the CE course. Because of the small sample size in the RCT and the lack of rigorous $\mathrm{CE}$ studies, the results must be interpreted cautiously. However, this finding does not imply that $\mathrm{CE}$ is ineffective, although $\mathrm{CE}$ does not appear to be more effective than other interventions.

Training at home and in the child's natural environment has also been shown to enhance the transfer of motor skills $(3,4,77$ and Paper III). In the CE studies included in our systematic review $(67,70,140-142)$ and in our RCT (Paper IV), no information was given regarding the extent to which the $\mathrm{CE}$ elements were practiced at home or at kindergarten, except the information collected in the log regarding the use of CE equipment and rhythmical intention. Therefore, the training context might contribute to explaining the lack of added effects from CE.

According to the reference curves of gross motor function $(21,60)$, children with $\mathrm{CP}$ have, on average, reached $90 \%$ of their gross motor capability by the age of 5 years old, and children with lower GMFCS levels reach their gross motor potential even earlier. Considering the median age of 4 years old and that half of the participating children in our RCT were at GFMCS levels IV and V, this finding might suggest that a majority of the children had reached their gross motor developmental potential through a large amount of conventional training. This finding might also contribute to explaining the small changes added by $\mathrm{CE}$ on the GMFM-66. However, when the effects of CE, compared to another intensive intervention, were measured based on a self-reported individualised outcome measurement and GMFM-88 (157), no group differences were established. Ødman and Øberg (157) questioned whether the added value of the CE course was limited because of the large amount of conventional training and because the children appeared to function close to their optimal levels. More rigours research is required that investigates the added effects of $\mathrm{CE}$ to conventional training and that allows for subgroup analyses because some subgroups might benefit from CE. 
Few controlled trials have established a statistically significant difference between intensive interventions and a comparator of the GMFM-66 (paper III) before six months of follow-up, even using a lower clinically meaningful change of 5\% (157). Only one of nine studies included in the systematic review (Paper III) showed improvements on the GMFM-88 or -66 after six weeks of intensive gross motor training (158). However, this study had a high risk of bias. Newer controlled trials with older children (159) or very young children $(132,133)$ have found no effect of intensive motor training compared to conventional training on gross motor function over 6 months or less. The primary outcome of gross motor function (GMFM-66) was assessed four months after baseline in our RCT (Paper IV). However, in clinical practice and in the much cited reference curves of gross motor function, the GMFM-66 was assessed after six months in young children (60). The findings from the reference curves, the systematic review (Paper III) and clinical practice might indicate that the follow-up was too short to establish clinically important differences between the groups in the RCT (Paper IV).

One significant group difference was established in the RCT, which showed that parents in the $\mathrm{CE}$ group received higher levels of specific information about their children than the waiting list group. This specific information might have empowered the parents and could contribute to explaining the trend identified in "Enabling and partnership" (MPOC-20 scale 1). Tetzchner et al. (25) and Ødman et al. (160) found that parents experienced hope and empowerment by attending Doman and a CE program, respectively, even if no effects were identified in their children's function. However, the results of our RCT must be interpreted cautiously because of the small sample size and the possibility of type II errors. Nevertheless, there might be added family-related effects of these intensive programs that are valued (160), and they must be further investigated in a larger trial.

\subsection{Parents' experiences of family-centred services}

Families of children with CP face a considerable number of challenges associated with the disease. Problems with cognition, vision, and epilepsy are common in children with $\mathrm{CP}$, as reported in the survey and the RCT, in addition to the dominant motor impairments. To address these challenges, FCS has been accepted as a "best practice" because optimal child functioning is believed to occur within a supportive family and community context (49). In the approach of FCS, the effectiveness of the interventions also depends on how an 
intervention and a service are delivered $(161,162)$. None of the studies included in the systematic review (Paper III) used the MPOC-20 to collect such information, but the survey and the RCT (Papers II and IV) collected data on how the training was delivered using the MPOC-20.

As far as we know, the parents' experiences of FCS reported in Paper II are the only published MPOC-20 data from primary health care settings. Other Norwegian studies have investigated FCS in specialist health care (163-165). The parents in these studies rated familycentred behaviour higher than the parents' in primary health care. Because of the low response rate in the survey, the results must be interpreted cautiously. Generally, the results of the Norwegian MPOC-20 studies have been consistent with the results of international MPOC-20 studies among parents of children with CP in specialist health care (166-172).

The current evidence base for the MPOC-20 shows that "Provision of respectful and supportive care" (scale 5) achieved the highest score in both specialist and primary health care (166172 and Paper II). The parents perceived that they experienced "Respectful and supportive care" to a fairly great extent. The practices reported in our survey and RCT and other mentioned FCS studies might have been more influenced by relational help giving practices, which are identified by respectful professional behaviours, than by participatory practices, which include information-sharing and the active involvement of parents in decision making, as suggested in the study by Dunst (82).

In Paper II, the MPOC-20 scale of "Provision of general information" (scale 2) achieved the lowest score, compared to other Norwegian MPOC-20 studies (163-165) and to international MPOC-20 studies (166-172). The parents reported that the "Provision of general information" occurred to a small extent. King et al. (173) suggested that one reason for the paucity of general information sharing identified by both therapists and parents might be that service delivery models in paediatric rehabilitation do not view the provision of general information to be an important role for therapists. Therapists might feel that providing general information is the responsibility of other disciplines, such as social work or nursing. However, sharing of both general and specific information must be repeatedly practiced by therapists in primary and specialist health care to provide family-centred care and to enable parents to make informed decisions about their young children (87). 
The parents generally rated "Provision of specific information about the child" higher in all of the mentioned MPOC studies than "Provision of general information." A possible explanation for this finding might be that parents and therapists have different perceptions of what is included in general information, whereas specific information is more easily related to specific children. Additionally, therapists working in specialist health care and in CE courses see more children with $\mathrm{CP}$ and therefore have more experience and specific knowledge about this group of patients. The parents in the CE course were encouraged to ask the CE specialist questions about their children's development and other relevant questions (Paper IV). This fact might explain why they rated the provision of specific information higher than the waiting list group. In the survey (Paper II), the parents reported a lack of information-sharing behaviours in primary health care. Jeglinsky et al. (170) found that physiotherapists working in primary health care also rated their own family-centredness lower than physiotherapists working in specialist health care. This finding might be the result of many therapists in primary health care working alone and having less experience and specific knowledge of children with $\mathrm{CP}$ and the FCS approach.

Increasing evidence has shown that the need for general information among parents of children with CP is not met, accordingly representing an area for improvement, as identified in Paper II. In the survey, the parents requested more information about their children's type of disability, the types of services offered, and information about how to contact other families in similar situations. All of this information is critical for enabling parents to make informed decisions for their children, as acknowledged by the EBR and FCS. These results must be interpreted cautiously because of the low response rate and high education levels among the respondents in the survey. However, the need for more information about available treatments and services is common among parents caring for children with CP (174). Therefore, therapists should be aware of their own preferences and biases abut treatments when offering such information (174) because some parents have experienced information barriers when seeking information about CE (65).

The lack of information sharing is not unique to paediatric rehabilitation services. The WHO addressed the issue of information-sharing behaviours and health literacy (175), which aim to make people more capable of caring for their own health and more likely to act upon reliable health information. Based on the findings from our survey and other published MPOC studies, there is a need for different methods of facilitating families' access to reliable 
information and their ability to use this information. Accessible and rigorous systematic reviews, available patient information materials and Web sites are important tools for empowering families and improving paediatric rehabilitation services (176). Another aspect of information-sharing is the use of parent-reported data in controlled trials, e.g., when assessing quality of life, parents' experiences of interventions and services, and how these interventions and services were provided. This thesis extensively relied on parent-reported data because of the posed research questions and the acknowledgement of information sharing as a method for improving paediatric rehabilitation services. Self-reported data on children's everyday lives, function and performed training have also been proposed to constitute a valid outcome measurement, compared to therapist-assessed outcomes because of the belief that the patients are the best judges of the outcome $(177,178)$.

\subsection{Strengths and limitations}

The main strengths and limitations of the thesis' four papers are presented below.

The main limitations of the survey (Papers I and II) were the low response rate and that a majority of the respondents were mothers with high education levels. Therefore, the low response rate might have weakened the internal and external validity of the survey. Low response rates are common in postal surveys in Norway (179) and in other studies conducted for paediatric rehabilitation research $(180,181)$. In this field, the respondents are typically mothers with high educations $(28,82)$. As many as $71 \%$ of the mothers had more than 12 years of education in the survey, compared to $40 \%$ in the general Norwegian population of the same age (182). The high education level among the mothers might have influenced the generalisability of the results. No significant differences were identified between the children's characteristics among participants and non-participants, indicating that the sample was representative of young children with CP in Norway. The current absence of psychometric testing of the HabServ questionnaire should also be considered when interpreting the results.

The main limitation of our systematic review (Paper III) was the lack of the inclusion of studies awaiting assessments in their results and conclusions. These studies were included in the thesis. Because of the small sample size and inconclusive results, they did not change the overall outcomes of intensive gross or fine motor training. However, although an extensive 
search was conducted, there might be relevant studies that were not included in Paper III. The research production of CIMT studies is extensive, and it is difficult to perform a comprehensive systematic review with a completely updated and incorporated search. We did not consider whether the characteristics of the children might have influenced the outcomes. Because this was a systematic review, and we did not contact the authors with missing data, we relied on the information provided in the included studies. This was not a problem when critically assessing the studies for the risk of bias, but it was more problematic when categorising the interventions because some were poorly reported. Two reviewers independently extracted data for the intervention descriptions to obtain accurate descriptions. Otherwise, we followed the methodology of systematic reviews and the PRISMA guidelines, thus strengthening the internal and external validity of our systematic review.

The small sample size was the main source of bias in the RCT. Therefore, the results must be considered in light of possible type II statistical errors. It is questionable whether a larger sample size would have changed the results significantly because of the characteristics of the children, the large amount of conventional training, and the other discussed studies, which reported similar results. Nevertheless, a larger trial would have allowed for sub-group analyses because some sub-groups might have benefitted from CE. Three GMFM-66 assessors were required because of the few eligible participants and long travel distances. They were all experienced assessors, but no inter-rater agreement was assessed. This lack might present a threat to the study's validity. We followed the method suggested by the CONSORT statement, and we protected the study against selection and detection bias using random concealed allocation and blinding of the outcome assessors. This has strengthened the internal and external validity of the RCT.

\subsection{Implications for practice and future research}

In the survey, the parents reported that approximately two-thirds of the motor training was goal-directed and that the use of goals was associated with higher parent-reported child benefits. Because of the low response rate, our results must be interpreted cautiously. However, goal-directed functional training has been well documented in clinical research and is believed to be a part of standard care (4). Therefore, practice of the specific goals set in cooperation between the family and the therapist is encouraged to be continued in Norwegian paediatric rehabilitation. Few of the controlled trials included in our systematic review 
measured the effects of intensive training on the measurements of goals. Because of the heterogeneity of children with $\mathrm{CP}$, the use of parents or self-reported individualised outcome measurements, such as GAS and COPM, is recommended in controlled trials if no other selfreported functional outcome measurements are used.

Based on the findings of Paper III and other systematic reviews (3-5,9,23), the documentation of intensive fine motor training was rigorous and extensive, suggesting that the CIMT should be a part of the standard care for young children with CP. However, the evidence is only based on unilateral $\mathrm{CP}$. There has been a lack of studies focusing on hand function in children with bilateral CP. We have no information regarding the types of fine motor training practiced according to the survey and the RCT. Therefore, we require studies that investigate whether the practices are based on well-documented training.

According to the systematic review, the studies targeting gross motor function were fewer, had a higher risk of bias and were less effective than the studies targeting hand function. In contrast, the parents in the survey and in the RCT reported that gross motor training was more common than fine motor training. Although the survey and RCT were prone to biases, that both of the studies' results were consistent strengthens the results. This finding indicates that, to offer effective interventions in clinical practice, more rigorous controlled trials of intensive gross motor function are required, with different types of intensities and performed in different contexts.

Because of the small sample size of the RCT, there is the possibility of type II errors. Moreover, the included children in the RCT had different motor functions. Subgroups (e.g., children with GMFCS levels I-III) might benefit more from CE than children with lower functional levels. Therefore, large-scale studies are required that allow for sub-group analyses, based on age and GMFCS level.

It is unlikely that one specific interventional approach will be identified as the gold standard intervention, considering the many factors that contribute to a child's functional independence (49). Therefore, as long as the CE course shows improvements similar to those of other intensive interventions, this program might be considered as a part of the family of interventions that will be identified and used selectively to achieve the best fit with each child's unique abilities, needs, and circumstances. Children with $\mathrm{CP}$ are different and belong 
to families with individual needs and strengths. Hence, it is not surprising that different forms of support and intervention have been sought (65). The RCT, together with Ødman et al. (160), suggested that CE had a positive influence on parent-related outcomes. However, Ødman et al. (160) conducted non-randomised controlled trials, and our RCT had a small sample size, indicating that plausible bias might raise some doubt about the results. However, quantitative and qualitative research is required to explore parents' experiences with CE.

The FCS approach might contribute to explaining why an intervention does not show the intended effects in clinical research by focusing on how the intervention was delivered. None of the included studies of the systematic review used the MPOC-20. If we embrace the approach of FCS in clinical practice, we require more controlled trials that include the MPOC-20 as an outcome measurement when investigating the effects of intensive and conventional training.

An increasing base of evidence (163-165), including the results from Paper II, has suggested that the provision of general information must be improved to meet the information requirements of the families of young children with CP in Norway. Although the survey had a low response rate, the findings were consistent with those of other Norwegian and international studies, thus strengthening the results. The parents asked for general and specific information about the diagnosis, prognosis and treatment options. In addition, general information, provided as leaflets, on Web sites and through contact with other families in the same situation, was requested. More research is required that investigates the barriers to information sharing behaviours and how to make valid and relevant information more readily accessible. Based on the findings of this thesis, therapists working in primary and specialist health care services in Norway are encouraged to strive for information-sharing behaviours and to avoid biased information-sharing, to provide better family-centred care. 


\section{Conclusion}

The aim of this thesis was to increase the knowledge of intensive training in young children with CP, specifically examining the characteristics and effects of intensive training and parents' experiences of FCS. Parents' experiences were collected in a Norwegian survey, and the characteristics and effects of intensive motor function and functional skills training were collected in a systematic review, based on international studies and on a pragmatic randomised controlled trial conducted in Norway. The four papers included in this thesis had several strengths and limitations, and any conclusions must be considered in this light. The following conclusions could be drawn:

- Intensive training was characterised by training sessions, repetitions of goal-directed everyday activities incorporated into daily routines or a combination of both. Intensive training was often accompanied by home training, made possible by parent involvement and parent education, as shown in the systematic review, the survey, the $\mathrm{RCT}$ and the other discussed literature.

- Studies that targeted intensive gross motor function were fewer, older and consisted of fewer training sessions over longer training periods and less home training than studies targeting hand function, as identified in the systematic review.

- Equal improvements were identified between intensive training and conventional training, as well as between two different intensive interventions, in a majority of the studies included in the systematic review.

- Six meta-analyses have supported the exciting evidence of CIMT for hand function and functional skills. CIMT was often characterised by a large amount of intensive training for a short duration, performed at home and at a clinic with a large amount of parental involvement, as identified in the systematic review and in the other discussed literature.

- The amount, the duration, the context, and the manner in which the training was organised, in addition to the child's characteristics, might contribute to explaining the outcomes of intensive training. Because the child population with $\mathrm{CP}$ is heterogeneous, and the performed training programs are often complex, it is unlikely that only one characteristic, such as the intensity of training, will explain the outcomes. Rather, the outcomes have a multifactorial explanation, as discussed in this thesis. 
- No added effects of CE were identified in the CE group followed by conventional training, compared to the waiting list group, which received conventional training. The large amount of conventional training reported at follow-up might explain the lack of additional effects of the CE course in the RCT.

- In the survey, the parents also reported that the conventional motor training was performed from at least three times per week to several times per day and was frequently incorporated into daily routines. Moreover, the parents often reported goaldirected training with high levels of parental involvement. Goal-directed training was associated with higher parent-reported child benefits, as identified in the survey.

- The parents' experiences with FCS in primary health care were generally worse than the parents' experiences of FCS in specialist health care. The parents rated the "provision of general information" the lowest and the "provision of respectful and supportive care" the highest in the survey and in the other discussed literature.

This thesis supports the following implications for practice:

- Home training as a method for increasing the amount of practice and the transfer of motor skills to daily activities, as shown in the systematic review, in the RCT and in other discussed literature;

- The use of goals in intensive training, as identified in the survey, in the systematic review and in the other discussed literature; and

- The use of CIMT to improve hand function in young children with CP, as shown in the systematic review and in other discussed literature;

- Increased focus on participatory family-centred practices that encourage information sharing and parents' participation in decision making, as suggested in the survey and in other discussed literature. Moreover, unbiased general and specific information is requested by the parents of young children with $\mathrm{CP}$, as identified in the survey, in the RCT and in other discussed studies.

- More general information of diagnosis, prognosis and treatment options, available in booklets and on Web sites, based on sound, summarised and accessible research, is required.

This thesis supports further research, including: 
- Controlled trials investigating the effects of intensive gross motor and functional skills training performed in different contexts and with outcome measurements that capture actual performance, as shown in the systematic review and in other discussed literature; and

- Controlled trials investigating the effects of CE. Large studies are required that describe adjacent conventional training and that allow for sub-group analysis, as identified in the systematic review and in the RCT.

- Studies investigating the barriers to and facilitators of information sharing-behaviours in paediatric rehabilitation services. 


\section{References}

1. Myrhaug H T, Østensjø S, Lerdal B, Skranes J, Hammerstrøm K T, Risberg K, et al. [Intensiv trening/habilitering til barn med medfødt og ervervet hjerneskade]. Oslo:

Nasjonalt kunnskapssenter for helsetjenesten; 2008. Rapport fra Kunnskapssenteret - nr. $27-2008$.

2. Rosenbaum P, Paneth N, Leviton A, Goldstein M, Bax M, Damiano D, et al. A report: the definition and classification of cerebral palsy. Dev Med Child Neurol Suppl. 2007;109: 8-14.

3. Sakzewski L, Ziviani J, Boyd RN. Efficacy of upper limb therapies for unilateral cerebral palsy: a meta-analysis. Pediatrics. 2014;133:e175-e204.

4. Novak I, McIntyre S, Morgan C, Campbell L, Dark L, Morton N, et al. A systematic review of interventions for children with cerebral palsy: state of the evidence. Dev Med Child Neurol. 2013;55:885-910.

5. Dong VA, Tung IH, Siu HW, Fong KN. Studies comparing the efficacy of constraint induced movement therapy and bimanual training in children with unilateral cerebral palsy: a systematic review. Dev Neurorehabil. 2013;16:133-143.

6. Franki I, Desloovere K, De Cat J, Feys H, Molenaers G, Calders P, et al. The evidencebase for conceptual approaches and additional therapies targeting lower limb function in children with cerebral palsy: a systematic review using the ICF as a framework. J Rehabil Med. 2012; 44:396-405.

7. Martin L, Baker R, Harvey A. A systematic review of common physiotherapy interventions in school-aged children with cerebral palsy. Phys Occup Ther Pediatr. 2010;30:294-312.

8. Arpino C, Vescio MF, De LA, Curatolo P. Efficacy of intensive versus nonintensive physiotherapy in children with cerebral palsy: a meta-analysis. Int J Rehabil Res. 2010; 33:165-171.

9. Huang HH, Fetters L, Hale J, McBride A. Bound for success: a systematic review of constraint-induced movement therapy in children with cerebral palsy supports improved arm and hand use. Phys Ther. 2009; 89:1126-1141.

10. Cunningham JB, Rosenbaum PL. Measure of Processes of Care: a review of 20 years of research. Dev Med Child Neurol. 2014;56:445-452.

11. Ministry of Health and Care Services. St.meld. 16 (2011-2015). [The Nasjonal healthand care plan]. Oslo: HOD; 2011

12. Norwegian Directorate of Health. [Action plan for rehabiliation of children and youth]. 09/2009. Oslo: Helsedirektoratet; 2009.

13. Law M, Polloc N and Stewart D. Evidence-based occupational therapy: Concepts and strategies. New Zealand Journal of Occupational Therapy. 2004;51(1):14-22. 
14. Novak I. Evidence to Practice Commentary: Is More Therapy Better. Phys \& Occup Ther Pediatr. 2012;32(4):383-387.

15. Nudo RJ, Wise BM, SiFuentes F, Milliken GW. Neural substrates for the effects of rehabilitative training on motor recovery after ischemic infarct. Science. 1996;21(272):1791-4.

16. Nudo RJ. Plasticity. NeuroRx. 2006;3:420-27.

17. Tahayori B and Koceja DM. Activity-Dependent Plasticity of Spinal Circuits in the Developing and Mature Spinal Cord. A review article. Neural Plasticity. 2012;1-11. doi:10.1155/2012/964843

18. Schertz M, Gordon AM. Changing the model: a call for re-examination of intervention approaches and translation research in children with developmental disabilities. Dev med child neurol. 2009;51: 6 .

19. Dodd KJ, Taylor NF, Graham HK. A randomized clinical trial of strength training in young people with cerebral palsy. Dev Med Child Neurol. 2003;(10):652-7.

20. Tsorlakis N, Evaggelinou C, Grouios G, Tsorbatzoudis C. Effect of intensive neurodevelopmental treatment in gross motor function of children with cerebral palsy. Dev Med Child Neurol. 2004;46(11):740-5.

21. Rosenbaum PL, Walter SD, Hanna SE, Palisano RJ, Russell DJ, Raina P, et al. Prognosis for gross motor function in cerebral palsy: creation of motor development curves. JAMA. 2002;288(11):1357-63

22. Holmefur M, Krumlinde-Sundholm L, Bergstrøm J. Longitudinal development on hand function in children with unilateral cerebral palsy. Dev Med Child Neurol. 2010;52:352-357.

23. Eliasson A-C, Krumlinde-Sundholm L, Gordon A, Feys H, Klingels K, Aarts PB, et al. Guidelines for future research in constraint induced movement therapy for children with unilateral cerebral palsy: an expert consensus. Dev Med Child Neurol. 2014;56:125137.

24. Palisano RJ, Murr S. Intensity of therapy services: what are the considerations? Phys Occup Ther Pediatr. 2009;29:107-112.

25. von Tetzchner S, Verdel M, Barstad BG, Gravås EM, Jahnsen R, Krabbe S, et al. The effect of interventions based on the programs of The Institutes for the Achievement of Human Potential and Family Hope Center. Dev Neurorehabil. 2013;16(4):217-29. doi: 10.3109/17518423.2012.739211.

26. Bax M. Does “therapy” have a future? Dev Med child Neurol. 2001;43:3.

27. Myklebust G, Jahnsen R, Elkjær S. Registration of interventions in children with cerebral palsy during three years - a population based study. Dev Med Child Neurol. 2009; 51:suppl.5 
28. Palisano RJ, Begnoche DM, Chiarello LA, Bartlett DJ, Westcott McCoy S, Chang H-J. Amount and focus of physical therapy and occupational therapy for young children with cerebral palsy. Phys \& Occup Ther Pediatr. 2012; 32:368-382.

29. World Health Organisation. International Classification of Functioning, Disability and Health. http://www.who.int/classifications/icf/en/ Accessed 10.10.2013

30. Clover A, Fairhurst C, Pharoah POD. Cerebral palsy. The Lancet. 2013;20: 1-10.

31. Andersen GL, Irgens LM, Haagaas I, Skranes JS, Meberg AE, Vik T. Cerebral palsy in Norway: prevalence, subtypes and severity. Eur J Paediatr Neurol. 2008;12(1):4-13.

32. Yeargin-Allsopp M, Van Naarden Braun K, Doernberg NS, Benedict RE, Kirby RS, et al. Prevalence of cerebral palsy in 8-year-old children in three areas of the United States in 2002: a multisite collaboration. Pediatrics. 2008;121:547-54.

33. Standely FJ, Watson L. Trends in perinatal mortality and cerebral palsy in Western Australia, 1967 to 1985 . BMJ. 1992; 304:1658-63.

34. Hagberg B, Hagberg G, Beckung E, Uvebrandt P. Changing panorama of cerebral palsy in Sweden. VIII. Prevalence and origin in the birth year period 1991-94. Acta Paediatr. 2001;90:271-77.

35. Odding E, Roebroeck ME, Stam HJ. The epidemiology of cerebral palsy: incidence, impairments and risk factors. Disabil Rehabil. 2006;28(4):183-91.

36. Pharoah PO. Risk of cerebral palsy in multiple pregnancies. Obstet Gynecol Clin North Am. 2005;32(1):55-67, viii.

37. McIntrye S, Taitz D, Keogh J, Goldsmith S, Badawi N, Blair E. A systematic review of risk factors for cerebral palsy in children born at term in developed countries. Dev Med Child Neurol. 2013; 55: 499-508.

38. Andersen GL, Irgens LM, Skranes J, Salvesen KA, Meberg A, Vik T. Is breech presentation a risk factor for cerebral palsy? A Norwegian birth cohort study. Dev Med Child Neurol. 2009;51(11):860-5. doi: 10.1111/j.1469-8749.2009.03338.x.

39. Aisen ML, Kerkovich D, Mast J, Mulroy S, Wren TAL, Kay RM, Rethlefsen SA. Cerebral palsy: clinical care and neurological rehabilitation. Lancet Neurol. 2011; 10:844-52.

40. World Health Organisation. Towards a Common Language for Functioning, Disability and Health ICF. Geneva, World Health Organization, 2002.

41. Smith LB, Thelen E. A dynamic systems approach to development: Applications. Cambridge 1993, MA: The MIT Press/Bradford Books.

42. Thelen E. Motor development. A new synthesis. American psychologist. 1995; 50(2): 79-95.

43. Thelen E, Bates E. Connectionism and dynamic systems: are they really different? Developmental Science. 2003;6:378-391. 
44. Spencer JP, Perone S, Buss AT. Twenty years and going strong: A dynamic systems revolution in motor and cognitive development. Child Dev Perspect. 2011;5(4):260266.

45. Law M, Darrah J, Polloc N, King G, Rosenbaum P, Russell D, et al. Family-centered functional therapy for children with cerebral palsy: an emerging practice model. Phys Occup Ther Pediatr. 1998;18:83-102.

46. Gesell A, Thompson H. The phsychology of early growth including norms of infant behavior and a method of genetic analysis. New York: Macmillan; 1938.

47. Howle J. Neurodevelopmental treatment approach: Theoretical foundations and Principles of Clinical practice. Laguna Beach, CA: Neurodevelopmental Treatment Association; 2002.

48. Hadders-Algra M. The neuronal group selection theory: a framework to explain variation in normal motor development. Dev Med Child Neurol. 2000;42:566-72.

49. Law M, Darrah J. Emerging Therapy Approaches: An Empasis on Fuction. Journal of Child neurology. 2014;1-7.

50. Ketelaar M, Vermeer A, Hart H, van Petegem-van Beek E, Helders PJ. et al. Effects of a functional therapy program on motor abilities of children with cerebral palsy. Phys Ther. 2001;81:1534-1545.

51. Lowing K, Bexelius A, Brogren CE. Activity focused and goal directed therapy for children with cerebral palsy--do goals make a difference? Disability \&

Rehabilitation.2009; 31(22), 1808-1816. doi:911802937 [pii];10.1080/09638280902822278

52. Law MC, Darrah J, Pollock N, Wilson B, Russell DJ, Walter SD. et al. Focus on function: a cluster, randomized controlled trial comparing child- versus context-focused intervention for young children with cerebral palsy. Dev Med Child Neurol. 2011; 53(7):621-629. doi:10.1111/j.1469-8749.2011.03962.x

53. Holt RL, Mikati MA. Care for children development: basic science rational and effects of interventions. Pediatr Neurol. 2011;44:239-53.

54. Damiano DL. Activity, activity, activity: rethinking our physical therapy approach to cerebral palsy. Phys Ther. 2006;86(11):1534-40.

55. Johansson BB. Environmental influence on outcome after experiment brain infarction. Acta Neurochir Suppl. 1996;66:63-7.

56. Palisano RJ, Murr S. Intensity of therapy services: what are the considerations? Phys Occup Ther Pediatr. 2009;29:107-112.

57. Desloovere K, De Cat J, Molenaers G, Franki I, Himpens E, Van Waelvelde H, et al. The effect of different physiotherapy interventions in post-BTX-A treatment of children with cerebral palsy. Eur J Paediatr Neurol. 2012;16(1):20-8. doi:

10.1016/j.ejpn.2011.08.009. 
58. Andersen JC, Majnemer A, O'Grady K, Gordon AM. Intensive upper extremity training for children with hemiplegia: from science to practice. Semin Pediatr Neurol. 2013 ;20(2):100-5. doi: 10.1016/j.spen.2013.06.001.

59. Eliasson AC, Holmefur M. The influence of early modified constraint-induced movement therapy training on the longitudinal development of hand function in children with unilateral cerebral palsy. Dev Med Child Neurol. 2015;57(1):89-94. doi: $10.1111 / \mathrm{dmcn} .12589$.

60. Hanna SE, Bartlett DJ, Rivard LM, Russell DJ. Reference curves for the Gross Motor Function Measure: percentiles for clinical description and tracking over time among children with cerebral palsy. Phys Ther. 2008;88:596-607. doi: 10.2522/ptj.20070314.

61. Haley SM, Coster WJ, Ludlow LH, Haltiwanger JT, Andrellos PJ. Pediatric Evaluation of Disability Inventory: development, standardization, and administration manual, version 1.0. Boston: Trustees of Boston University, Health and Disability Research Institute; 1992.

62. Ketelaar M, Gorter JW, Westers P, Hanna S, Verhoef M. Developmental trajectories of mobility and self-care capabilities in young children with cerebral palsy. J

Pediatr. 2014;164(4):769-774.e2. doi: 10.1016/j.jpeds.2013.11.070

63. Hari M, Akos K. Conductive education. London: Routledge; 1988.

64. Sutton A, Maquire G. Internationalising conductive education. Reports of recent advances in conductive education. Birmingham, UK: Conductive Education Press; 2010 .

65. Bourk-Taylor H, O’Shea R, Gaebler-Spira D. Conductive education: a function skills program for children with cerebral palsy. Phys Occup Ther Paediatr. 2007;27:45-62.

66. Yang L, Wu D, Tang JL, Jin L, Li XY. Effect of conductive education combined with Frenkel training on balance disability in children with cerebral palsy. Zhongguo Dang Dai Er Ke Za Zhi. 2009;11(3):207-9.

67. Reddihough DS, King J, Coleman G, Catanese T. Efficacy of programmes based on Conductive Education for young children with cerebral palsy. Dev Med Child Neurol. 1998;40:763-70.

68. Darrah J, Watkins B, Chen I, Bonin C. Conductive education intervention for children with cerebral palsy: an AACPDM evidence report. Dev Med Child Neurol. 2004;46:187-203.

69. Ludwig S, Legget P, Harstall C. Conductive education for children with cerebral palsy. Canada: Alberta Heritage Foundation for medical Research, 2000.

70. Hur JJ-A. Skills for independence for children with cerebral palsy: a comparative longitudinal study. Int J Disabil Dev Educ. 1997;44:263-74.

71. Sutton A. Introduction to Conduction education, 2006. e-conduction.org. Accessed 03.04.2013 
72. Leeber J. Conductive education and the mediated learning experience theory of Feuerstein. European Journal of Special needs Eudcation. 1995;10:.

73. Baristow P, Cochrane R, Hur J. Evaluation of Conductive education for chidren with cerebral palsy final report (part II). London: HMSO; 1993.

74. Hari M, Akos K. Conductive Education, 1971. Translated by Smith and Stevens. London: Routledge; 1988.

75. Dunst CJ, Bruder MB, Trivette CM, Hamby DW. Everyday Activity Settings, Natural Learning Environments, and Early Intervention. Practices. Journal of Policy and Practice in Intellectual Disabilities. 2006;3(1): 3-10.

76. Novak I. Parent experience of implementing effective home programs. Phys Occup Ther Pediatr. 2011;31:198-213.

77. Shumway-Cook A, Wollacot MH. Motor control: translating research into clinical practice. Philadelphia: Lippincott Williams \& Wilkins; 2007.

78. Dunst, Trivette, Humphries, Raab, Roper. Contrasting approaches to natural learning environement interventions. Infant and young children. 2001;14:48-63

79. Dunst CJ, Bruder MB, Trivette CM, Hamby DW. Young children's natural learning environments: contrasting approaches to early childhood intervention indicate differential learning opportunities. Psychol Rep. 2005;96(1):231-4.

80. Humphry R, Wakeford L. An occupation-centered discussion of development and implications for practice. Am J Occup Ther. 2006;60(3):258-67.

81. King S, Rosenbaum P, King G. Evaluating health service delivery to children with chronic conditions and their families: development of a refined measure of process of care (MPOC-20). Children's Health Care. 2004;33(1): 35-57.

82. Dunst CJ, Trivette CM, Hamby DW. Meta-analysis of family-centered helpgiving practices research. Mental Retardation and Developmental Disabilities 2007;13(4): 370378. doi: $10.1002 / \operatorname{mrdd} .20176$

83. Baker T, Haines S, Yost J, DiClaudio S, Braun C, Holt S. The role of family-centred therapy when used with physical or occupational therapy in children with congenital or acquired disorders. Physical Therapy Reviews. 2012;17(1):29-36.

84. Law M, Darrah J. Emerging Therapy Approaches: An Emphasis on Function. J Child Neurol. 2014 May 7. [Epub ahead of print]

85. Dunst C, Dempsey I. Family-professional partnerships and parenting competence, confidence, and enjoyment. International Journal of Disability, Development and Education. 2007;54(3): 305-318.

86. Bamm EL, Rosenbaum P. Family-centered theory: origins, development, barriers, and supports to implementation in rehabilitation medicine. Archives of Physical Medicine and Rehabilitation. 2008; 89(8):1618-1624. 
87. King S, Teplicky R, King G, Rosenbaum P. Family-Centered Service for Children With Cerebral Palsy and Their Families: A Review of the Literature. Seminars in Pediatric Neurology. 2004;11(1):78-86.

88. Law M, MacDermid J. Evidence-based rehabilitation. A guide to practice. Thorofare: Slack incorporated; 2008

89. Herbert R, Jamtevdt G, Hagen KB, Mead J. Practical evidence-based physiotherapy. Second edition. Elseiver 1td; 2011.

90. Sackett DL, Straus SE, Richardson WS, Rosenberg W, Haynes RB. Evidence-Based Medicine: How to Practice and Teach EBM, $2^{\text {nd }}$ edition. Edinburgh: Churchill Livingstone; 2000.

91. Haynes RB. What kind of evidence is it that evidence- based Medicine advocates want health care providers and consumers to pay attention to? BMC Health Services Research.2004; $2: 3$.

92. Dijkers MP, Murphy SL, Krellman J. Evidence-based practice for rehabilitation professionals: Concepts and controversies. Special communication. Arch Phys med Rehabil. 2012; 93(2):164-176.

93. Moher D, Liberati A, Tetzlaff J, Altman DG; PRISMA Group. Preferred reporting items for systematic reviews and meta-analyses: the PRISMA statement. J Clin Epidemiol. 2009; 62(10):1006-12. doi: 10.1016/j.jclinepi.2009.06.005.

94. PROSPERO. http://www.crd.york.ac.uk/PROSPERO/. Accsessed 20.10.2011

95. Brown CA, Lilford RJ. The stepped wedge trial design: a systematic review. BMC Med Res Methodol. 2006;8:54.

96. Hart T, Bagiella E. Design and Implementation of clinical trals in rehabilitation research. Special communication. Arch Phys Med Rehabil. 2012; 93:117-126

97. Herbert R. Explanatory and pragmatic clinical trials. In: Gad SC, (Ed), Clinical trials handbook. New Jersey: John Wiley \& Sons; 2009.

98. Schulz KF, Altman DG, Moher D; CONSORT Group. CONSORT 2010 Statement: updated guidelines for reporting parallel group randomised trials. BMC Med. 2010 24;8:18. doi: 10.1186/1741-7015-8-18.

99. Russel DJ, Avery LM, Rosenbaum PL, Raina PS, Walter SD, Palisano RJ. Improved scaling of the Gross Motor Fuction Measure for children with cerebral palsy: evidence of reliability and validity. Phys Ther. 2000;80:873-85.

100. Palisano R, Rosenbaum P, Bartlett D. Gross motor function classification systemexpanded and revised (GMFCS-E\&R). CanChild Centre for Childhood Disability Research, McMaster University. Michael Livingston; 2007.

101. Eliasson AC, Krumlinde-Sundholm L, Rosblad B, Beckung E, Arner M, Ohrvall AM. et al. The Manual Ability Classification System (MACS) for children with cerebral palsy: scale development and evidence of validity and reliability. Developmental Medicine \& 
Child Neurology. 2006;48(7):549-554. doi:S0012162206001162

[pii];10.1017/S0012162206001162

102. Varni JW. 1998. http://www.pedsql.org/ translated to Norwegian in 2002 by Reinfjell T and Diseth TH. Accepted by Varni JW, 2003.

103. WahI A, Burckhardt C, Wiklund I, Hanestad BR. The Norwegian Version of the Quality of Life Scale (QOLS-N). Scand J Caring Sci. 1998;12:215-22.

104. Taylor E, Schachar R, Thorley G,Wieselberg M. Parental Account of Children's Symptoms. Norwegian translation by Zeiner P 1989, revised Nøvik T 1992, revised by Diseth 1992, 2003. British Journal of Psychiatry. 1986;149:760-767

105. Reinfjell T, Lofstad GE, Nordahl HM, Vikan A, Diseth TH. Children in remission from acute lymphoblastic leukaemia: mental health, psychosocial adjustment and parental functioning. European Journal of Cancer Care. 2009;18:364-370

106. CPHAB. Children with Cerebral palsy and habilitation. http://www.med.uio.no/helsam/forskning/prosjekter/cphab/

107. King S, Rosenbaum P, King G. The measure of processes of care (MPOC) - a means to assess family-centred behaviours of health care providers. Neurodevelopmental Clinic Research Unit, McMaster University and Chedoke-McMaster Hospitals, Canada, 1995.

108. Siebes RC, Ketelaar M, Wijnroks L, van Schie PE, Nijhuis BJ, Vermeer A, Gorter JW. Family-centred services in The Netherlands: validating a self-report measure for paediatric service providers. Clin Rehabil. 2006; 20(6):502-12.

109. Hagen AK, Bjorbækmo WS. Parents evaluation of the processes of care in child rehabilitation: a reliability study of the Norwegian translation of MPOC-20. Child: Care Health and Development. 2010;38(1): 48-53. doi:10.1111/j.1365-2214.2010.01192.x

110. Palisano RJ, Cameron D, Rosenbaum PL, Walter SD, Russell D. Stability of the gross motor function classification system. Dev Med Child Neurol. 2006; 48(6):424-8.

111. Russell DJ, Rosenbaum PL, Cadman DT, Gowland C, Hardy S, Jarvis S. The gross motor function measure: a means to evaluate the effects of physical therapy.

Developmental Medicine and Child Neurology. 1989;31:341-352.

112. Russell DJ, Rosenbaum PL, Avery L, Lane M. Gross motor function measure (GMFM66 and GMFM-88) user's manual: clinics in developmental medicine. London, England: Mac Keith press; 2002.

113. Avery LM, Russell DJ, Raina PS, Walter SD, Rosenbaum PL. Rasch analysis of the Gross Motor Function Measure: validating the assumptions of the Rasch model to create an interval-level measure. Arch Phys Med Rehabil. 2003;84:697-705.

114. Burrows L. Gross Motor Ability Estimator (software). Hamilton, Ontario, Canada: CanChild Centre for Childhood Disability Research. McMaster University; 1999 (Software available from the CanChild website: http://www.motorgrowth.canchild.ca/en/GMFM/gmae.asp 
115. Russel DJ, Avery LM, Rosenbaum PL, Raina PS, Walter SD, Palisano RJ. Improved scaling of the gross motor function Measure for children with cerebral palsy: evidence of reliability and validity. Phys Ther. 2000;80:873-85.

116. Russell DJ, Leung KM, Rosenbaum PL. Accessibility and perceived clinical utility of the GMFM-66: evaluating therapists' judgements of a computer-based scoring program. Phys Occup Ther Pediatr. 2003;23(2):45-58.

117. Wang HY, Yang YH. Evaluating the responsiveness of 2 versions of the gross motor function measure for children with cerebral palsy. Arch Phys Med Rehabil. 2006; 87(1):51-6.

118. Russell DJ, Rosenbaum PL, Avery LM, Lane M. Gross Motor Function Measure (GMFM-66 og GMFM-88). User's Manual. London, Storbritannia: Mac Keith Press, 2002. Translated 2011 by Gerd Myklebust, Reidun Jahnsen, Oslo universitetssykehus, Rikshospitalet, Oslo and Anne Brit Sørsdahl, Høgskolen i Bergen. Based on the translation of GMFM-88 by Anne Brit Sørsdahl (1994).

119. Dumas H. Clinical review of the pediatric evaluation of disability inventory. Pediatr Phys Ther. 2001; 13(1):47-8.

120. Berg M, Jahnsen R, Frøslie KF, Hussain A. Reliability of the Pediatric Evaluation of Disability Inventory (PEDI). Phys Occup Ther Pediatr. 2004;24(3):61-77.

121. Berg M, Aamodt G, Stanghelle J, Krumlinde-Sundholm L, Hussain A. Cross-cultural validation of the Pediatric Evaluation of Disability Inventory (PEDI) norms in a randomized Norwegian population. Scand J Occup Ther. 2008; 15(3):143-52.

122. Reinfjell T, Diseth TH, Veenstra M Vikan A. Measuring health-related quality of life in young adolescents: Reliability and validity in the Norwegian version of the Pediatric Quality of Life Inventory ${ }^{\mathrm{TM}} 4.0$ (PedsQL) generic core scales. Health and Quality of Life Outcomes. 2006;4:61.

123. Wahl AK, Rustøen T, Hanestad BR, Lerdal A, Moum T. Quality of life in the general Norwegian population, measured by the Quality of Life Scale (QOLS-N). Qual Life Res. 2004;13:1001-9.

124. Kelly B, MacKay-Lyons MJ. Ethics of involving children in health-related research: Applying a decision-making framework to a clinical trial. Physiother Can. 2010; 62:338-346.

125. Meaux J, Bell P. Balancing recruitment and protection: children as research subjects. Iss Comp Pediatr Nurs. 2001; 24:241-51.

126. Review Manager Software (RevMan5). http://tech.cochrane.org/revman/download. Accessed 22.08.2013

127. Abd El-Kafy EM, Elshemy SA, Alghamdi MS. Effect of constraint-induced therapy on upper limb functions: a randomized control trial. Scand J Occup Ther. 2014, 21:11-23. doi: 10.3109/11038128.2013.837505. Epub 2013 Dec 11. 
128. Choudhary A, Gulati S, Kabra M, Singh UP, Sankhyan N, Pandey RM, Kalra V. Efficacy of modified constraint induced movement therapy in improving upper limb function in children with hemiplegic cerebral palsy: a randomized controlled trial. Brain Dev. 2013;35:870-6. doi: 10.1016/j.braindev.2012.11.001. Epub 2012 Dec 11.

129. Deppe W, Thuemmler K, Fleischer J, Berger C, Meyer S, Wiedemann B. Modified constraint-induced movement therapy versus intensive bimanual training for children with hemiplegia - a randomized controlled trial. Clin Rehabil. 2013; 27:909-20. doi: 10.1177/0269215513483764. Epub 2013 Jul 1.

130. Gelkop N, Burshtein DG, Lahav A, Brezner A, Al-Oraibi S, Ferre CL, et al. Efficacy of Constraint-Induced Movement Therapy and Bimanual Training in Children with Hemiplegic Cerebral Palsy in an Educational Setting. Phys Occup Ther Pediatr. 2014. [Epub ahead of print]

131. Mahasup N, Sritipsukho P, Lekskulchai R, Hansakunachai T. Effects of mirror neurons stimulation on motor skill rehabilitation in children with cerebral palsy: a clinical trial. $\mathrm{J}$ Med Assoc Thai. 2012;95:S166-72.

132. Mattern-Baxter K, McNeil S, Mansoor JK. Effects of home-based locomotor treadmill training on gross motor function in young children with cerebral palsy: a quasirandomized controlled trial. Arch Phys Med Rehabil. 2013; 94:2061-7. doi: 10.1016/j.apmr.2013.05.012. Epub 2013 Jun 5.

133. Shamir M, Dickstein R, Tirosh E. Intensive intermittent physical therapy in infants with cerebral palsy: a randomized controlled pilot study. Isr Med Assoc J. 2012;14:737-41.

134. Page SJ, Schmid A, Harris J. Optimizing Language for Stroke Motor Rehabilitation: Recommendations from the ACRM Stroke Movement Interventions Subcommittee. Arch Phys Med Rehabil. 2012; 93(8): 1395-1399. doi:10.1016/j.apmr.2012.03.005.

135. World Health Organization. International Classification of Functioning, disability and health-Children and Youth version. WHO: 2007.

136. Swanson J, Raab M, Dunst CJ. Strengthening family capacity to provide young children everyday natural learning. Journal of Early Childhood Research. 2011;9:66-80.

137. Dunst CJ, Trivette CM. Meta-analytic structural equation modeling of the influences of family-centered care on parent and child psychological health. Int J Pediatr. 2009;2009:576840. doi: 10.1155/2009/576840. Epub 2009 Nov 30.

138. Eliasson AC, Shaw K, Berg E, Krumlinde-Sundholm L. An ecological approach of constraint induced movement therapy for 2-3-year-old children: a randomized control trial. Res Dev Disabil. 2011;32:2820-8.

139. Eliasson AC, Bonnier B, Krumlinde-Sundholm L. Clinical experience of constraint induced movement therapy in adolescents with hemiplegic cerebral palsy--a day camp model. Dev Med Child Neurol. 2003;45:357-9.

140. Stiller C, Marcoux BC, Olson RE. The effect of conductive education, intensive therapy, and special education services on motor skills in children with cerebral palsy. Phys Occup Ther Pediatr. 2003;23:31-50 
141. Coleman GJ, King JA, Reddihough DS. A pilot evaluation of conductive educationbased intervention for children with cerebral palsy: the Tongala project. J Paediatr Child Health. 1995;31:412-7.

142. Dalvand H, Dehghan L, Feizy A, Amirsalai S, Bagheri H. Effect of the Bobath technique, conductive education and education to parents in activities of daily living in children with cerebral palsy in Iran. Hong Kong J Occup Ther. 2009;19:14-9.

143. Odman P, Richt B, Oberg B. Parent's conceptions of intensive group training. The case of cerebral palsy. Disabil Rehabil. 2009;31(4):293-301.

144. Øien I, Fallang B, Østensjø S. Goal-setting in paediatric rehabilitation: perceptions of parents and professional. Child Care Health Dev. 2010;36(4):558-65. doi:

10.1111/j.1365-2214.2009.01038.x.

145. Inguaggiato E, Sgandurra G, Perazzo S, Guzzetta A, Cioni G. Brain Reorganisation following Intervenions in Children with Cognital Hemplegia: A systematic review. Neural plasticity. 2013; Article ID 356275: 1-7. Doi: 10.1155/2013/356275

146. Delhusen KC, Arner M, Hägglund G. Association between gross motor function (GMFCS) and manual ability (MACS) in children with cerebral palsy. A populationbased study of 359 children. BMC Musculoskeletal Disorders. 2007;8:50 doi:10.1186/1471-2474-8-50

147. Compagnone E, Maniglio J, Camposeo S, Vespino T, Losito L, De Rinaldis M, et al. Functional classifications for cerebral palsy: correlations between the gross motor function classification system (GMFCS), the manual ability classification system (MACS) and the communication function classification system (CFCS). Res Dev Disabil. 2014;35(11):2651-7. doi: 10.1016/j.ridd.2014.07.005.

148. Imms C, Carlin J, Eliasson AC. Stability of caregiver-reported manual ability and gross motor function classifications of cerebral palsy. Dev Med Child Neurol. 2010; 52(2):153-9. doi: 10.1111/j.1469-8749.2009.03346.x. Epub 2009 May 21.

149. Sorsdahl AB, Moe-Nilssen R, Kaale HK, Rieber J, Strand LI. Change in basic motor abilities, quality of movement and everyday activities following intensive, goaldirected, activity-focused physiotherapy in a group setting for children with cerebral palsy. BMC Pediatr. 2010;27;10:26. doi: 10.1186/1471-2431-10-26.

150. Eliasson A-C, Krumlinde-Sundholm L, Shaw K, Wang C. Effects of on constraintinduced movement therapy in young children with hemiplegic cerebral palsy: an adapted model. Dev Med Child Neurol. 2005;47:266-75.

151. Hoare B, Imms C, Villanueva E, Rawicki HB, Matyas T, Carey L. Intensive therapy following upper limb botulinum toxin A injection in young children with unilateral cerebral palsy: a randomized trial. Dev Med Child Neurol. 2013; 55(3):238-47. doi: 10.1111/dmcn.12054. Epub 2012 Dec 12.

152. Sakzewski L, Ziviani J, Abbott DF, Macdonell RA, Jackson GD, Boyd RN. Randomized trial of constraint-induced movement therapy and bimanual training on activity outcomes forchildren with congenital hemiplegia. Dev Med Child Neurol. 2011; 53(4):313-20. doi: 10.1111/j.1469-8749.2010.03859.x. 
153. Morgan PJ, Barnett LM, Cliff DP, Okely AD, Scott HA, Cohen KE, et al. Fundamental movement skill interventions in youth: a systematic review and meta-analysis. Pediatrics. 2013;132(5):e1361-83. doi: 10.1542/peds.2013-1167. Epub 2013 Oct 28.

154. Case-Smith J, Frolek Clark GJ, Schlabach TL. Systematic review of interventions used in occupational therapy to promote motor performance for children ages birth-5 years. Am J Occup Ther. 2013;67(4):413-24. doi: 10.5014/ajot.2013.005959.

155. Anttila H, Suoranta J, Malmivaara A, Mäkelä M, Autti-Rämö I. Effectiveness of physiotherapy and conductive education interventions in children with cerebral palsy: a focused review. Am J Phys Med Rehabil. 2008;87(6):478-501. doi: 10.1097/PHM.0b013e318174ebed.

156. Tuersley-Dixon L, Frederickson N. Conductive education: appraising the evidence. Educ Psychol Pract. 2010;26:353-73.

157. Ødman P, Øberg B. Effectivness of intensive training for children with cerebral palsy-a comparison between child and youth rehabilitation and conductive education. J Rehabil Med. 2005;37:263-70.

158. Choi M, Lee D, Ro H. Effect of task-oriented training and neurodevelopmental treatment on the sitting posture in children with cerebral palsy. J Phys Ther Sci. 2011; 23:323-5.

159. Van Wely L, Balemans AC, Becher JG, Dallmeijer AJ. Physical activity stimulation program for children with cerebral palsy did not improve physical activity: a randomised trial. J Physiother. 2014;60(1):40-9. doi: 10.1016/j.jphys. 2013.12.007. Epub 2014 Apr 24.

160. Odman P, Krevers B, Oberg B. Parents' perceptions of the quality of two intensive training programmes for children with cerebral palsy. Dev Med Child Neurol. 2007; 49(2):93-100.

161. King G, King S, Rosenbaum P. Family-centered caregiving and well-being of parents of children with disabilities: linking process with outcome. Journal of Pediatric Psychology. 1999;24: 41-53.

162. Dempsey I, Keen D. A Review of Processes and Outcomes in Family-Centered Services for Children With a Disability. Topics in Early Childhood Special Education. 2008; 28 (1):42-52.

163. Lied, Ø, Lerdal, B.[Slik brukerne ser det. Brukerundersøkelse ved Habiliteringsseksjonen for barn og unge (HABU)]. HABU Rapport nr.15 (2010). Sørlandet sykehus,Helse Sør-Øst, 2009.

164. Ås S. [Foreldre erfaringer med barnehabiliterin. -En brukerundersøkelse i NordTrøndelag med the Measure of Processes of Care]. Nordiska høgskolen for folkehelsevitenskap, 2008.

165. Hereide E, Østensjø S. Family-centred services and parental quality of life. Dev Med Child Neurol. 2012;54 (1) Suppl.S3. 
166. Saleh M, Almasri NA. Use of the Measure of Processes of Care (MPOC-20) to evaluate health service delivery for children with cerebral palsy and their families in Jordan:

validation of Arabic-translated version (AR-MPOC-20). Child Care Health Dev. 2014; 40(5):680-8.

167. Wang M, Petrini MA, Guan Q. Evaluation of family-centred services from parents of Chinese children with cerebral palsy with the Measure of Processes of Care. Child Care Health Dev. 2014. doi: 10.1111/cch.12183. [Epub ahead of print]

168. Arnadottir U, Egilson ST. Evaluation of therapy services with the measure of processes of care (MPOC-20): the perspectives of Icelandic parents of children with physical disability. Journal of Child Health Care 2012;16:62-74.

169. Jeglinsky I, Autti-Ramø I, Brogran Calberg E. Two sides of the mirror: parents' and service providers' view on the family-centredness of care for children with cerebral palsy. Child: Care, Health and Development. 2011;38(1):79-86.

170. Jeglinsky I, Autti-Ramø I, Brogran Calberg E. Professional background and the comprehension of family-centredness of rehabilitation for children with cerebral palsy. Child: Care, Health and Development. 2011;38(1):70-78

171. Raghavendra P, Murchland S, Bentley M, Wake-Dyster W, Lyons T. Parents' and service providers' perceptions of family-centred practice in a community-based, paediatric disability service in Australia. Child: Care, Health and Development. 2007;33(5):586-592.

172. Granat T, Lagander B and Børjesson MC. Parental participation in the habilitation process - evaluation from a user perspective. Child: Care, Health \& Development. 2002;28(6):459-467.

173. King GA, Tucker MA, Baldwin PJ, Laporta JA. Bringing the life needs model to life: implementing a service delivery model for pediatric rehabilitation. Physical and Occupational Therapy in Pediatrics. 2006;26:43-70.

174. McHugh C, Bailey S, Shilling V, Morris C. Meeting the information needs of families of children with chronic health conditions. Physical \& Occupational Therapy in Pediatrics. 2013; 33(3): 265-270.

175. WHO. 7th Global Conference on Health Promotion: track themes. http://www.who.int/healthpromotion/conferences/7gchp/track2/en/-Accessed 12.06.2014

176. Novak I. Evidence-Based Diagnosis, Health Care, and Rehabilitation for Children With Cerebral Palsy. J Child Neurol. 2014;22;29(8):1141-1156. [Epub ahead of print]

177. Butler C. Outcomes that matter. Dev Med Child Neurol. 1995;37(9):753-4.

178. Donnelly C, Carswell A. Individualised outcome measures: a review of the literature. Can J Occup Ther. 2002;69: 84-94.

179. JohannessenA, Tufte P, Christoffersen I. Introduksjon til samfunnsvitenskapelig metode. Oslo: Abstrakt forlag AS; 2010. 
180. Fordham L, Gibson F, Bowes J. Information and professional support: key factors in the provision of family-centered early childhood intervention services. Child: Care, Health and Development. 2011;38(5): 647-653.

181. Sloper P, Greco V, Beecham J, Webb R. Key worker services for disabled children: what characteristics of services lead to better outcomes for children and families? Child: Care, Health and Development. 2006;32(2): 147-157.

182. Statistics Norway. [Level of education, sex and age, 2010]. Accessed 20.03.2012, from www.ssb.no/utniv/tab-2011-06-09-03.html 


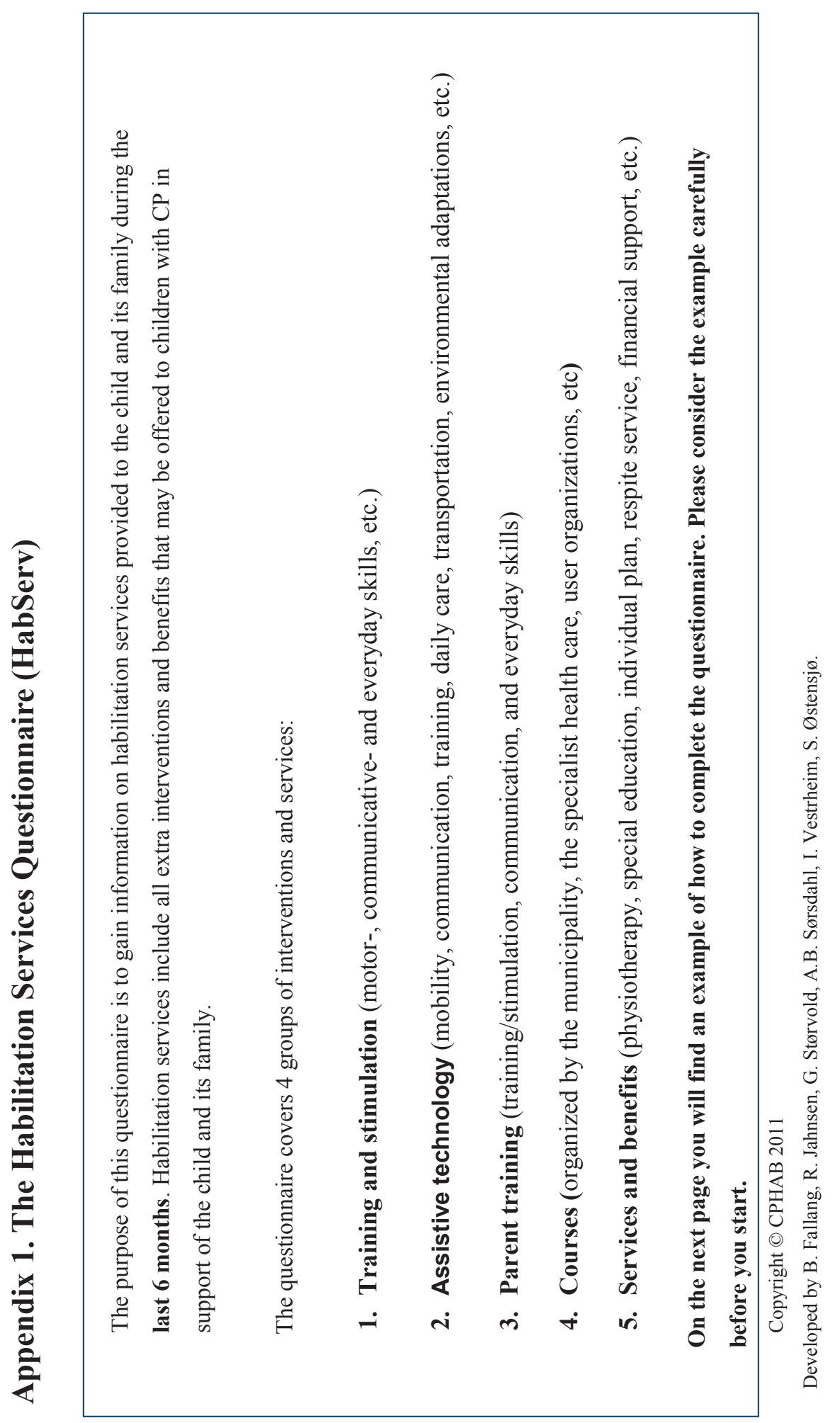




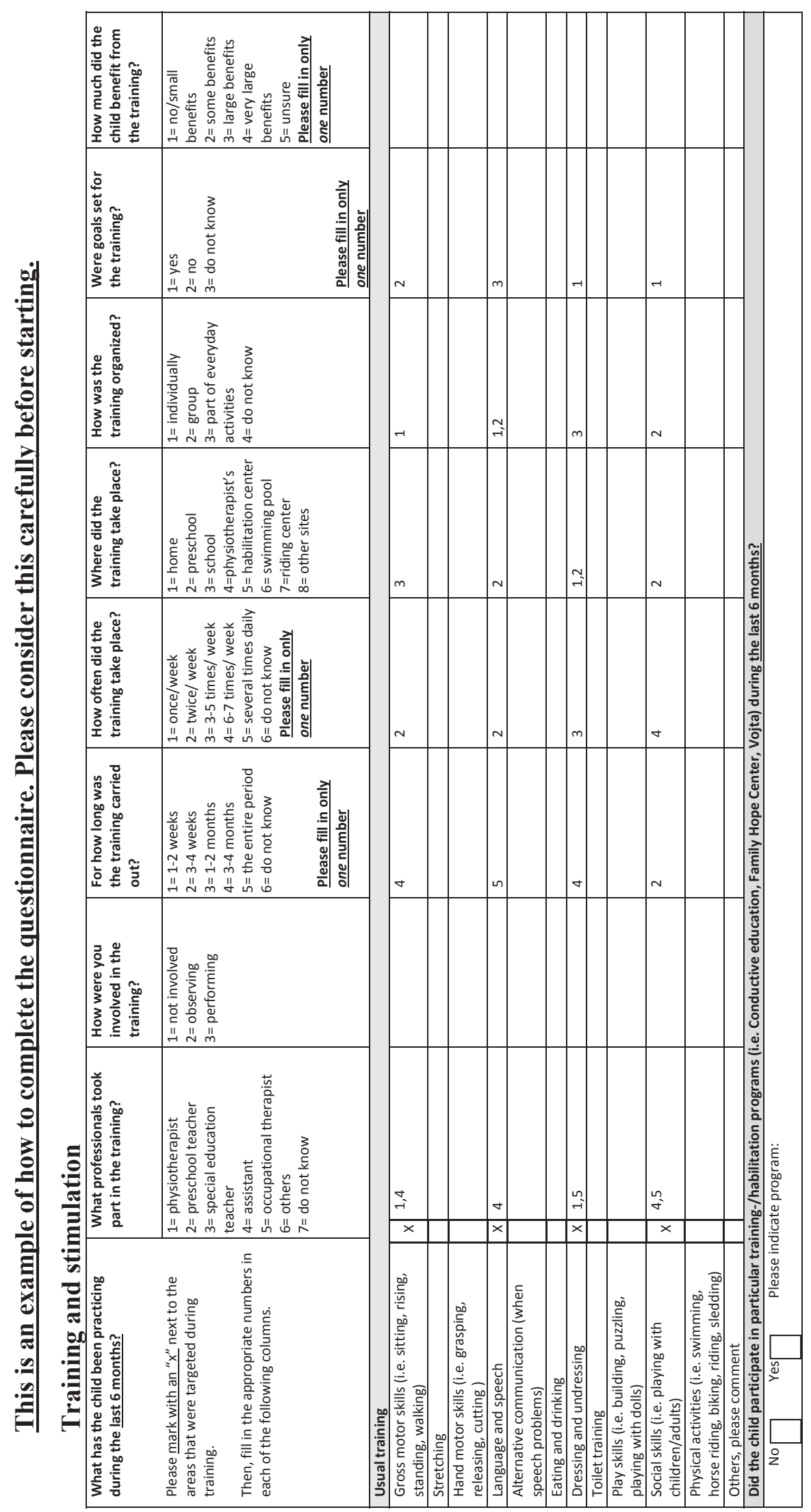




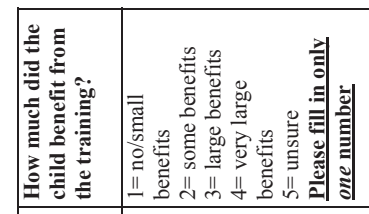

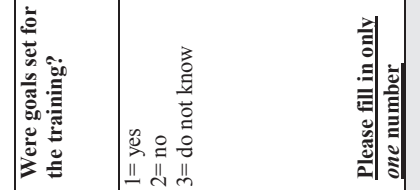

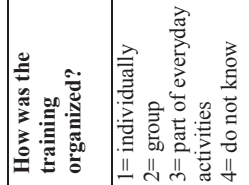

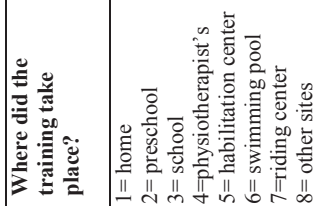

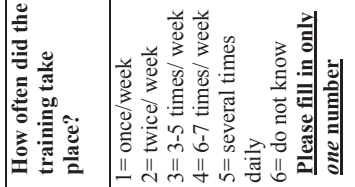

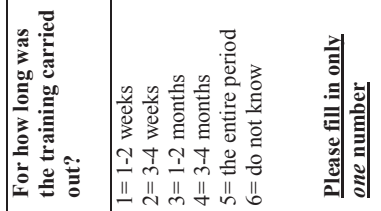

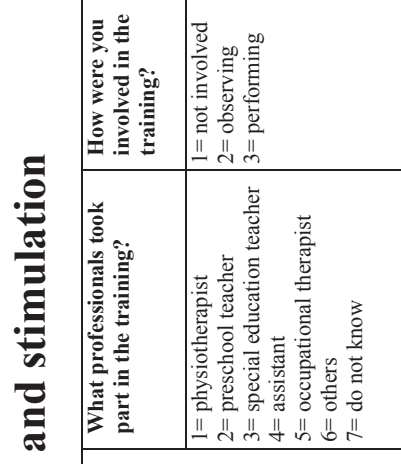

:

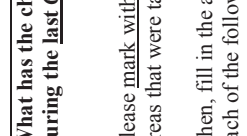

\begin{tabular}{|l|l|l|l|l|l|l|l|l|l|}
\hline & & & & & & & & & \\
\end{tabular} 

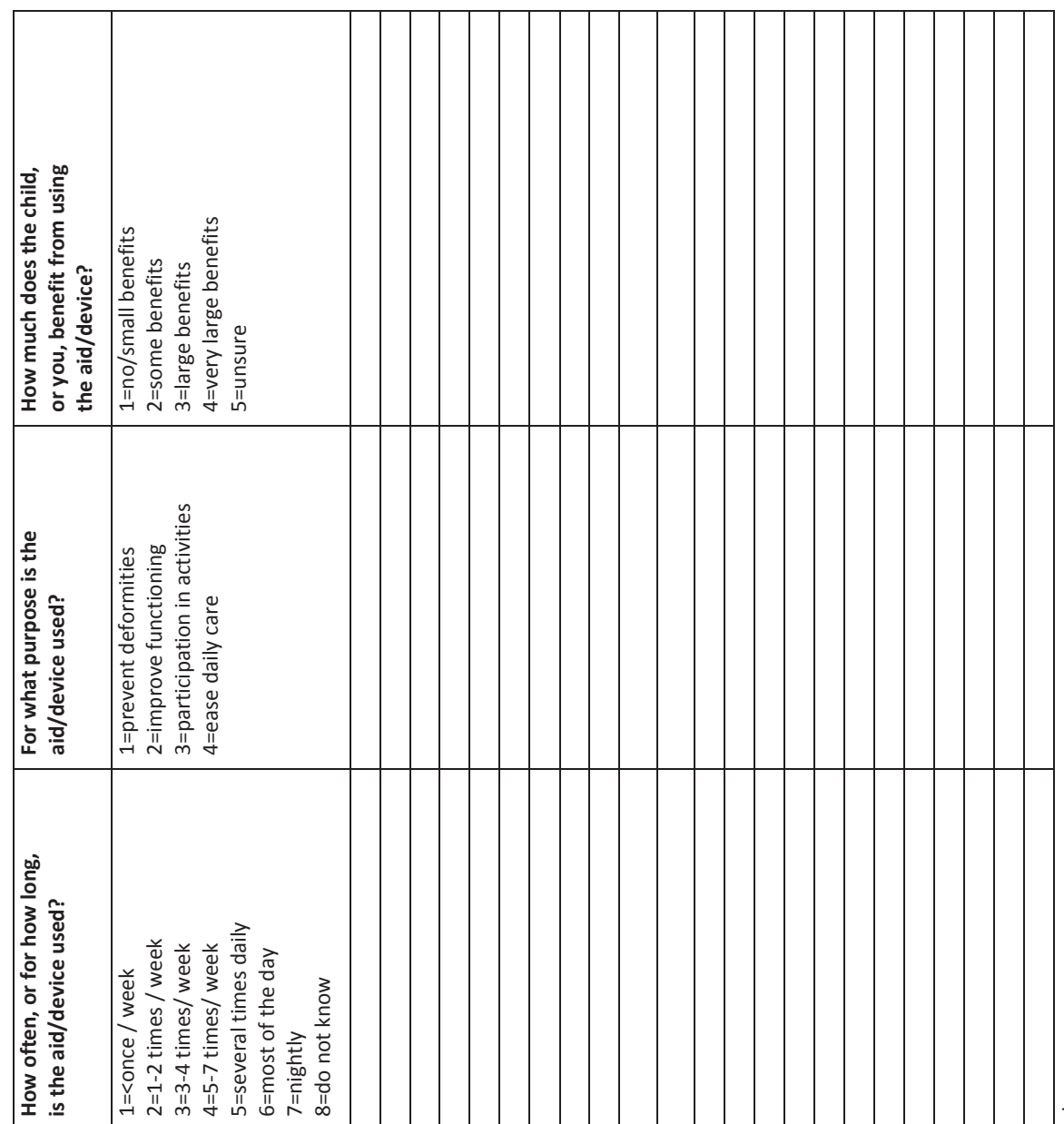

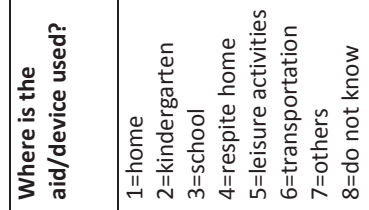

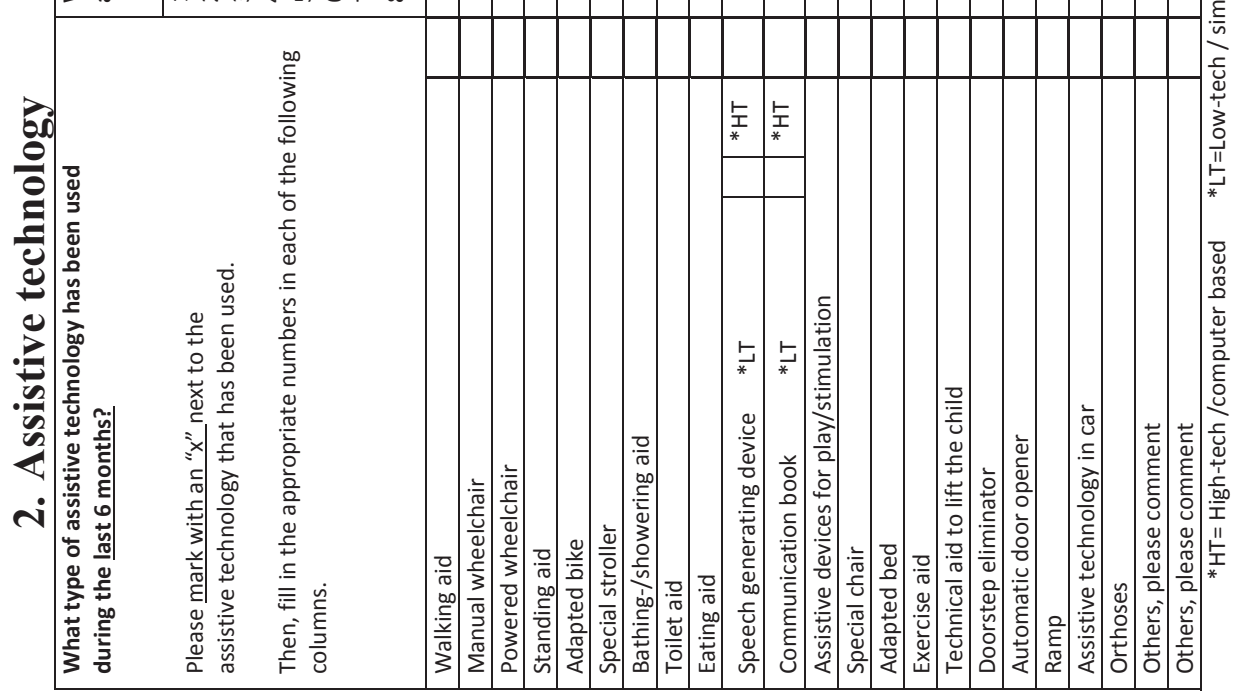



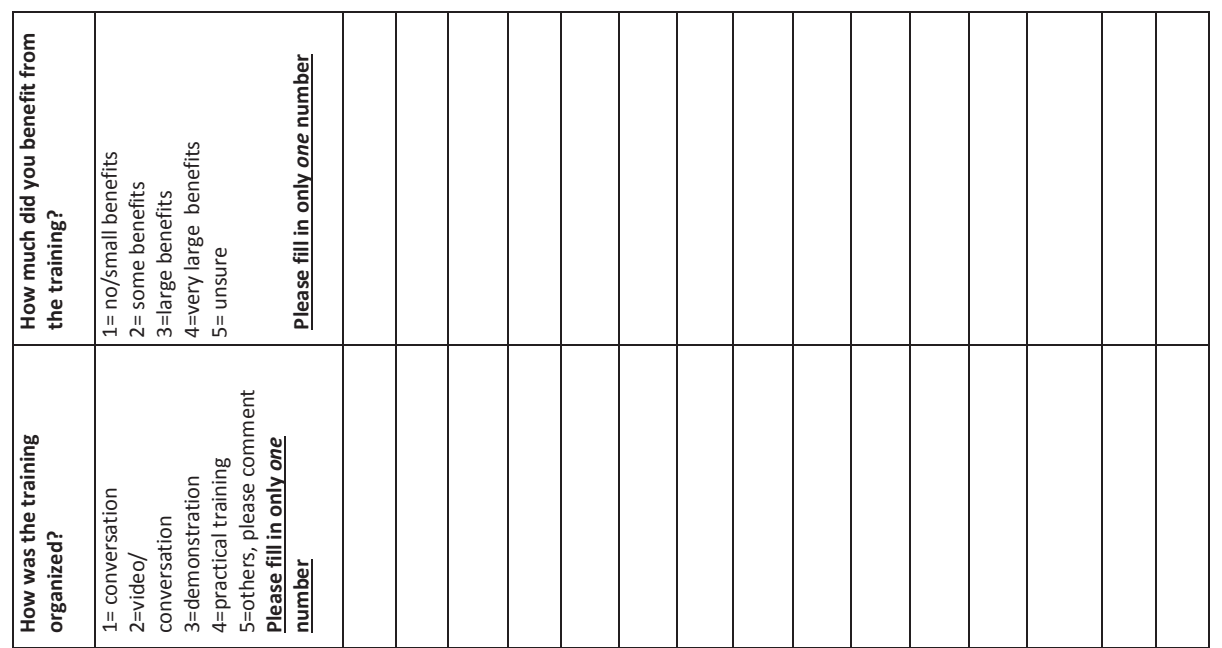

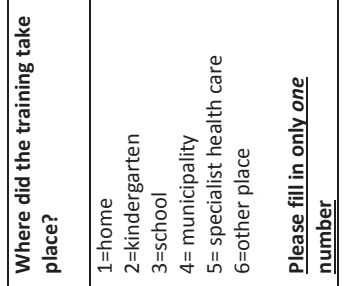

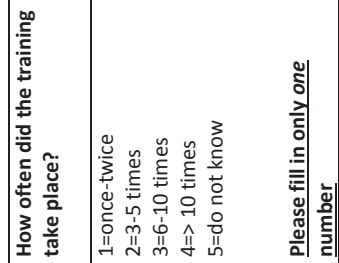

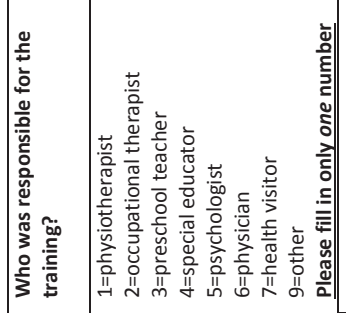

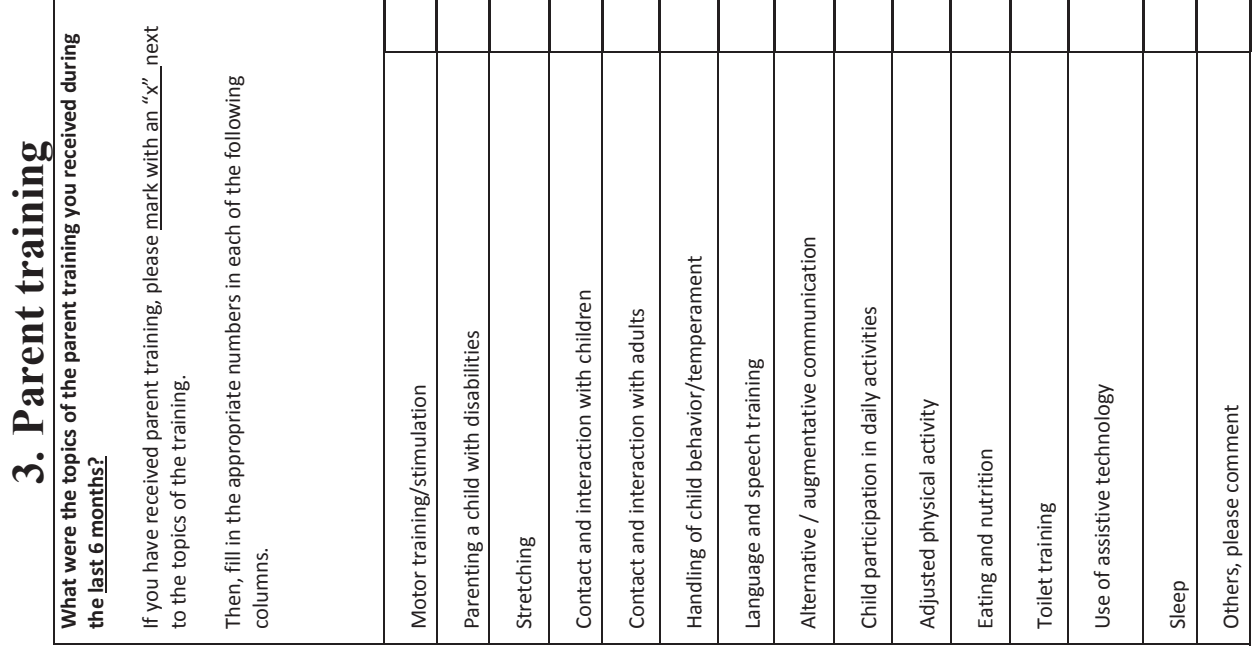



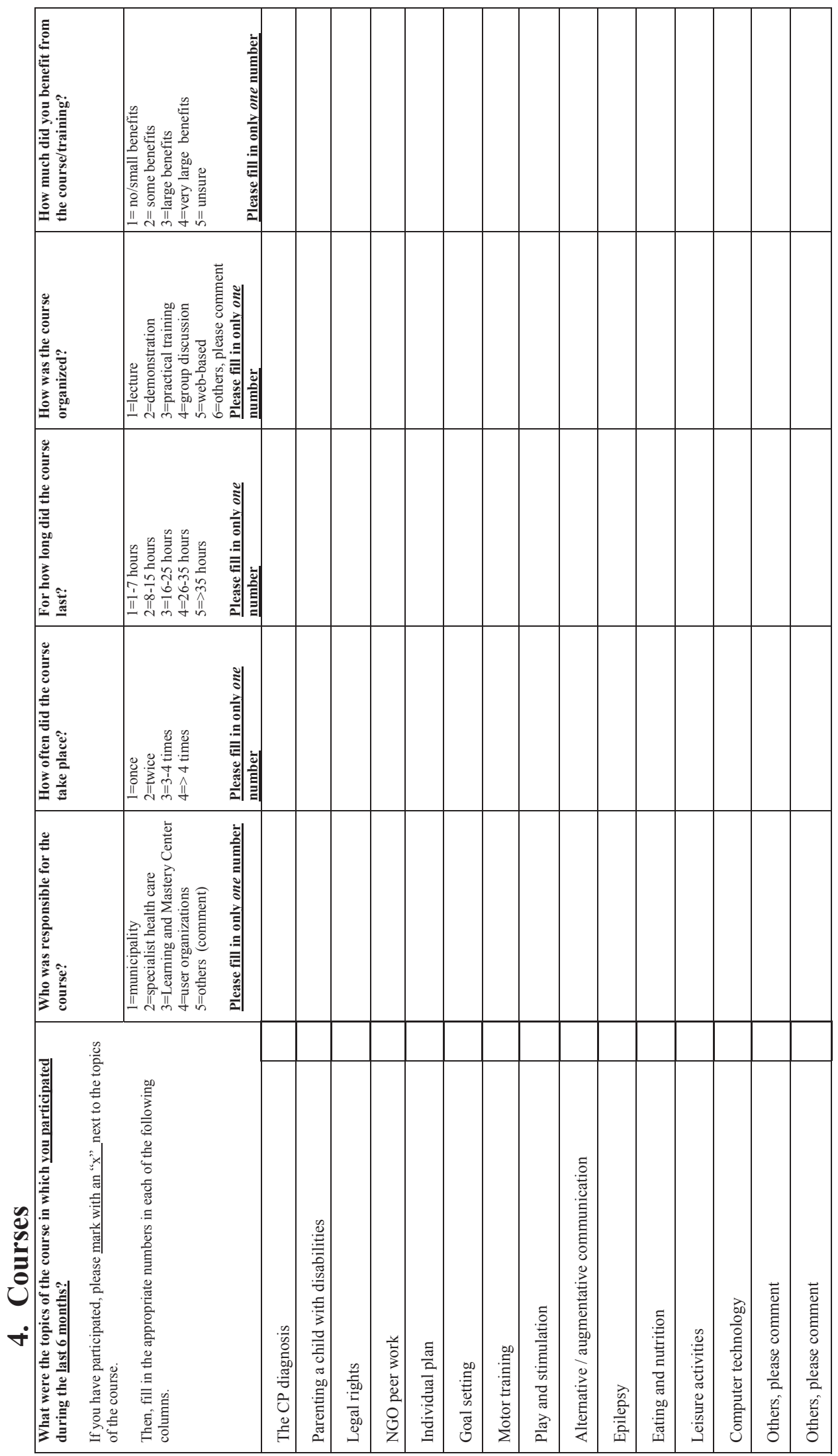

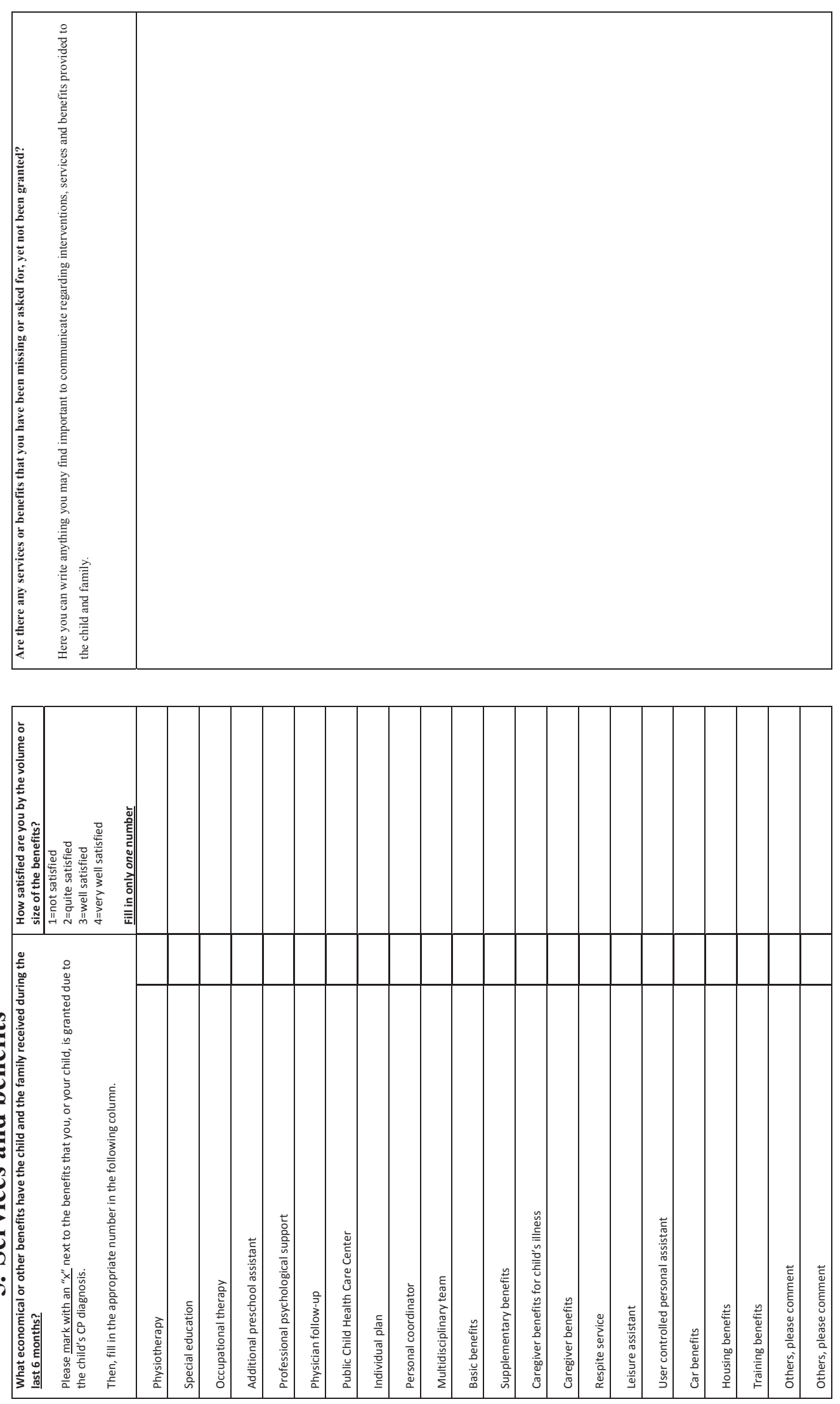


\section{Appendix 2. Questions in the log}

\section{Welcome to log training and other rehabilitation interventions in the PTØ-study!}

We ask you to fill in this log once every month as long as your child is included in the РTØstudy. The aim of this log is to gain more knowledge about what type of training and other rehabilitation interventions your child have performed/received, between the CE courses or at the waiting list. When your child is at the CE course, you are not supposed to fill in the log. Please log all training performed at home, in the kindergarten, at the physiotherapy centre or in other places.

Please tick off the relevant option.

Question 1. How many times has your child performed gross motor training (e.g., lifting up the head, sitting, walking and standing) the last week? Only one option is available.

1. None

2. 1-2 times per week

3. 3-6 times per week

4. Every day

5. Several times per day

6. Do not know

Question 2. Who has trained the child? Several options are available.

1. The parents

2. Assistant

3. Preschool teacher/special educator

4. Physiotherapist

5. Other

6. Do not know

Question 3. How many times has your child performed fine motor training (e.g., grasping, releasing, cutting, threading beads, drawing) the last week? Only one option is available.

1. None

2. 1-2 times per week

3. 3-6 times per week

4. Every day

5. Several times per day

6. Do not know 
Question 4. Who has trained the child? Several options are available.

1. The parents

2. Assistant

3. Preschool teacher/special educator

4. Occupational therapist

5. Physiotherapist

6. Others

7. Do not know

Question 5. How many times has your child performed language and speech training (e.g., sounds, words, naming things, sing, ask for something) the last week? Only one option is available.

1. None

2. 1-2 times per week

3. 3-6 times per week

4. Every day

5. Several times per day

6. Do not know

Question 6. Has your child performed alternative communication training (e.g., sign language, use of photos, pictogram, and voice machine) the last week?

1. Yes

2. No

Question 7. Who has trained the child? Several options are available.

1. Parents

2. Other family members

3. Assistant

4. Preschool teacher/special educator

5. Occupational therapist

6. Others

7. Do not know

Question 8. How many times has your child performed training on eating and drinking the last week? Only one option is available.

1. None

2. 1-2 times per week

3. 3-6 times per week

4. Every day

5. Several times per day

6. Do not know 
Question 9. Who has trained the child? Several options are available.

1. Parents

2. Other family members

3. Assistant

4. Occupational therapist

5. Physiotherapist

6. Others

7. Do not know

Question 10. How many times has your child performed training of getting dressed and undressed the last week? Only one option is available.

1. None

2. 1-2 times per week

3. 3-6 times per week

4. Every day

5. Several times per day

6. Do not know

Question 11. Who has trained the child? Several options are available.

1. Parents

2. Other family members

3. Assistant

4. Occupational therapist

5. Physiotherapist

6. Preschool teacher/special educator

7. Others

8. Do not know

Question 12. How many times has your child performed training on playing skills (e.g., building, puzzles, playing with dolls, role-play) the last week? Only one option is available.

1. None

2. 1-2 times per week

3. 3-6 times per week

4. Every day

5. Several times per day

6. Do not know

Question 13. Who has trained the child? Several options are available.

1. Parents

2. Other family members

3. Assistant

4. Preschool teacher/special educator 
5. Occupational therapist

6. Others

7. Do not know

Question 14. How many times has your child performed training of social skills (e.g., played with children or adults, participated in conversations) the last week? Only one option is available.

1. None

2. 1-2 times per week

3. 3-6 times per week

4. Every day

5. Several times per day

6. Do not know

Question 15. Who has trained the child? Several options are available.

1. Parents

2. Other family members

3. Assistant

4. Preschool teacher/special educator

5. Others

6. Do not know

Question 16. How many times has your child participated in physical activities (e.g., swimming, riding, sledding, biking)? Only one option is available.

1. None

2. 1-2 times per week

3. 3-6 times per week

4. Every day

5. Several times per day

6. Do not know

Question 17. Have you participated in parent education, attended courses or received other parent training the last week?

1. No

2. Yes.

Question 18. What was the topic of the parent training? 
Question 19. Which professionals or agencies have you been in contact with the last week? Several options are available.

1. Physiotherapist

2. Special educator

3. Occupational therapist

4. Medical doctor

5. Psychologist

6. Personal coordinator (multidisciplinary team/individual plan)

7. Norwegian labour and welfare administration (NAV)

8. Paediatric rehabilitation service

9. Others, whom...

Only answer the next questions after you have attended a CE course

Question 20. How often has your child used CE-equipments (e.g., slatted wooden tables, ladder-back chairs) the last week? Only one option is available.

1. None

2. 1-2 times per week

3. 3-6 times per week

4. Every day

5. Several times per day

6. Do not know

Question 21. How often have you used song, rhythm, or rhyme the last week that your child has learned on a CE course? Only one option is available.

1. None

2. 1-2 times per week

3. 3-6 times per week

4. Every day

5. Several times per day

6. Do not know

Question 22: Do you have any other information about your child's training or rehabilitation interventions the last week that you want to describe?

(please write here) 



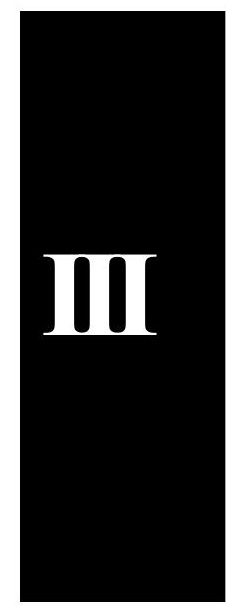





\title{
Intensive training of motor function and functional skills among young children with cerebral palsy: a systematic review and meta-analysis
}

\author{
Hilde Tinderholt Myrhaug ${ }^{1,2^{*}}$, Sigrid Østensj $\varnothing^{1 \dagger}$, Lillebeth Larun ${ }^{2 \dagger}$, Jan Odgaard-Jensen ${ }^{3 \dagger}$ and Reidun Jahnsen ${ }^{1,4+}$
}

\begin{abstract}
Background: Young children with cerebral palsy (CP) receive a variety of interventions to prevent and/or reduce activity limitations and participation restrictions. Some of these interventions are intensive, and it is a challenge to identify the optimal intensity. Therefore, the objective of this systematic review was to describe and categorise intensive motor function and functional skills training among young children with $\mathrm{CP}$, to summarise the effects of these interventions, and to examine characteristics that may contribute to explain the variations in these effects.

Methods: Ten databases were searched for controlled studies that included young children (mean age less than seven years old) with CP and assessments of the effects of intensive motor function and functional skills training. The studies were critically assessed by the Risk of bias tool (RoB) and categorised for intensity and contexts of interventions. Standardised mean difference were computed for outcomes, and summarised descriptively or in meta-analyses.
\end{abstract}

Results: Thirty-eight studies were included. Studies that targeted gross motor function were fewer, older and with lower frequency of training sessions over longer training periods than studies that targeted hand function. Home training was most common in studies on hand function and functional skills, and often increased the amount of training. The effects of constraint induced movement therapy (CIMT) on hand function and functional skills were summarised in six meta-analyses, which supported the existing evidence of CIMT. In a majority of the included studies, equal improvements were identified between intensive intervention and conventional therapy or between two different intensive interventions.

Conclusions: Different types of training, different intensities and different contexts between studies that targeted gross and fine motor function might explain some of the observed effect variations. Home training may increase the amount of training, but are less controllable. These factors may have contributed to the observed variations in the effectiveness of CIMT. Rigorous research on intensive gross motor training is needed.

Systematic review registration number: CRD42013004023.

Keywords: Young children, Cerebral palsy, Intensive training, Motor function, Functional skills, Systematic review

\footnotetext{
*Correspondence: hitimy@hioa.no

${ }^{\dagger}$ Equal contributors

${ }^{1}$ Faculty of Health Sciences, Oslo and Akershus University College of Applied

Sciences, St. Olavs plass, Postbox 4, 0130 Oslo, Norway

${ }^{2}$ Primary Health Care Unit, Norwegian Knowledge Centre for the Health

Services, St. Olavs plass, Postbox 7004, 0130 Oslo, Norway

Full list of author information is available at the end of the article
}

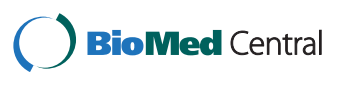

(C) 2014 Tinderholt Myrhaug et al.; licensee BioMed Central Ltd. This is an Open Access article distributed under the terms of the Creative Commons Attribution License (http://creativecommons.org/licenses/by/4.0), which permits unrestricted use, distribution, and reproduction in any medium, provided the original work is properly credited. The Creative Commons Public Domain Dedication waiver (http://creativecommons.org/publicdomain/zero/1.0/) applies to the data made available in this article, unless otherwise stated. 


\section{Background}

All young children, including children with cerebral palsy (CP) develop basic motor function and learn a variety of functional skills during their first years of life $[1,2]$. However, children with CP need more support in this developmental process, and therefore receive a variety of interventions with different intensities and diverse results on activity and participation [3-5]. It is a challenge to identify the optimal intensity of these interventions.

Research on intensive interventions of gross motor function and functional skills is limited, inadequately described, and its effects are inconclusive [6]. In contrast, the body of evidence targeting hand function has shown promising results [4,8-10]. A review from 2014 [10] showed that constraint induced movement therapy (CIMT) led to better hand function compared with conventional therapy. When CIMT was compared at an equal intensity of bimanual training, both intervention groups showed similar improvements in hand function $[8,10]$. Earlier systematic reviews included children with a wide age range $[4,7,10]$. In children with $\mathrm{CP}$, intensive intervention before the age of seven is recommended for optimizing motor function and learning functional skills, because from a maturational and neuroplasticity perspective the greatest gains will be made during this window $[1,2,11]$.

Intensive interventions for children with $\mathrm{CP}$ refer to the frequency and amount of training, the duration of the training session (minutes or hours), and the duration of the training period (weeks or months) [12,13]. The studies included in the systematic reviews of physiotherapy (PT) often define intensity as the frequency of therapy or training sessions [5,7]. Arpino et al. [6] operationally defined any treatment provided more than three times per week as intensive. However, Sakzewski et al. [10] used both the frequency and duration of each session to describe the intensity of therapy. Physiotherapy sessions are typically offered 1-2 times per week to young children with $\mathrm{CP}$ as reported in Norway, Canada and the US $[14,15]$. Therefore, we chose to define intensive training as more than two times per week.

In an editorial commentary, Palisano and Murr made a distinction between intensive interventions, which was defined by the frequency of therapy sessions, and the practice of activities in natural environments [12]. Home practice has been shown to augment and increase the amount of training [10]. However, compliance is a challenge. It has been reported that parents taught to carry out a therapist set program in home environments are less compliant compared with parents taught to use everyday activities as learning opportunities [16,17]. The optimal intensity in relation to the type, setting, and organisation of the intervention is a concern and requires further exploration.
The aim of this systematic review was to describe and categorise intensive motor function and functional skills training among young children with $\mathrm{CP}$, and to summarise the effects of these interventions. Systematic descriptions will allow comparisons of the characteristics of the different types of interventions, as well as the investigation of characteristics that may explain the observed variations in effects.

\section{Methods}

The protocol of this systematic review was registered in PROSPERO table with registration number CRD42013 004023. Ethical approval was not required.

\section{Search strategy}

MEDLINE, Embase, PsycINFO, Cochrane Library, ERIC, OT Seeker, Cinahl, ISI Web of Science, SveMed+, and PEDro were searched in October 2012. The search strategy used free text word and subject headings adapted to each database. The full electronic search strategy for Ovid MEDLINE(R) is found in Additional file 1. The reference lists of relevant systematic reviews were also manually searched. An updated search was conducted in the Cochrane Central Register of Controlled Trials (Central), PEDro and ISI Web of science in September 2014. A list of included studies of awaiting assessment is attached (Additional file 2).

\section{Selection criteria}

We included trials with the following criteria: (a) a study population of $\mathrm{CP}$ with a mean age less than seven years; (b) evaluated the effects of motor function (e.g., mobility and grasping) and functional skills training (e.g., eating and playing) performed three times or more per week at the clinic, in the kindergarten, or at home; (c) was compared to another intervention (e.g., conventional therapy), the same type of intervention provided less frequently, or another intensive intervention; and (d) with outcomes in the activity and participation components of the ICF [3], measured as hand function, gross motor function, and/or functional skills. In addition, the included studies were required to be controlled trials, published in peer review journals in the period from 1948 to October 2012 in English or a Scandinavian language. Studies were excluded if the training was combined with passive interventions (e.g., botulinum toxin-A (BoNT) injections, massage, or neuromuscular stimulation), or if the outcomes were only within the body functions and structures component of the ICF (e.g., range of motion and spasticity).

\section{Selection of studies and data extraction}

All steps in the selection and extraction processes (i.e., the study selection, data extraction, and risk of bias evaluation) were assessed independently by two reviewers. Any 
disagreement between the reviewers in these processes was resolved by discussions with the group of authors. The titles and abstracts of all retrieved references were screened. The full texts of relevant publications were reviewed and were included if they met the inclusion criteria. The data from the included studies were extracted using a piloted data extraction form, which included information on the study population, design, interventions, comparison, outcome measures, and results (Additional file 3). Authors of included studies were not contacted for missing data.

\section{Risk of bias}

The risk of bias tool [18] includes the following items: sequence generation, allocation concealment, integrity of blinding, the completeness of outcome data, selective reporting, and other potential sources of bias. The items in the risk of bias assessment were classified according to the extent to which bias was prevented and included ratings of low, high, or unclear. An overall assessment of the risk of bias was assigned to each included study as suggested in the Cochrane Handbook [18]. When five items were assessed as a low risk of bias within a study, the study was assigned an overall low risk of bias. This characterisation indicates that bias is unlikely to affect the results.

\section{Data analysis}

Intervention characteristics were categorised according to the outcome (hand function, gross motor function, and functional skills), intensity (amount and duration of training), and context of intervention (setting, organisation, goals, and parental involvement) (Table 1). The intensity of training was described as the amount of training and duration of the training periods. The amount was categorised into four groups according to frequency of sessions and use of home training: (1) 2-7 training sessions per week with additional home training, (2) 3-7 training sessions per week, (3) training more than one hour per day, and (4) training more than one hour per day with additional home training (Table 1). The duration was categorised as $\leq$ four weeks, 5-12 weeks, or $>12$ weeks. The characteristics were coded as met or not met.

Standardised mean differences (SMD) were computed for outcomes based on post treatment mean scores for the study groups, except for studies that showed clinically or statistically significant baseline differences or where the post treatment mean scores were not reported. The results from these studies were not calculated, due to lack of information. Review Manager Software (RevMan5; Cochrane Information Management System) was used to compute the SMD and to summarise statistically randomised controlled data if the included studies were comparable in terms of the type of training, amount of training, and outcomes. In the metaanalyses, the outcomes were categorised as unimanual or bimanual hand function, gross motor function, and functional skills. A random effects model was used to account for pooling effects due to the clinical heterogeneity of the included studies. Double-data entries were performed. We aimed to examine characteristics that may have contributed to explain the variations in effects. However, the meta-regression analyses could not be performed because of the small number of studies and the clinical heterogeneity between studies.

\section{Results}

The results of the search strategy are shown in Figure 1. The search yielded 5,553 unique references, of which, 5,413 references were excluded based on the screening of their titles and abstracts; 140 articles were reviewed in full text. Forty articles, which corresponded to 38 studies from Asia $(n=12)$, Australia $(n=3)$, Europe $(n=11)$, and North America $(\mathrm{n}=12)$, were included.

An overview of the included studies is presented in Additional file 4. The 38 studies included 1407 children with all levels of gross and fine motor function [58,59]. The studies utilised 31 assessment tools, which are described in Additional file 4.

Twenty-nine studies were randomised controlled studies, and nine studies were controlled before and after studies. The risk of bias within studies is shown in Figure 2. Nine studies had a low risk of bias [20,21,24,29,30, $34,36,46,49,60], 11$ articles of 10 studies had an unclear risk of bias $[22,23,28,31-33,35,37,43,47,52]$, and 19 studies had a high risk of bias [19,25-27,38-42,44,45,48,50, 51,53-57].

\section{Characteristics of interventions}

The characteristics of the intensive interventions included in this systematic review are coded and shown in Table 1. The interventions were categorised according to the outcome, intensity, and context of interventions. Interventions reported as conventional therapy, usual care, conventional paediatric treatment and standard care refer to interventions performed less than three times per week and the type of training was seldom described and not categorised in Table 1.

\section{Characteristics of interventions that aimed to improve hand function}

Of the 23 studies that reported outcomes for hand function, seven studies reported 2-7 sessions per week with additional home training [20,21,23,30-32,34,38], five studies reported daily training of more than one hour per day [22,27,29,33,35,36], and five studies with a high amount of training ( $>$ one hour per day) reported additional home training [19,24-26,60]. Seventeen studies 
Tinderholt Myrhaug et al. BMC Pediatrics 2014, 14:292

Page 4 of 19

http://www.biomedcentral.com/1471-2431/14/292

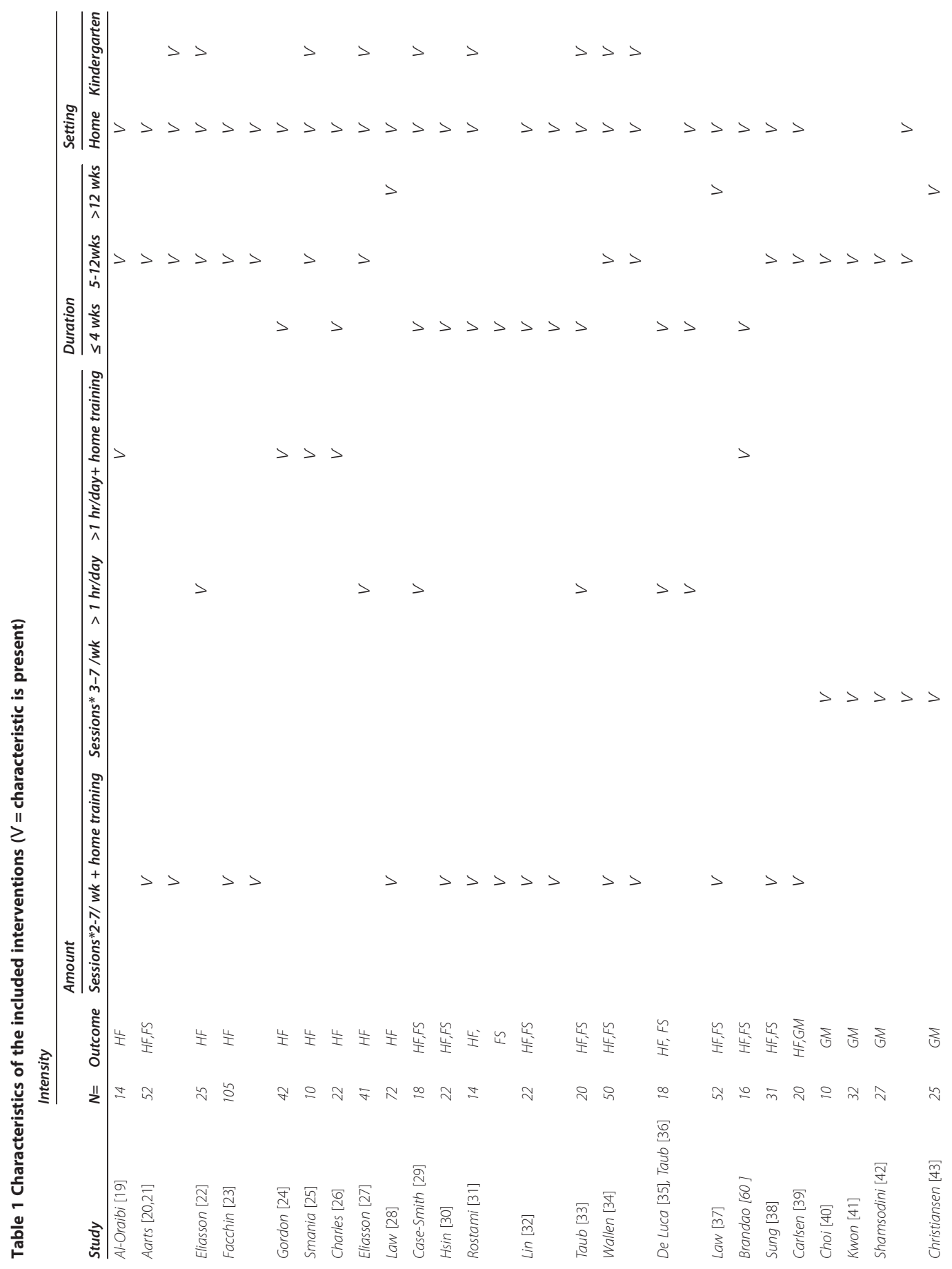


Tinderholt Myrhaug et al. BMC Pediatrics 2014, 14:292

Page 5 of 19

http://www.biomedcentral.com/1471-2431/14/292

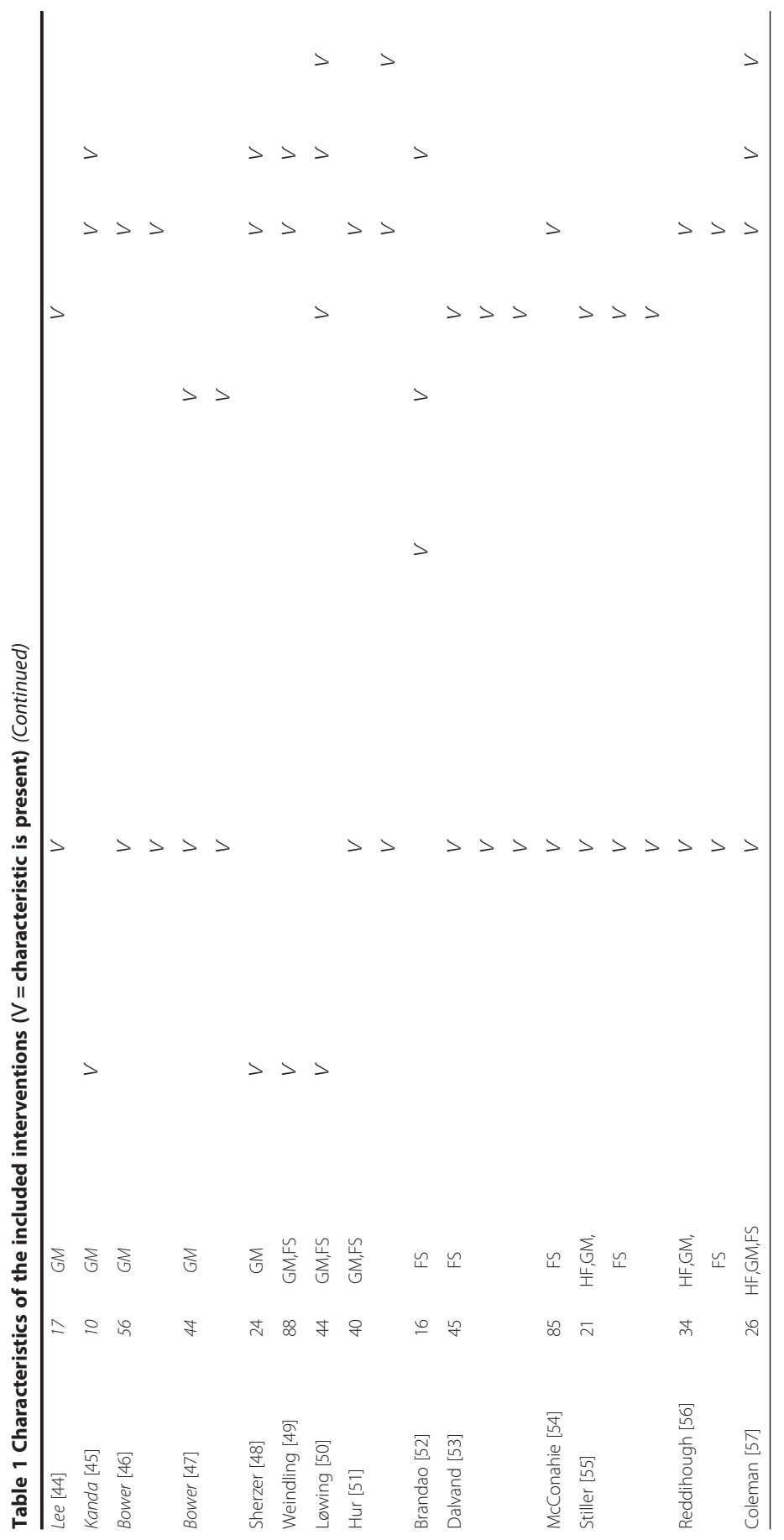


Tinderholt Myrhaug et al. BMC Pediatrics 2014, 14:292

Page 6 of 19

http://www.biomedcentral.com/1471-2431/14/292

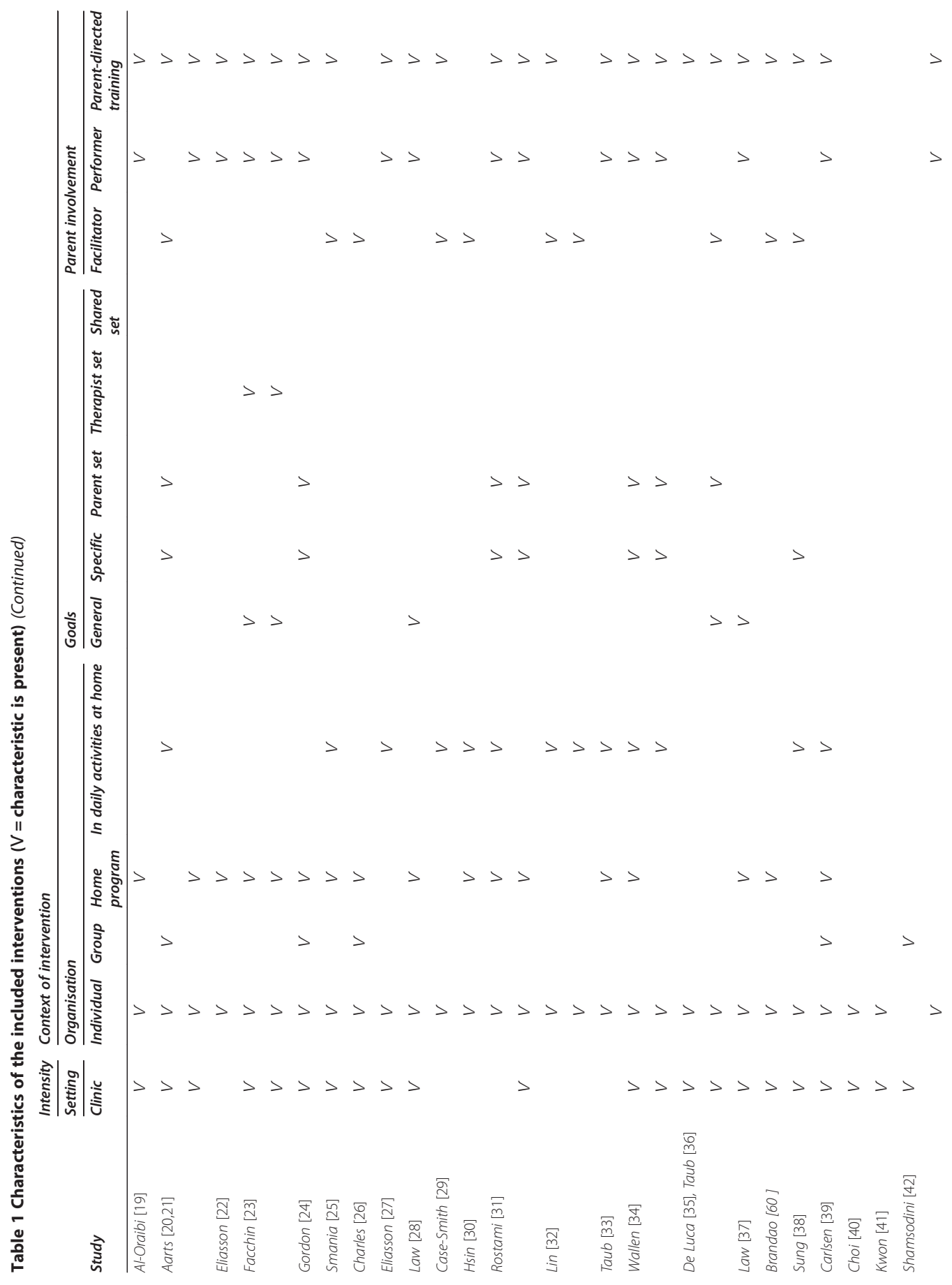


Tinderholt Myrhaug et al. BMC Pediatrics 2014, 14:292

Page 7 of 19

http://www.biomedcentral.com/1471-2431/14/292

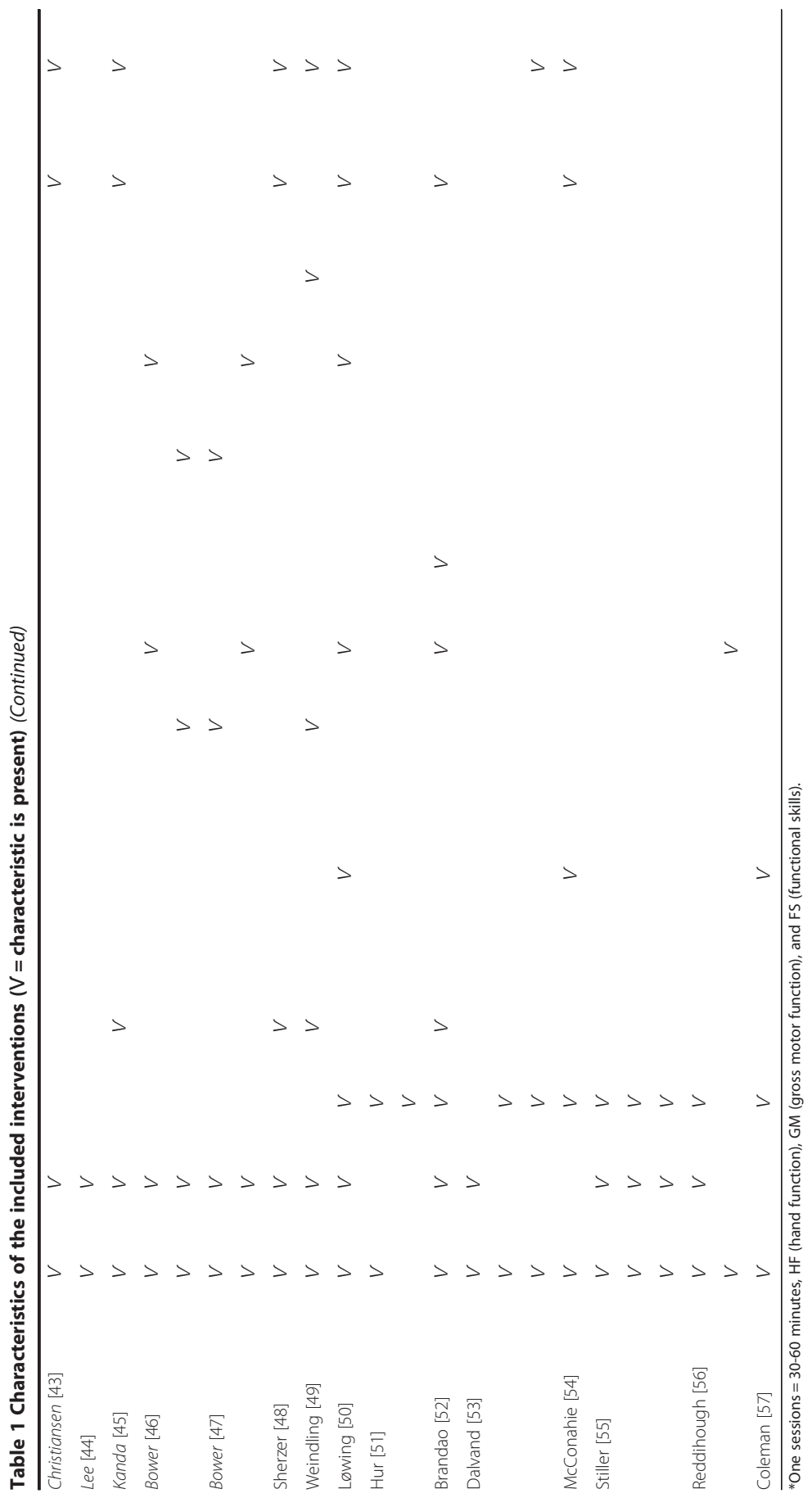




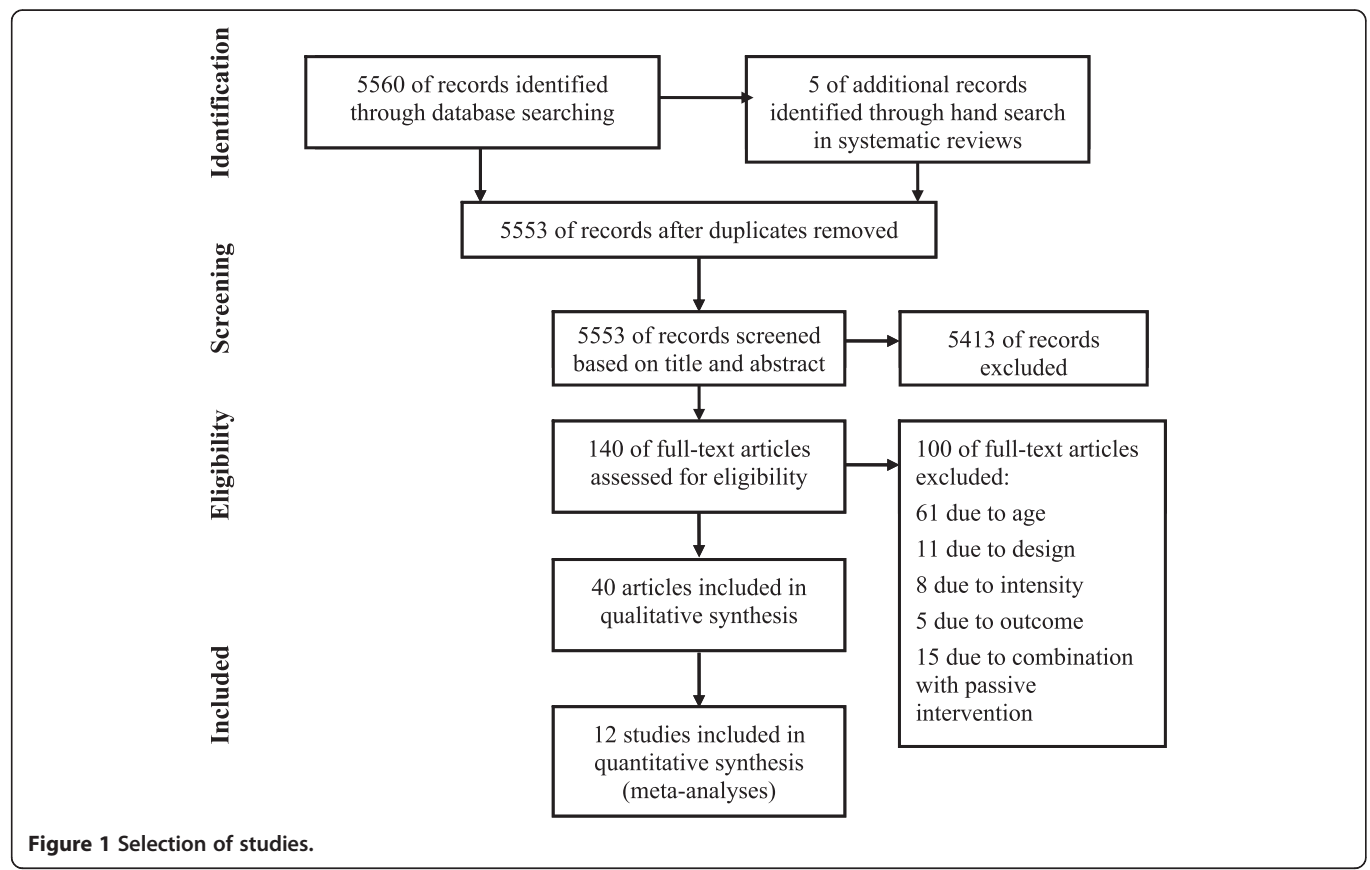

evaluated the effect of constraint induced movement therapy (CIMT), constraint induced therapy (CI), or eco-CI, modified CIT (mCIT), and modified CIMT (mCIMT); hereinafter called CIMT. These 17 CIMT studies were compared with conventional therapy [19,22,25-27,30,33, $35,36,38,60]$, intensive bimanual therapy [20,21,23,24,32,34], more intensive CIMT [29], or intensive training in a different context [31]. The duration of the different CIMT interventions was in all studies less than 12 weeks and took place at the clinic $(n=13)$ and at home $(n=17)$. The training was carried out individually $(\mathrm{n}=17)$ and/or as group training sessions $(n=3)$. Five studies reported therapist set home programs that were incorporated into daily activities $[25,30,31,33,34]$, while six studies reported practices that were only integrated with daily routines of the family $[20,21,27,29,32,34,38]$. The use of general and specific goals was more prevalent in the studies combined with home training $(n=7)$ compared with the studies without home training $(n=1)$. In the studies with home training, all the parents acted as performers or were asked by the therapists to facilitate the child's everyday skills training at home. The parents were offered parent education except in two studies [26,30] (Table 1).

Among the six remaining studies reporting on hand function, three were studies of intensive neurodevelopmental treatment (NDT) [39] and casting [28,37]. These studies included training of hand function over 2-7 sessions per week with additional home training were compared to occupational therapy (OT) [37,39], regular NDT with and without casting [28], and intensive NDT [28]. The intensive NDT lasted more than five weeks and was performed at the clinic and in combination with a home program. Moreover, the training was provided individually $(n=3)$ and in groups $(n=1)$. Law [28,37] reported the use of general goals. Parents acted as performers of home training and received supervision. In the remaining three studies [55-57], intensive conductive education (CE) was compared with intensive NDT [56], traditional early intervention program [57], intensive OT and physiotherapy (PT) [55], or intensive special education [55]. The interventions were all performed as 3-7 training sessions per week and lasted 5-12 weeks or more than 12 weeks. Moreover, the training was performed in group training sessions at the clinic, with no home training, defined goals, or parental involvement.

\section{Characteristics of interventions that aimed to improve gross motor function}

Sixteen studies reported outcomes on gross motor function. Five of these studies reported gross motor function targeted with Vojta training [45], home programs to facilitate motor development [48], goal-directed functional training [50] intensive PT [49], and intensive NDT [39], all performed over $2-7$ sessions per week with additional 


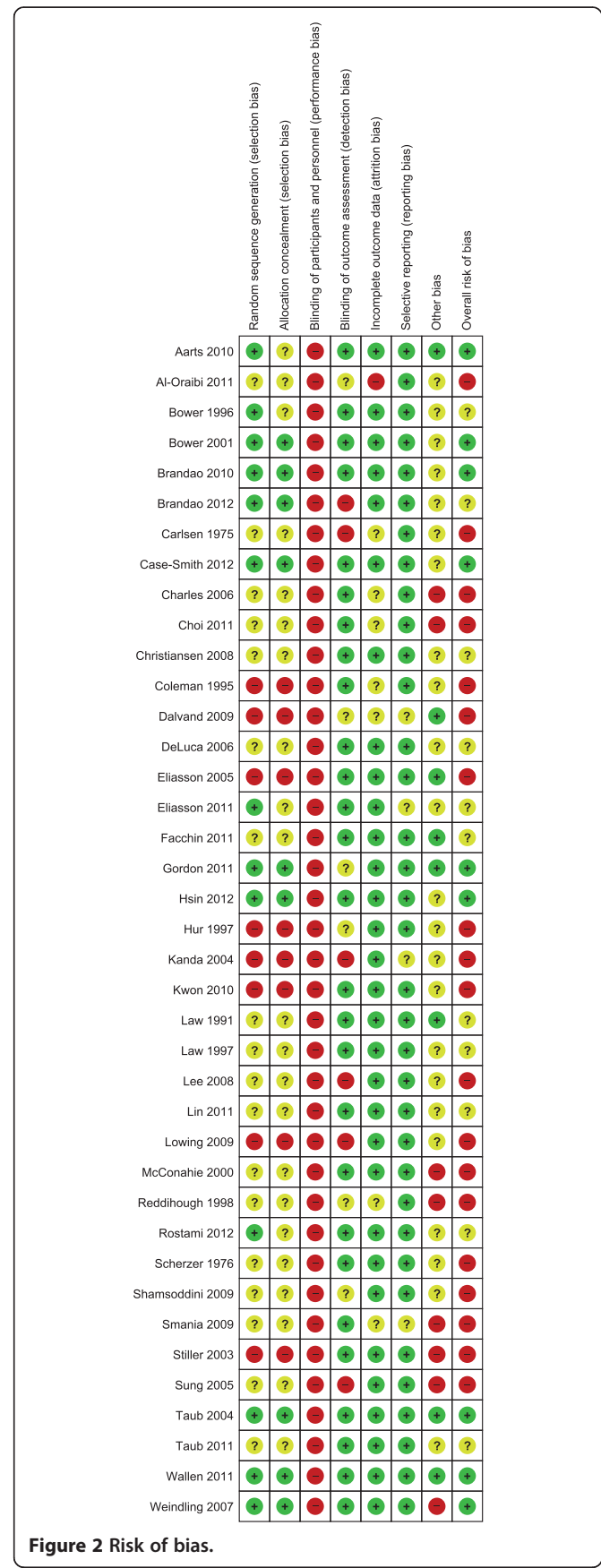

home training. These interventions were compared with non-intensive Vojta treatment [45], traditional passive motion exercises [48], activity-focused training [50], PT and visits by a family support worker (FSWG) [49] or OT [39]. The intensive interventions lasted 5-12 weeks or more than 12 weeks. The training was provided individually $(n=5)$ and in groups $(n=1)$ at home and/or at the clinic. Four studies reported therapist set home programs $[39,45,48,49]$, whereas two studies reported practice that was integrated with daily activities [39,50]. Weindling [49] and Løwing [50] used general and specific goals, respectively. Active parental involvement in training, and parent directed training were also reported $(\mathrm{n}=5)$ (Table 1).

The remaining eleven studies that targeted gross motor training were performed 3-7 sessions per week within a task-oriented approach [40], hippotherapy and NDT [41], sensory integration therapy [42], intensive and other types of PT [43,44,46,47] or CE [51,55-57]. These interventions were compared with NDT $[40,41,56,57]$, home program with OT [42], other types of PT $[43,44,46,47,55]$ or intensive special education $[51,55]$. The training lasted from less than four weeks to more than 12 weeks. It was provided individually $(n=8)$ and/or in groups $(n=5)$ only at the clinic. The use of general and specific goals was only reported in two studies [46,47]. Shamsoddini [42] and Christiansen [43] reported parental involvement. The characteristics of CE reported by Hur [51], Stiller [55], Reddihough [56], and Coleman [57] were the same as that described for hand function.

\section{Characteristics of interventions that aimed to improve functional skills}

Of the 20 studies that reported outcomes on functional skills, nine studies reported 2-7 sessions per week with additional home training [20,21,30-32,34,37,38,49,50], six studies reported training over 3-7 sessions per week [51,53-57], three studies and four articles reported training of more than one hour per day [29,33,35,36], and two studies reported more than one hour of training per day with additional home training $[52,60]$. The characteristics of these studies are presented in relation to hand or gross motor function, except for the studies by Hur [51], Dalvand [53], McConahie [54], and Brandao [52]. In the studies by Hur [51] and Dalvand [53], the effect of CE performed over 3-7 times per week was compared with intensive special education [51] and NDT or education to parents [53]. Otherwise, the characteristics were similar to the other CE-studies presented earlier. McConahie [54] reported the outcomes of training over 3-7 sessions per week for more than 12 weeks. The intervention was an urban daily mother-child group that took place at the clinic, where the mothers were actively involved and received supervision. In the report by 
Table 2 Summary of the results

\begin{tabular}{|c|c|c|c|c|c|c|c|}
\hline $\begin{array}{l}\text { Study [ref] } \\
\text { (Risk of bias) }^{\mathrm{A}}\end{array}$ & $\begin{array}{l}\text { Outcome (outcome } \\
\text { measurement) }\end{array}$ & $\begin{array}{c}\text { Treatment } \\
\text { duration, wk }\end{array}$ & $\mathrm{n}$ & $\begin{array}{l}\text { Post treatment, } \\
\text { mean score (SD) }\end{array}$ & $\mathrm{n}$ & $\begin{array}{l}\text { Post control, } \\
\text { mean score (SD) }\end{array}$ & SMD $(95 \% \mathrm{Cl})^{*}$ \\
\hline Aarts [20] & HF (VOAA-DDD, capacity) & 8 & 28 & $40.5(29.2)$ & 22 & $28.6(28.8)$ & $0.40(-0.16,0.97)$ \\
\hline Aarts [21] & HF (VOAA-DDD, performance) & 8 & 28 & $69.6(21.4)$ & 22 & $50.4(28.5)$ & $0.76(0.18,1.34)^{*}$ \\
\hline \multicolumn{8}{|l|}{ (Low) } \\
\hline Facchin [23] & HF (QUEST) & 10 & 20 & 72.8 & 33 & 72.9 & $\begin{array}{l}\text { Could not be } \\
\text { estimated }^{\mathrm{B}}\end{array}$ \\
\hline \multirow[t]{3}{*}{ (Unclear) } & HF (QUEST) & 10 & 19 & 72.8 & 33 & 68.4 & $\begin{array}{l}\text { Could not be } \\
\text { estimated }^{\mathrm{B}}\end{array}$ \\
\hline & HF (Besta Scale, quality of grasp) & 10 & 20 & 3.15 & 33 & 2.88 & $\begin{array}{l}\text { Could not be } \\
\text { estimated }^{\mathrm{B}}\end{array}$ \\
\hline & HF (Besta Scale, quality of grasp) & 10 & 19 & 3.15 & 33 & 3.02 & $\begin{array}{l}\text { Could not be } \\
\text { estimated }\end{array}$ \\
\hline Gordon [24] & HF (JTTHF) & 3 & 21 & $-233.1(173.8)$ & 21 & $-249.6(173.8)$ & $0.09(-0.51,0.70)$ \\
\hline \multicolumn{8}{|l|}{ (Low) } \\
\hline Smania [25] & HF (Use test) & 5 & 5 & NR & 5 & NR & $\begin{array}{l}\text { Could not be } \\
\text { estimated }\end{array}$ \\
\hline (High) & HF (Function test) & 5 & 5 & NR & 5 & NR & $\begin{array}{l}\text { Could not be } \\
\text { estimated }^{\mathrm{B}}\end{array}$ \\
\hline Charles [26] & HF (JTTHF) & 2 & 11 & $-278.5(240.6)$ & 11 & $-301.0(182.2)$ & $0.10(-0.73,0.94)$ \\
\hline (High) & HF (BOTMP subtest 8) & 2 & 11 & $7.2(2.9)$ & 11 & $5.2(4.2)$ & $0.53(-0.32,1.39)$ \\
\hline \multicolumn{8}{|l|}{ Law [28] } \\
\hline \multirow[t]{2}{*}{ (Unclear) } & HF (PDMS, fine motor scale) & 24 & 18 & $28.1(18.4)$ & 18 & $30.8(21.3)$ & $-0.13(-0.79,0.52)$ \\
\hline & HF (QUEST) & 24 & 18 & $47.9(26.8)$ & 18 & $47.2(28.9)$ & $0.02(-0.63,0.68)$ \\
\hline Case-Smith [29] & $\mathrm{HF}(\mathrm{AHA})$ & 3 & 9 & $0.84(3.3)$ & 9 & $3.03(3.9)$ & $-0.58(-1.53,0.37)$ \\
\hline (Low) & FS (PMAL (QOU)) & 3 & 9 & $3.40(1.40)$ & 9 & $3.43(0.80)$ & $-0.03(-0.95,0.90)$ \\
\hline Hsin [30] & FS (PMAL (QOU)) & 4 & 11 & $2.6(0.3)$ & 11 & $2.3(0.2)$ & $1.13(0.22,2.05)^{*}$ \\
\hline \multicolumn{8}{|l|}{ (Low) } \\
\hline \multicolumn{8}{|l|}{ Rostami [31] } \\
\hline (Unclear) & FS (PMAL (QOU)) & 3.35 & 7 & $2.26(0.29)$ & 7 & $2.23(0.30)$ & $0.10(-0.95,1.14)$ \\
\hline \multicolumn{8}{|l|}{ Lin [32] } \\
\hline & HF (BOTMP-MUE) & 4 & 10 & $9.00(5.91)$ & 11 & $5.77(6.33)$ & $0.51(-0.37,1.38)$ \\
\hline \multirow[t]{2}{*}{ (Unclear) } & HF (PDMS-grasp) & 4 & 10 & $45.9(7.82)$ & 11 & $44.27(6.23)$ & $0.22(-0.64,1.08)$ \\
\hline & FS (PMAL (QOU)) & 4 & 10 & $2.84(0.96)$ & 11 & $2.26(0.88)$ & $0.61(-0.27,1.49)$ \\
\hline Taub [33] & HF (INMAP) & 3 & 10 & $35.9(6.2)$ & 10 & $27.8(6.6)$ & $1.21(0.24,2.18)^{*}$ \\
\hline (Unclear) & FS (PMAL) & 3 & 10 & $3.5(0.6)$ & 10 & $1.4(0.5)$ & $3.64(2.11,5.18)^{*}$ \\
\hline Wallen [34] & FS (COPM, performance) & 8 & 25 & $6.1(2.3)$ & 25 & $6.0(1.7)$ & $0.05(-0.51,0.60)$ \\
\hline \multirow[t]{2}{*}{ (Low) } & FS (COMP, satisfaction) & 8 & 25 & $6.5(2.4)$ & 25 & $6.7(2.2)$ & $-0.09(-0.64,0.47)$ \\
\hline & FS (PMAL (QOU)) & 8 & 25 & $59.6(23.6)$ & 25 & $51.3(19.7)$ & $0.38(-0.18,0.94)$ \\
\hline DeLuca [35] & HF (QUEST) & 3 & 9 & NR & 9 & NR & $\begin{array}{l}\text { Could not be } \\
\text { estimated }^{\mathrm{B}}\end{array}$ \\
\hline (Unclear) & HF (EBS) & 3 & 9 & NR & 9 & NR & $\begin{array}{l}\text { Could not be } \\
\text { estimated }^{\mathrm{B}}\end{array}$ \\
\hline Taub [36] & FS (PMAL (AOU)) & 3 & 9 & NR & 9 & NR & $\begin{array}{l}\text { Could not be } \\
\text { estimated }^{\mathrm{B}}\end{array}$ \\
\hline \multirow[t]{3}{*}{ (Low) } & FS (PMAL (OOL)) & 3 & 9 & NR & 9 & NR & $\begin{array}{l}\text { Could not be } \\
\text { estimated }^{\mathrm{B}}\end{array}$ \\
\hline & $\mathrm{HF}(\mathrm{EBS})$ & 3 & 9 & $21.5(4.45)$ & 9 & $15(5.66)$ & $1.22(0.19,2.24)^{*}$ \\
\hline & FS (PMAL (QOU)) & 3 & 9 & $2.7(0.97)$ & 9 & $1.9(1.13)$ & $0.72(-0.24,1.69)$ \\
\hline
\end{tabular}


Table 2 Summary of the results (Continued)

\begin{tabular}{|c|c|c|c|c|c|c|c|}
\hline & HF (TAUT) & 3 & 9 & NR & 9 & NR & $\begin{array}{l}\text { Could not be } \\
\text { estimated }^{B}\end{array}$ \\
\hline Law [37] & HF (PDMS, fine motor scale) & 16 & 26 & $21.8(8.5)$ & 24 & $20.9(9.0)$ & $0.10(-0.45,0.66)$ \\
\hline \multirow[t]{3}{*}{ (Unclear) } & HF (QUEST) & 16 & 26 & $53.3(22.9)$ & 24 & $47.3(27.7)$ & $0.23(-0.32,0.79)$ \\
\hline & FS (COPM, performance) & 16 & 26 & $6.5(1.6)$ & 24 & $5.7(1.4)$ & $0.52(-0.04,1.09)$ \\
\hline & FS (COPM, satisfaction) & 16 & 26 & $7.1(1.9)$ & 24 & $5.8(1.8)$ & $0.69(0.12,1.26)^{*}$ \\
\hline Brandao [60] & FS (PEDI, independence) & 2 & 8 & $70.25(8.90)$ & 7 & $68.37(3.61)$ & $0.25(-0.77,1.27)$ \\
\hline \multicolumn{8}{|l|}{ (Low) } \\
\hline Sung [38] & HF (BBT, affected limb) & 6 & 18 & $10.50(5.73)$ & 13 & $9.54(7.14)$ & $0.15(-0.57,0.86)$ \\
\hline \multirow[t]{2}{*}{ (High) } & HF (BBT, unaffected limb) & 6 & 18 & $18.12(10.06)$ & 13 & $23.15(17.12)$ & $-0.36(-1.08,0.36)$ \\
\hline & $\mathrm{HF}(\mathrm{EDPA})$ & 6 & 18 & $7.64(1.65)$ & 13 & $7.06(1.42)$ & $0.36(-0.36,1.08)$ \\
\hline Carlsen [39] & $\begin{array}{l}\text { HF (Denver Development } \\
\text { subscales) }\end{array}$ & & 6 & NR & 6 & NR & $\begin{array}{l}\text { Could not be } \\
\text { estimated }^{\mathrm{B}}\end{array}$ \\
\hline (High) & $\begin{array}{l}\text { GM (Denver Development } \\
\text { subscales) }\end{array}$ & & 6 & NR & 6 & NR & $\begin{array}{l}\text { Could not be } \\
\text { estimated }^{\mathrm{B}}\end{array}$ \\
\hline Choi [40] & GM (GMFM-88, sitting) & 6 & 5 & $9.4(3.11)$ & 5 & $2.0(2.12)$ & $2.51(0.63,4.39)^{C_{*}}$ \\
\hline \multicolumn{8}{|l|}{ (High) } \\
\hline Kwon [41] & GM (GMFM-66) & 8 & 16 & $73.7(8.3)$ & 16 & $70.1(8.1)$ & $0.43(-0.27,1.13)$ \\
\hline (High) & GM (gait analysis, speed) & 8 & 16 & $-60.7(0.1)$ & 16 & $-68.0(0.2)$ & $45.01(-33.21,56.80)$ \\
\hline Shamsoddini [42] & GM (GMFM-88) & 12 & 14 & $90.1(11.62)$ & 10 & $86.3(7.93)$ & $0.36(-0.46,1.18)$ \\
\hline \multicolumn{8}{|l|}{ (High) } \\
\hline Christiansen [43] & GM (GMFM-66) & 30 & 10 & $54.9(16.5)$ & 14 & $55.6(19.7)$ & $-0.04(-0.85,0.77)$ \\
\hline \multicolumn{8}{|l|}{ (Unclear) } \\
\hline Lee [44] & GM (GMFM-88) & 5 & 9 & $86.9(13.4)$ & 8 & $85.4(13.5)$ & $0.11(-0.85,1.06)$ \\
\hline (High) & GM (Gait analysis, speed) & 5 & 9 & $74.6(38.7)$ & 8 & $68.2(42.9)$ & $\begin{array}{l}\text { Could not be } \\
\text { estimated }^{\mathrm{B}}\end{array}$ \\
\hline Kanda [45] & GM (Able to stand or walk $5 \mathrm{sec}$ ) & 208 & 5 & 4 & 5 & 0 & $\begin{array}{l}\text { Could not be } \\
\text { estimated }^{\mathrm{B}}\end{array}$ \\
\hline \multicolumn{8}{|l|}{ (High) } \\
\hline Bower [46] & GM (GMFM-88) & 24 & 15 & NR & 13 & NR & $\begin{array}{l}\text { Could not be } \\
\text { estimated }^{B}\end{array}$ \\
\hline \multicolumn{8}{|l|}{ (Low) } \\
\hline \multicolumn{8}{|l|}{ Bower [47] } \\
\hline & GM (GMFM-88) & 2 & 22 & NR & 22 & NR & $\begin{array}{l}\text { Could not be } \\
\text { estimated }^{B}\end{array}$ \\
\hline \multicolumn{8}{|l|}{ (Unclear) } \\
\hline Scherzer [48] & GM (Motor dev eval form) & 24 & 11 & NR & 11 & NR & $\begin{array}{l}\text { Could not be } \\
\text { estimated }^{\mathrm{B}}\end{array}$ \\
\hline \multicolumn{8}{|l|}{ (High) } \\
\hline Weindling [49] & GM (GMFM-88) & 24 & 12 & $50.0(25.8)$ & 28 & $45.5(29.7)$ & $0.15(-0.52,0.83)$ \\
\hline \multirow[t]{3}{*}{ (Low) } & GM (GMFM-88) & 24 & 13 & $50.0(25.8)$ & 23 & $48.0(30.7)$ & $0.07(-0.61,0.75)$ \\
\hline & FS (Vineland Daily living) & 24 & 12 & $25.5(11.0)$ & 28 & $24.5(17.1)$ & $0.07(-0.47,0.61)$ \\
\hline & FS (Vineland Daily living) & 24 & 13 & $25.5(11.0)$ & 22 & $25.5(16.3)$ & $0.00(-0.57,0.57)$ \\
\hline \multicolumn{8}{|l|}{ Løwing [50] } \\
\hline & GM (GMFM-66) & 12 & 22 & $63.59(13.15)$ & 22 & $64.15(17.33)$ & $-0.04(-0.63,0.56)^{\mathrm{D}}$ \\
\hline \multirow[t]{2}{*}{ (High) } & FS (PEDI, self-care) & 12 & 22 & $57.35(9.40)$ & 22 & $58.66(11.63)$ & $-0.12(-0.71,0.47)$ \\
\hline & FS (PEDI, mobility) & 12 & 22 & $61.44(13.89)$ & 22 & $62.48(17.75)$ & $-0.06(-0.66,0.53)$ \\
\hline
\end{tabular}


Table 2 Summary of the results (Continued)

\begin{tabular}{|c|c|c|c|c|c|c|c|}
\hline & FS (Social function) & 12 & 22 & $61.22(8.85)$ & 22 & $63.61(10.25)$ & $-0.25(-0.84,0.35)$ \\
\hline Hur [51] & GM (VAB, videotaped, gross motor) & 56 & 19 & $13.5(6.2)$ & 17 & $16.2(12.4)$ & $-0.27(-0.93,0.38)$ \\
\hline \multirow[t]{4}{*}{ (High) } & $\begin{array}{l}\text { GM (Developmental profile2, } \\
\text { physical) }\end{array}$ & 56 & 19 & $26.5(13.1)$ & 17 & $24.7(11.4)$ & $0.14(-0.51,0.80)$ \\
\hline & $\begin{array}{l}\text { FS (VAB, videotaped, play and } \\
\text { leisure) }\end{array}$ & 56 & 19 & $39.1(19.4)$ & 17 & $51.7(22.1)$ & $-0.59(-1.27,0.08)$ \\
\hline & FS (VAB, videotaped, daily living) & 56 & 19 & $34.1(14.1)$ & 17 & $32.3(10.6)$ & $0.14(-0.52,0.80)$ \\
\hline & $\begin{array}{l}\text { FS (Developmental profile2, self- } \\
\text { help) }\end{array}$ & 56 & 19 & $50.2(18.2)$ & 17 & $42.2(18.3)$ & $0.43(-0.23,1.09)$ \\
\hline Brandao [52] & FS (COPM, performance) & 3 & 8 & $5.54(1.7)$ & 8 & $6.58(1.19)$ & $-0.67(-1.69,0.35)$ \\
\hline \multirow[t]{3}{*}{ (Unclear) } & FS (COMP, satisfaction) & 3 & 8 & $5.68(2.06)$ & 8 & $6.78(1.64)$ & $-0.56(-1.56,0.45)$ \\
\hline & FS (PEDI, self-care skills) & 3 & 8 & $60.12(6.13)$ & 8 & $63.5(5.01)$ & $-0.57(-1.58,0.44)$ \\
\hline & FS (PEDI, independence) & 3 & 8 & $29.12(7.26)$ & 8 & $31.75(4.4)$ & $-0.41(-1.41,0.58)$ \\
\hline \multicolumn{8}{|l|}{ Dalvand [53] } \\
\hline \multirow[t]{2}{*}{ (High) } & FS (CDER) & 12 & 7 & $42.80(40.04)$ & 15 & $36.80(34.42)$ & $0.16(-0.74,1.06)$ \\
\hline & FS (CDER) & 12 & 8 & $42.80(40.04)$ & 15 & 34.60 & $0.23(-0.64,1.09)$ \\
\hline $\begin{array}{l}\text { McConahie [54] } \\
\text { (High) }\end{array}$ & FS (IBAS) & $80-96$ & 11 & $-2.75(1.62)$ & 16 & $-3.11(1.10)$ & $0.26(-0.51,1.03)$ \\
\hline \multicolumn{8}{|l|}{ Stiller [55] } \\
\hline & HF (PDMS, fine motor, grasping) & 5 & 7 & $1.00(-1.29)$ & 8 & $0.25(1.28)$ & $0.55(-0.49,1.59)^{c}$ \\
\hline \multirow[t]{9}{*}{ (High) } & HF (PDMS, fine motor, hand use) & 5 & 7 & $-2.12(2.49)$ & 8 & $-0.28(1.29)$ & $-0.89(-1.97,0.19)^{c}$ \\
\hline & GM (GMFM-88, lying \& rolling) & 5 & 7 & $1.43(3.69)$ & 8 & $0.50(2.14)$ & $0.30(-0.73,1.32)^{c}$ \\
\hline & GM (GMFM-88, Sitting) & 5 & 7 & $2.43(3.10)$ & 8 & $0.63(5.07)$ & $0.40(-0.63,1.42)^{c}$ \\
\hline & $\begin{array}{l}\text { GM (GMFM-88, crawling \& } \\
\text { kneeling) }\end{array}$ & 5 & 7 & $0.14(1.57)$ & 8 & $2.75(1.91)$ & $-1.39(-2.56,-0.23)^{C_{*}}$ \\
\hline & $\begin{array}{l}\text { GM (GMFM-88, walking, running, } \\
\text { jumping) }\end{array}$ & 5 & 7 & $3.29(4.42)$ & 8 & $2.63(4.93)$ & $-0.13(-1.15,0.88)^{c}$ \\
\hline & GM (GMFM-88, standing) & 5 & 7 & $-1.29(2.87)$ & 8 & $0.63(2.00)$ & $-0.74(-1.80,0.32)^{c}$ \\
\hline & FS (PEDI, self-care) & 5 & 7 & $5.29(9.55)$ & 8 & $7.00(5.55)$ & $-0.21(-1.23,0.81)^{c}$ \\
\hline & FS (PEDI, mobility) & 5 & 7 & $2.57(4.04)$ & 8 & $1.25(2.60)$ & $0.37(-0.65,1.40)^{c}$ \\
\hline & FS (PEDI, social function) & 5 & 7 & $4.00(5.75)$ & 8 & $5.50(3.85)$ & $-0.29(-1.31,0.73)^{C}$ \\
\hline Reddihough [56] & HF (VAB, videotaped, fine motor) & 24 & 17 & $5.15(2.68)$ & 17 & $5.47(3.11)$ & $-0.11(-0.78,0.57)$ \\
\hline \multirow[t]{8}{*}{ (High) } & GM (GMFM-88) & 24 & 9 & $33.20(13.82)$ & 13 & $28.64(17.83)$ & $0.27(-0.59,1.12)$ \\
\hline & GM (VAB, videotaped, gross motor) & 24 & 17 & $6.29(2.24)$ & 17 & $5.76(2.64)$ & $0.21(-0.46,0.89)$ \\
\hline & FS (VAB, videotaped, feeding) & 24 & 17 & $5.29(2.95)$ & 17 & $4.65(2.63)$ & $0.22(-0.45,0.90)$ \\
\hline & FS (VAB, videotaped, play) & 24 & 17 & $5.87(3.82)$ & 17 & $5.14(3.41)$ & $0.20(-0.48,0.87)$ \\
\hline & $\begin{array}{l}\text { FS (VAB, caregiver reported, } \\
\text { feeding) }\end{array}$ & 24 & 17 & $5.06(0.89)$ & 17 & $4.26(0.95)$ & $0.85(0.14,1.55)^{*}$ \\
\hline & $\begin{array}{l}\text { FS (VAB, caregiver reported, } \\
\text { dressing) }\end{array}$ & 24 & 17 & $1.72(1.62)$ & 17 & $3.69(1.42)$ & $-1.26(-2.01,-0.52)^{*}$ \\
\hline & FS (VAB, caregiver reported, play) & 24 & 17 & $6.31(0.75)$ & 17 & $5.78(1.12)$ & $0.54(-0.14,1.23)$ \\
\hline & $\begin{array}{l}\text { FS (VAB, caregiver reported, } \\
\text { toileting) }\end{array}$ & 24 & 17 & $3.69(1.67)$ & 17 & $3.02(1.22)$ & $0.45(-0.23,1.13)$ \\
\hline Coleman [57] & HF (VAB, videotaped, fine motor) & 24 & 11 & $3.67(1.87)$ & 9 & $3.88(1.97)$ & $-0.11(-0.99,0.78)$ \\
\hline \multirow[t]{3}{*}{ (High) } & GM (VAB, videotaped, gross motor) & 24 & 11 & $3.53(1.51)$ & 9 & $3.76(1.51)$ & $-0.15(-1.03,0.74)$ \\
\hline & FS (VAB, videotaped, feeding) & 24 & 11 & $4.43(1.65)$ & 9 & $4.27(2.16)$ & $0.08(-0.80,0.96)$ \\
\hline & $\begin{array}{l}\text { FS (VAB, Caregiver reported, } \\
\text { feeding) }\end{array}$ & 24 & 11 & $2.75(1.68)$ & 9 & $3.36(1.57)$ & $-0.36(-1.25,0.53)$ \\
\hline
\end{tabular}


Table 2 Summary of the results (Continued)

$\begin{array}{lcccccc}\begin{array}{l}\text { FS (VAB, Caregiver reported, } \\ \text { dressing) }\end{array} & 24 & 11 & 2.11(1.07) & 9 & 2.32(1.42) & -0.16(-1.05,0.72) \\ \text { FS (VAB, Caregiver reported, play) } & 24 & 11 & 4.51(1.31) & 9 & 4.69(0.89) & -0.15(-1.03,0.73) \\ \begin{array}{l}\text { FS (VAB, Caregiver reported, } \\ \text { toileting) }\end{array} & 24 & 11 & 3.03(1.59) & 9 & 3.48(1.23) & -0.30(-1.19,0.59)\end{array}$

A: Low risk of bias indicates that bias is unlikely to affect the results; B: Could not be estimated due to a lack of reported estimates; C: Estimated extracted from change scores; D: Calculated SMD is not consistent with the result found in the article because of the use of change scores; HF (hand function); GM (gross motor function); and FS (functional skills). ${ }^{*} \mathrm{p}<0.05$.

Brandao [52], CIMT was performed for more than one hour per day with additional home training and was compared to intensive bimanual therapy based on functional skills only. The duration of therapy was less than four weeks. The intervention was performed at home with a therapist-set home program and at the clinic in groups. The use of parent set specific goals and parental involvement were also reported.

\section{Effects on hand function}

The results from the 23 studies that targeted hand function are presented in Table 2 or in the meta-analyses [19,21-39,55-57,60], of which, 17 studies evaluated CIMT.

Four meta-analyses based on 10 studies that targeted hand function were performed (Figures 3, 4, 5 and 6). When compared with conventional therapy, CIMT performed for more than one hour per day showed significant effects on unilateral hand function in one metaanalysis ( $\mathrm{N}=2$, [33,60] SMD 0.79 (95\% CI 0.03, 1.55), $\mathrm{p}=0.04$ ) (Figure 3 ). The CIMT was practiced at the clinic [60], as home program [33,60], and incorporated into daily activities [33]. The CIMT groups performed 15-28 hours more training per week, which resulted in a difference of 29-84 training hours over two to three weeks compared with the conventional therapy groups. Unilateral hand function was assessed by the Jebsen Taylor hand function and Paediatric arm function tests. The meta-analysis was based on studies of low [60] and unclear [33] risks of bias. With regards to bimanual hand function, no significant differences were found between CIMT performed for more than one hour per day and conventional therapy (Figure 4). The CIMT was practiced as home program $[19,22]$ or incorporated in daily activities [27]. The CIMT group had between 80-108 hours of more training compared with the conventional therapy group during the eight-week intervention period. Comparisons between CIMT performed 2-7 times per week with additional home training, or more than one hour per day at home, compared to intensive bimanual training, showed no significant findings on uni-and bimanual hand function (Figure 5, 6).

\section{Effects on gross motor function}

The results from the 16 studies that targeted gross motor function are presented in Table 2 [39-51,55-57]. The interventions and outcomes in included studies on gross motor function were considered too heterogeneous to be pooled in meta-analyses. The results from two single studies supported the effects of intensive interventions on gross motor skills. Compared with NDT, an intensive task oriented approach performed over 3-7 sessions per week yielded higher Gross Motor Function Measure 88 (GMFM-88) scores (sitting dimension), (SMD 2.51 (CI 95\% 0.63, 4.39) [40]. The task oriented intervention was performed at the clinic as individual training and without home program. Moreover, compared with $\mathrm{CE}$, intensive $\mathrm{PT}$ and OT (control) performed over 3-7 sessions per week led to higher scores on the GMFM-88 (crawling and kneeling dimension) (SMD -1.39 (95\% CI -2.56, -0.23) [55]. Both of the intensive interventions were performed at the clinic without home program. Of the 16 studies that targeted gross motor function, eight studies had less than 25 participants. All studies with significant results in favour of intensive training that targeted gross motor function had a high risk of bias (Table 2 and Figure 2). No other significant findings were observed regarding intensive interventions and gross motor function (Table 2).

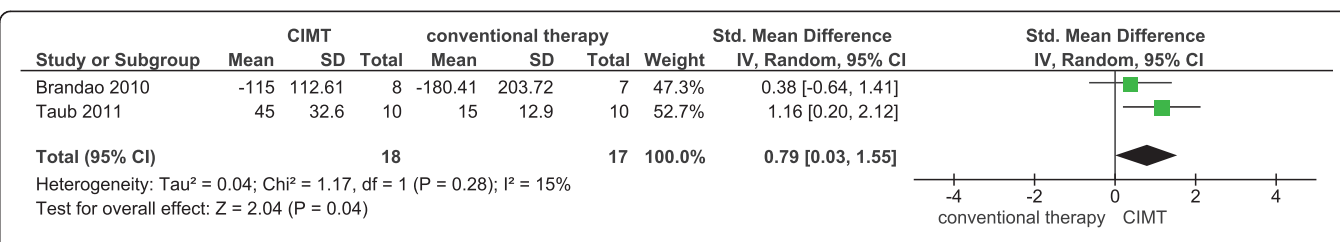

Figure 3 Comparison of CIMT versus conventional therapy on unimanual hand function after 3 weeks. 


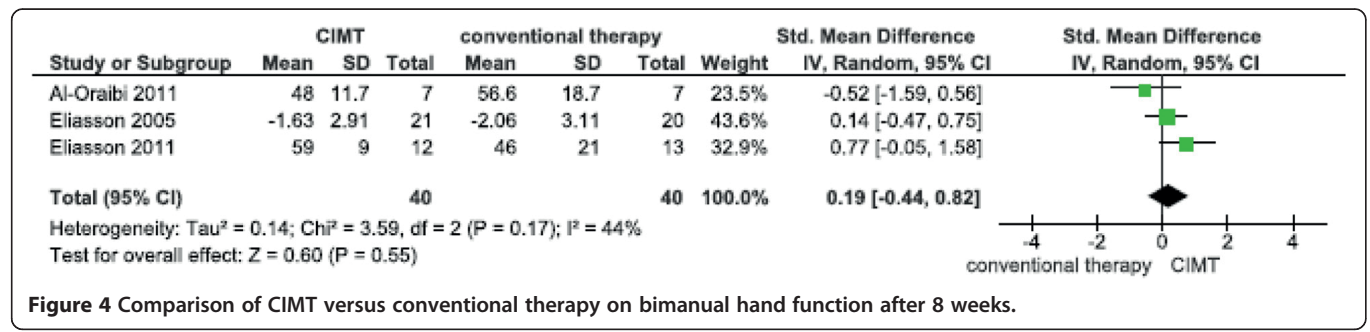

\section{Effects on functional skills}

The results from the 20 studies that targeted functional skills are presented in Table 2. Three studies measured functional skills as the only outcome [52-54], 11 studies measured functional skills in combination with hand function [21,29-38,60], three studies measured functional skills in combination with gross motor function [50,51], and three studies measured functional skills in combination with both hand function and gross motor function [55-57]. Two meta-analyses based on seven studies were performed (Figures 7,8). CIMT was shown to affect functional skills in two meta-analyses (Figures 7, 8). The first analysis showed the following: (1) CIMT performed at least 2-7 sessions per week with additional home training achieved more improvements in functional skills compared with conventional therapy $(\mathrm{N}=3$, [36,38,60] SMD 0.82 (95\% CI 0.26, 1.38), p=0.004) (Figure 7); and (2) CIMT performed 2-7 sessions per week with additional home training achieved more improvements in functional skills compared with intensive bimanual home training $(\mathrm{N}=4,[21,30,32,34]$ SMD 0.50 (95\% CI 0.16, 0.83), p=0.004) (Figure 8). Functional skills were assessed with the Paediatric Evaluation Disability Inventory (PEDI), the WeeFim, the Paediatric Motor Activity Log (PMAL), and the ABILHAND-kid. The CIMT was performed at the clinic $[21,34,36,38,60]$, as home program $[21,30,34,60]$ and/or in daily activities $[30,32,38]$. In Figure 7 , the CIMT group received 15-28 hours more training per week compared with the conventional therapy group. In the second meta-analysis (Figure 8), it was not possible to calculate the differences in the amount of training between the intensive interventions and intensive control groups because the amount of home-training was not reported. One of the studies reported a difference of 24.5 hours of training per week between the intervention and control groups [32]. The first meta-analysis included two studies with a low risk of bias and one study with a high risk of bias, whereas the second meta-analysis included three studies with a low risk of bias and one study with an unclear risk of bias (Figure 2). In addition, we ran sensitivity analyses by excluding studies of high risk of bias. This did not change the significant and non-significant results.

Intensive training showed a significant effect on functional skills in two single studies $[37,56]$. First, compared with intensive NDT, CE performed over 3-7 sessions per week achieved greater improvements on the subscales of the Vulpe Assessment Battery (VAB), feeding, and dressing (SMD 0.85 (95\% CI 0.14, 1.55); (SMD -1.26 (95\% CI $-2.01,-0.52)$ ) [56] (Table 1). The CE was performed at clinic without any home program. Second, compared with regular OT, intensive NDT and casting performed over 2-7 sessions per week with additional home training led to higher improvements on the Canadian Occupational Performance Measure (COPM, satisfaction scale) (SMD 0.69 (95\% CI 0.12, 1.26)) [37] (Table 2). These results were based on studies with high and unclear risks of bias [37,56] (Table 2 and Figure 2). No other significant differences were identified for functional skills (Table 2).

\section{Discussion}

This systematic review, which included 38 studies, describes and categorises intensive motor function and

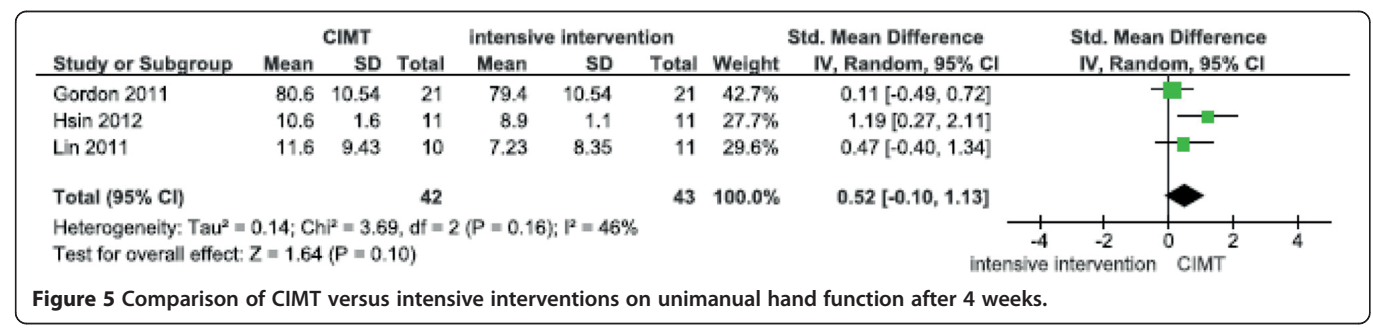




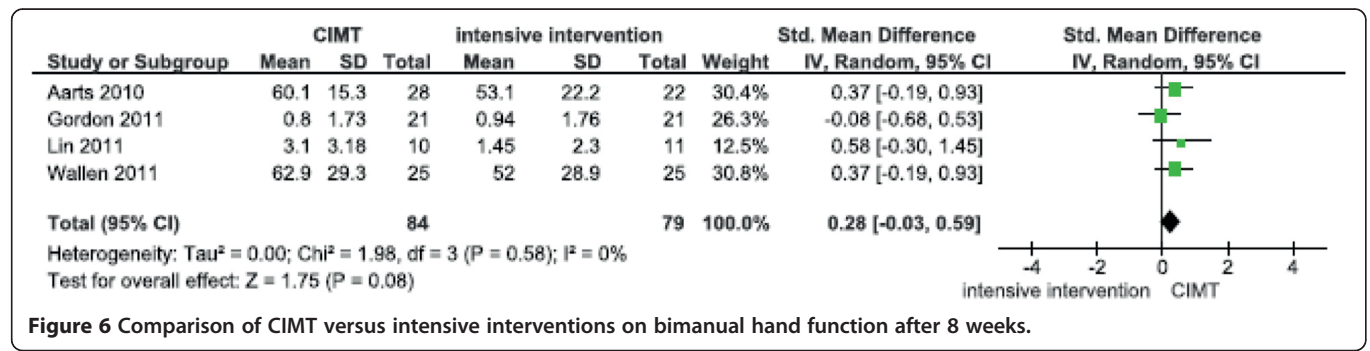

functional skills training among young children with $\mathrm{CP}$, and summarises the effects of these interventions. Among the studies published in the previous five years, 13 studies targeted hand function, six studies targeted gross motor functions, and 11 studies targeted functional skills. In a majority of the studies, equal improvements in motor function and functional skills were identified for intensive interventions and conventional therapy or between two different intensive interventions (Table 2).

\section{What works and why?}

Two meta-analyses of CIMT compared with conventional therapy showed increased improvements in unilateral hand function and functional skills and were characterised by high intensity of training (Figures 3 and 7). Over a two to three week period, the CIMT groups performed 29-84 more training hours compared with the conventional therapy groups. The CIMT was performed at the clinic and home as home programs or implemented in daily activities. In contrast, when CIMT and intensive bimanual training were compared, the improvements in hand function was similar in both groups (Figures 5, 6). The included studies of these metaanalyses reported also home program and/or CIMT incorporated into daily activities. These findings suggest that in addition to different types of training the intensity of training may explain the difference in improvement between the groups, and thus be equally important as the type and context of training in determining the final outcome. These results are consistent with other systematic reviews $[8,10,13]$. The majority of these pooled studies had a low risk of bias, which indicates that plausible bias was unlikely to alter the results. In the non-significant metaanalysis on bimanual hand function (Figure 4), the CIMT group had 80-108 more training hours during the eight week intervention period compared with the conventional therapy group. The CIMT was practiced at the clinic and at home as home program or in daily activities. This finding is in contrasts to meta-analyses 3 and 7, and might imply that the optimal intensity is difficult to detect, which has been suggested in several systematic reviews $[5-7,10,13]$. As previously demonstrated, basic motor functions in young children do develop, but not at the same rate and time points as their peers [1,2]. Moreover, CIMT showed increased improvements compared with intensive bimanual training on the acquisition of functional skills (Figure 8). Three out of the four pooled studies had a low risk of bias. Eliasson [13] reported similar findings for CIMT compared with intensive bimanual training when using parent questionnaires and measures of goal-directed daily activity performance, as included in our review. However, Dong et al. [8] identified greater improvements on functional skills following intensive bimanual training compared with CIMT. A possible explanation for our finding might be the inclusion of other studies with younger participants compared with the participants included in Dong et al. [8].

Contextual factors are also important for the learning of hand function and functional skills, as they enhance the transfer of new skills to the environments where they are meant to be used [61]. We identified home training in more than $50 \%$ of the included studies. Sakzewski et al. [10] reported that $50-80 \%$ of the anticipated training dose relied on practicing at home. Home

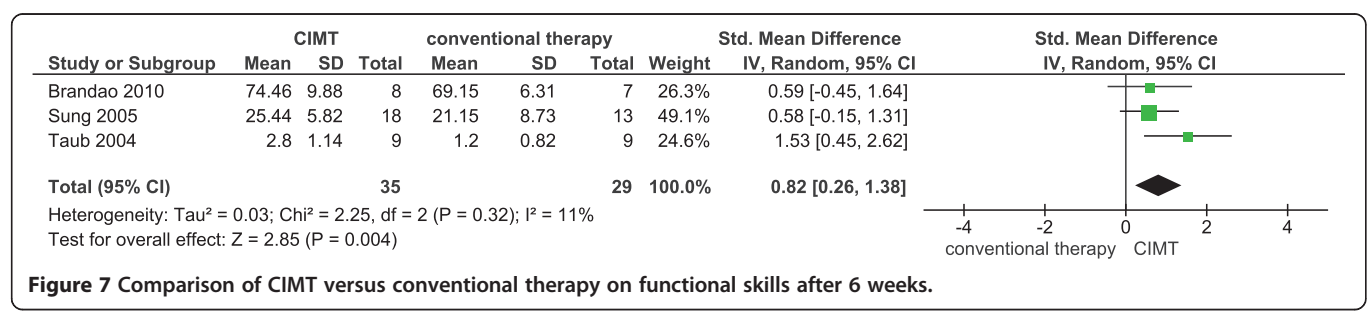




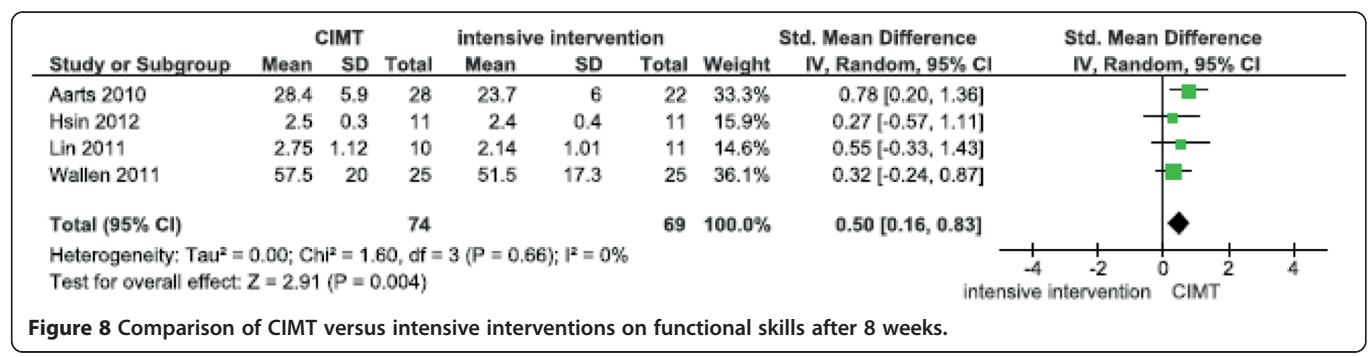

training has been found to be essential in many interventions because it can increase the total amount of training and enhance the transfer of hand function and functional skills to natural environments [10,62]. Dunst et al. [16] found that therapist-set home programs were related to decreased parent well-being and suggested that these programs might be in conflict with the families' everyday routines and values. Additionally, he questioned whether participation in the program was actually voluntary [16]. Both Dunst [16] and Novak [62] found positive effects of home programs where parents were actively involved in goal-setting and training and received education compared with no home program. Of the 11 articles in this review that reported a significant effect of intensive interventions on motor function and functional skills [19-22,30,33,36,37,40,55,56], four studies did not have therapist-set home programs or practice incorporated in daily activities [36,40,55,56] (Tables 1 and 2 ). Only one study included practice incorporated in daily activities and showed inconclusive results [20,21]. In contrast, Eliasson et al. [13] noted that training and practice undertaken at home or in kindergarten tended to be below the target hours and duration. This finding might indicate that the use of a home program is less controllable and does not only increase the intensity of training but might also contribute to the variations of effects due to variable compliance [13]. To increase and maintain compliance, parents must receive adequate education and support to enable their voluntary and active involvement in goal-setting and training integrated in daily activities $[16,17]$. In this review, more than half of the effective interventions reported parent education and active parental involvement in training.

When comparing the training intensity (amount and duration of training periods) of studies that targeted hand function and gross motor function, the CIMT studies lasted between two and eight weeks with a high number of training sessions per week, and the gross motor interventions often lasted more than 12 weeks with fewer training sessions per week. As summarised above, some significant results were found for intensive interventions that targeted hand function. This review identified two studies $[40,55]$ with a high risk of bias that showed effects on gross motor function, while other systematic reviews showed inconclusive results of intensive gross motor training [4,6,7]. One might ask if a higher number of training sessions per week for a shorter period practiced at home produced more motor and functional skills improvements compared with a lower number of training sessions per week for a longer period without home program. If so, this finding might suggest that the gross motor training was not sufficiently intensive and not incorporated into the child's natural context. Some of this training might be redefined to non-intensive training, since it was performed less than one hour per session, three times per week and without home training. However, the development of gross motor function and the learning of functional skills require different physical and cognitive personal resources, as well as different contexts, and maybe different intensity than the training of hand function. This issue is unresolved and requires further investigation.

Two studies showed the effects of CE [56] and intensive NDT and casting [37] on functional skills. A high risk of bias was identified in all CE studies, whereas the intensive NDT study [37] had an unclear risk of bias, which indicated that plausible bias seriously weakens confidence in the results or raises doubt regarding the results, respectively. However, the evidence base for NDT with and without casting is conflicting [4,7]. Furthermore, Novak et al. [4] reported conflicting results for CE. Group training was present in all CE studies that targeted both motor and functional skills and seldom in CIMT that targeted hand function and functional skills. Significant effects on hand function and functional skills were identified in both interventions. One could ask whether individual training might be more effective for the learning of specific goal-directed skills, whereas group-training might be more motivational and enhance social participation. However, because the CE studies were more prone to a high risk of bias, the influence from group training on the results remains unclear. $\mathrm{CE}$ is offered to young children with $\mathrm{CP}$, and robust research is necessary to investigate the effects. 
The majority of included studies reported the activity component of ICF, and only four studies [50,55-57] reported the participation component, such as subtests of the VAB and PEDI. This is consistent with Franki et al.'s findings [5]. One possible explanation for these findings might be that activity related outcomes capture the learning of basic motor function and functional skills that are learned during young age, and that the social skills are more evident during preschool age [11].

\section{Limitation}

Children with different subtypes of $\mathrm{CP}$ and functional levels might require different approaches and intensities of therapy. This aspect is not part of the scope of this review, but represents a limitation that needs to be considered when the results are interpreted. Although we have searched extensively, we may have missed relevant studies. Small studies, often without power calculations, were also included. This might indicate that some studies lacked the power to detect differences between groups. Sakzewski et al. [10] also pointed to this limitation in her review. A variety of interventions were used to improve gross motor function and functional skills, which prevented the pooling of results in the meta-analyses. Thirty-one assessment tools were used, most of which have been validated, except in studies of CE. Blinding of participants or therapists was not feasible but may still represent a risk of bias. Nineteen studies had a high risk of bias. This finding indicates that approximately half of the studies' results are likely to be affected by bias, and therefore, the effects remain unclear.

\section{Conclusions}

The present and other recently published systematic reviews have demonstrated the extensive and increasing evidence regarding CIMT. Studies on hand function had lower risks of bias compared with studies of gross motor function. Moreover, studies on gross motor function were typically characterised by a lower number of training sessions and longer training periods without home programs compared with studies that targeted hand function, which were characterised by higher number of training sessions and shorter training periods including home programs. These findings might suggest that more intensive training for a shorter period including practicing in the child's natural environment may be more effective for learning functional skills. Home training appears to play an important role in increasing the intensity of training. How to implement home training without disturbing the family's daily life in a negative manner remains to be resolved. Equal improvements in motor function and functional skills were reported for intensive interventions and conventional therapy or between two different intensive interventions in a majority of the included studies. The identification of the optimal intensity of interventions that target motor function and functional skills, as well as the possible harmful effects of intensive training, requires further investigation.

\section{Additional files}

\section{Additional file 1: Search strategy.}

Additional file 2: List of included studies awaiting assessment.

Additional file 3: Data extraction form.

Additional file 4: Characteristics of included studies.

\section{Competing interests}

The authors report no competing of interest. The authors alone are responsible for the content and writing of this paper.

\section{Authors' contributions}

HTM has contributed substantial to the design of the systematic review, performed the selection of studies and data extraction, run the metaanalyses, interpreted the analyses under supervision of the other co-authors, and drafted the paper. $S \varnothing, L L$ and RJ have contributed substantially to the design of the systematic review, performed the selection of studies and data extraction, interpretation of analyses and critically revised the paper. JOJ has contributed to the design of the systematic review, supervised the calculation of the effect sizes and the performance of meta-analyses, and critically revised the paper. All authors have read and approved the final manuscript.

\section{Acknowledgements}

We are grateful for the assistance from Karianne Thune Hammerstrøm in developing the search strategy and performing the search and Elisabet Hafstad for updating the search. We thank Kjetil G. Brurberg and Christine Rognlien for useful suggestions and editing.

A grant for this research was provided by the Oslo and Akershus University College of Applied Sciences.

\section{Author details}

${ }^{1}$ Faculty of Health Sciences, Oslo and Akershus University College of Applied Sciences, St. Olavs plass, Postbox 4, 0130 Oslo, Norway. ${ }^{2}$ Primary Health Care Unit, Norwegian Knowledge Centre for the Health Services, St. Olavs plass, Postbox 7004, 0130 Oslo, Norway. ${ }^{3} \mathrm{Global}$ Health Unit, Norwegian

Knowledge Centre for the Health Services, St. Olavs plass, Postbox 7004, 0130 Oslo, Norway. ${ }^{4}$ Department of Clinical Neuroscience for Children, Oslo University Hospital, Rikshospitalet, Postbox 4950, Nydalen 0424, Oslo, Norway.

Received: 7 July 2014 Accepted: 10 November 2014 Published online: 05 December 2014

\section{References}

1. Rosenbaum PL, Walter SD, Hanna SE, Palisano RJ, Russel DJ, Raina P, Wood E, Barlett DJ, Galuppi BE: Prognosis for gross motor function in cerebral palsy: creation of motor development curves. JAMA 2002, 288:1357-1363.

2. Holmefur M, Krumlinde-Sundholm L, Bergstrøm J: Longitudinal development on hand function in children with unilateral cerebral palsy. Dev Med Child Neurol 2010, 52:352-357.

3. World Health Organization: International Classification of Function, Disability and Health (ICF). Geneva: World Health Organization; 2001.

4. Novak I, Mclntyre S, Morgan C, Campbell L, Dark L, Morton N, Stumbles E, Wilson SA, Goldsmith S: A systematic review of interventions for children with cerebral palsy: state of the evidence. Dev Med Child Neurol 2013, 55:885-910.

5. Franki I, Desloovere $\mathrm{K}, \mathrm{De}$ Cat J, Feys $\mathrm{H}_{t}$ Molenaers $\mathrm{G}$, Calders $\mathrm{P}$, Vanderstraeten G, Himpens $E$, Van Broeck C: The evidence-base for conceptual approaches and additional therapies targeting lower limb function in children with cerebral palsy: a systematic review using the ICF as a framework. J Rehabil Med 2012, 44:396-405 
6. Arpino C, Vescio MF, De LA, Curatolo P: Efficacy of intensive versus nonintensive physiotherapy in children with cerebral palsy: a meta-analysis. Int J Rehabil Res 2010, 33:165-171.

7. Martin L, Baker R, Harvey A: A systematic review of common physiotherapy interventions in school-aged children with cerebral palsy. Phys Occup Ther Pediatr 2010, 30:294-312.

8. Dong VA, Tung $\mathrm{H}_{\text {, }}$ Siu HW, Fong KN: Studies comparing the efficacy of constraint-induced movement therapy and bimanual training in children with unilateral cerebral palsy: a systematic review. Dev Neurorehabil 2013, 16:133-143.

9. Huang HH, Fetters L, Hale J, McBride A: Bound for success: a systematic review of constraint-induced movement therapy in children with cerebral palsy supports improved arm and hand use. Phys Ther 2009, 89:1126-1141.

10. Sakzewski L, Ziviani J, Boyd RN: Efficacy of upper limb therapies for unilateral cerebral palsy: a meta-analysis. Pediatrics 2014, 133:e175-e204.

11. Haley SM, Coster WJ, Ludlow LH, Haltiwanger JT, Andrellos PJ: Pediatric Evaluation of Disability Inventory: Development, Standardization, and Administration Manual, Version 1.0. Boston: Trustees of Boston University, Health and Disability Research Institute; 1992.

12. Palisano RJ, Murr S: Intensity of therapy services: what are the considerations? Phys Occup Ther Pediatr 2009, 29:107-112.

13. Eliasson A-C, Krumlinde-Sundholm L, Gordon A, Feys H, Klingels K, Aarts PB, Rameckers E, Autti-Rämö I, Hoare B: Guidelines for future research in constraint-induced movement therapy for children with unilateral cerebral palsy: an expert consensus. Dev Med Child Neurol 2014, 56:125-137.

14. Palisano RJ, Begnoche DM, Chiarello LA, Bartlett DJ, Westcott McCoy S, Chang $\mathrm{H}-\mathrm{J}$ : Amount and focus of physical therapy and occupational therapy for young children with cerebral palsy. Phys \& Occup Ther Pediatr 2012, 32:368-382.

15. Myklebust $G$, Jahnsen R, Elkjær S: Registration of interventions in children with cerebral palsy during three years - a population based study. Dev Med Child Neurol 2009, 51(suppl.5):65.

16. Dunst CJ, Bruder MB, Trivette CM, Hamby DW: Everyday activity settings, natural learning environments, and early intervention practices. J Polic Pract Intellect Disabil 2006, 3:3-10.

17. Novak I: Parent experience of implementing effective home programs. Phys Occup Ther Pediatr 2011, 31:198-213.

18. Higgins J, Green S: Cochrane Handbook for Systematic Reviews of Interventions. Chichester, UK: Wiley-Blackwell; 2008.

19. Al-Oraibi S, Eliasson AC: Implementation of constraint-induced movement therapy for young children with unilateral cerebral palsy in Jordan: a home-based model. Disabil Rehabil 2011, 33:2006-12.

20. Aarts PB, Jongerius PH, Geerdink YA, Van LJ, Geurts AC: Modified constraintinduced movement therapy combined with bimanual training (mCIMT-BiT) in children with unilateral spastic cerebral palsy: how are improvements in arm-hand use established? Res Dev Disabil 2011, 32:271-9.

21. Aarts $P B$, Jongerius $P H$, Geerdink YA, Van $L$, Geurts $A C$ : Effectiveness of modified constraint-induced movement therapy in children with unilateral spastic cerebral palsy: a randomized controlled trial. Neurorehabil Neural Repair 2010, 24:509-18.

22. Eliasson AC, Shaw K, Berg E, Krumlinde-Sundholm L: An ecological approach of constraint induced movement therapy for 2-3-year-old children: a randomized control trial. Res Dev Disabil 2011, 32:2820-8.

23. Facchin P, Rosa-Rizzotto M, Visona Dalla PL, Turconi AC, Pagliano E, Signorini S, Tornetta L, Trabacca A, Fedrizzi E: Multisite trial comparing the efficacy of constraint-induced movement therapy with that of bimanual intensive training in children with hemiplegic cerebral palsy: postintervention results. Am J Phys Med Rehabil 2011, 90:539-53.

24. Gordon AM, Hung YC, Brandao M, Ferre CL, Kuo HC, Friel K, Petra E, Chinnan A, Charles JR: Bimanual training and constraint-induced movement therapy in children with hemiplegic cerebral palsy: a randomized trial. Neurorehabil Neural Repair 2011, 25:692-702.

25. Smania N, Aglioti SM, Cosentino A, Camin M, Gandolfi M, Tinazzi M, Fiaschi A, Faccioli S: A modified constraint-induced movement therapy (CIT) program improves paretic arm use and function in children with cerebral palsy. European J Phys Rehabil Med 2009, 45:493-500.

26. Charles J, Gordon AM: Efficacy of hand-arm intensive bimanual training (HABIT) on upper extremity movement in children with hemiplegic cerebral palsy. Dev Med Child Neurol 2006, 48:24

27. Eliasson A-C, Krumlinde-Sundholm L, Shaw K, Wang C: Effects of on constraint-induced movement therapy in young children with hemiplegic cerebral palsy: an adapted model. Dev Med Child Neurol 2005, 47:266-75.

28. Law M, Cadman D, Rosenbaum P, Walter S, Russell D, DeMatteo C. Neurodevelopmental therapy and upper-extremity inhibitive casting for children with cerebral palsy. Dev Med Child Neurol 1991, 33:379-87.

29. Case-Smith J, Deluca S, Stevenson R, Ramey S: A multi-center randomized controlled trial of pediatric constraint-induced movement therapy: 6-month follow-up. Am J Occup Ther 2012, 66:15-23.

30. Hsin YJ, Chen FC, Lin KC, Kang LJ, Chen CL, Chen CY: Efficacy of constraintinduced therapy on functional performance and health-related quality of life for children with cerebral palsy: a randomized controlled trial. J Child Neurol 2012, 27:992-9.

31. Rostami HR, Malamiri RA: Effect of treatment environment on modified constraint-induced movement therapy results in children with spastic hemiplegic cerebral palsy: a randomized controlled trial. Disabil Rehabi 2012, 34:40-4

32. Lin KC, Wang TN, Wu CY, Chen CL, Chang KC, Lin YC, Chen YJ: Effects of home-based constraint-induced therapy versus dose-matched control intervention on functional outcomes and caregiver well-being in children with cerebral palsy. Res Dev Disabil 2011, 32:1483-91.

33. Taub E, Griffin A, Uswatte G, Gammons K, Nick J, Law CR: Treatment of congenital hemiparesis with pediatric constraint-induced movement therapy. J Child Neurol 2011, 26:1163-73.

34. Wallen M, Ziviani J, Naylor O, Evans R, Novak I, Herbert RD: Modified constraint-induced therapy for children with hemiplegic cerebral palsy: a randomized trial. Dev Med Child Neurol 2011, 53:1091-9.

35. DeLuca SC, Echols K, Law CR, Ramey SL: Intensive pediatric constraintinduced therapy for children with cerebral palsy: randomized, controlled, crossover trial. J Child Neurol 2006, 21:931-8.

36. Taub E, Ramey SL, Deluca S, Echols K: Efficacy of constraint-induced movement therapy for children with cerebral palsy with asymmetric motor impairment. Pediatrics 2004, 113:305-12.

37. Law M, Russell D, Pollock N, Rosenbaum P, Walter S, King G: A comparison of intensive neurodevelopmental therapy plus casting and a regular occupational therapy program for children with cerebral palsy. Dev Med Child Neurol 1997, 39:664-70.

38. Sung IY, Ryu JS, Pyun SB, Yoo SD, Song WH, Park MJ: Efficacy of forced-use therapy in hemiplegic cerebral palsy. Arch Phys Med Rehabil 2005, 86:2195-8.

39. Carlsen PN: Comparison of two occupational therapy approaches for treating the young cerebral-palsied child. Am J Occup Ther 1975, 29:267-72.

40. Choi M, Lee $\mathrm{D}, \mathrm{Ro} \mathrm{H}$ : Effect of task-oriented training and neurodevelopmental treatment on the sitting posture in children with cerebral palsy. J Phys Ther SC 2011, 23:323-5

41. Kwon JY, Chang HJ, Lee JY, Ha Y, Lee PK, Kim YH: Effects of hippotherapy on gait parameters in children with bilateral spastic cerebral palsy. Arch Phys Med Rehabil 2011, 92:774-9.

42. Shamsoddini AR, Hollisaz MT: Effect of sensory integration therapy on gross motor function in children with cerebral palsy. Iran J Child Neurol 2009, 3:43-8

43. Christiansen AS, Lange C: Intermittent versus continuous physiotherapy in children with cerebral palsy. Dev Med Child Neurol 2008, 50:290-3.

44. Lee JH, Sung IY, Yoo JY: Therapeutic effects of strengthening exercise on gait function of cerebral palsy. Disabil Rehabil 2008, 30:1439-44.

45. Kanda T, Pidcock FS, Hayakawa K, Yamori Y, Shikata Y: Motor outcome differences between two groups of children with spastic diplegia who received different intensities of early onset physiotherapy followed for 5 years. Brain Dev 2004, 26:118-26.

46. Bower E, Michell D Burnett M Campbell MJ McLellan DL R Randomized controlled trial of physiotherapy in 56 children with cerebral palsy followed for 18 months. Dev Med Child Neurol 2001, 43:4-15.

47. Bower E, McLellan DL, Arney J, Campbell MJ: A randomised controlled trial of different intensities of physiotherapy and different goal-setting procedures in 44 children with cerebral palsy. Dev Med Child Neurol 1996, 38:226-37

48. Scherzer AL, Mike V, Ilson J: Physical therapy as a determinant of change in the cerebral palsied infant. Pediatrics 1976, 58:47-52.

49. Weindling AM, Cunningham CC, Glenn SM, Edwards RT, Reeves DJ: Additional therapy for young children with spastic cerebral palsy: a randomised controlled trial. Health Technol Assess 2007, 11:iii-55. 
50. Lowing K, Bexelius A, Brogren CE: Activity focused and goal directed therapy for children with cerebral palsy-do goals make a difference? Disabil Rehabil 2009, 31:1808-16.

51. Hur JJ-A: Skills for independence for children with cerebral palsy: a comparative longitudinal study. Int J Disabil Dev Educ 1997, 44:263-74.

52. de Brito BM, Gordon AM, Mancini MC: Functional impact of constraint therapy and bimanual training in children with cerebral palsy: a randomized controlled trial. Am J Occup Ther 2012, 66:672-81.

53. Dalvand H, Dehghan L, Feizy A, Amirsalai S, Bagheri H: Effect of the Bobath technique, conductive education and education to parents in activities of daily living in children with cerebral palsy in Iran. Hong Kong J Occup Ther 2009, 19:14-9.

54. McConachie H, Huq S, Munir S, Ferdous S, Zaman S, Khan NZ: A randomized controlled trial of alternative modes of service provision to young children with cerebral palsy in Bangladesh. J Pediatr 2000, 137:769-76.

55. Stiller C, Marcoux BC, Olson RE: The effect of conductive education, intensive therapy, and special education services on motor skills in children with cerebral palsy. Phys Occup Ther Pediatr 2003, 23:31-50.

56. Reddihough DS, King J, Coleman G, Catanese T: Efficacy of programmes based on Conductive Education for young children with cerebral palsy. Dev Med Child Neurol 1998, 40:763-70.

57. Coleman GJ, King JA, Reddihough DS: A pilot evaluation of conductive education-based intervention for children with cerebral palsy: the Tongala project. J Paediatr Child Health 1995, 31:412-7.

58. Eliasson AC, Krumlinde-Sundholm L, Rosblad B, Beckung E, Arner M, Ohrvall AM, Rosenbaum P: The Manual Ability Classification System (MACS) for children with cerebral palsy: scale development and evidence of validity and reliability. Dev Med Child Neurol 2006, 48:549-54

59. Palisano R, Rosenbaum P, Walter S, Russell D, Wood E, Galuppi B: Development and reliability of a system to classify gross motor function in children with cerebral palsy. Dev Med Child Neurol 1997, 39:214-23.

60. Brandao M, Mancini MC, Vaz DV, de Melo APP, Fonseca ST: Adapted version of constraint-induced movement therapy promotes functioning in children with cerebral palsy: a randomized controlled trial. Clin Rehabil 2010, 24:639-47.

61. Shumway-Cook A, Wollacot MH: Motor Control: Translating Research into Clinical Practice. Philadelphia: Lippincott Williams \& Wilkins; 2007.

62. Novak I, Cusick A, Lannin N: Occupational therapy home programs for cerebral palsy: double-blind, randomized, controlled trial. Pediatrics 2009, 124:e606-14.

doi:10.1186/s12887-014-0292-5

Cite this article as: Tinderholt Myrhaug et al:: Intensive training of motor function and functional skills among young children with cerebral palsy: a systematic review and meta-analysis. BMC Pediatrics 2014 14:292.

\section{Submit your next manuscript to BioMed Central and take full advantage of:}

- Convenient online submission

- Thorough peer review

- No space constraints or color figure charges

- Immediate publication on acceptance

- Inclusion in PubMed, CAS, Scopus and Google Scholar

- Research which is freely available for redistribution

Submit your manuscript at www.biomedcentral.com/submit
() Biomed Central 
